Universidad de Lima

Escuela de Postgrado

Maestría en Derecho Empresarial

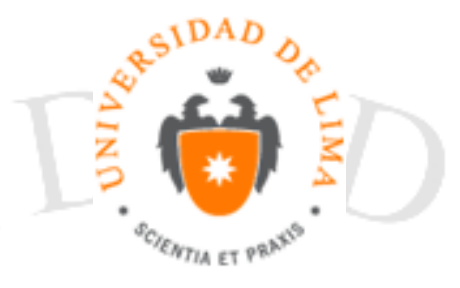

\title{
ANÁLISIS JURÍDICO E IMPLEMENTACIÓN EN EL PERÚ DE LOS PRINCIPIOS RECTORES SOBRE LAS EMPRESAS Y DERECHOS HUMANOS DE NACIONES UNIDAS
}

Trabajo de investigación para optar el Grado Académico de Maestro en Derecho Empresarial

Lidia Aymé Jara Munar

Código 19990462

Lima-Perú

2016 


\section{ANÁLISIS JURÍDICO E}

\section{IMPLEMENTACIÓN EN EL PERÚ DE}

\section{LOS PRINCIPIOS RECTORES SOBRE}

LAS EMPRESAS Y DERECHOS

HUMANOS DE NACIONES UNIDAS 


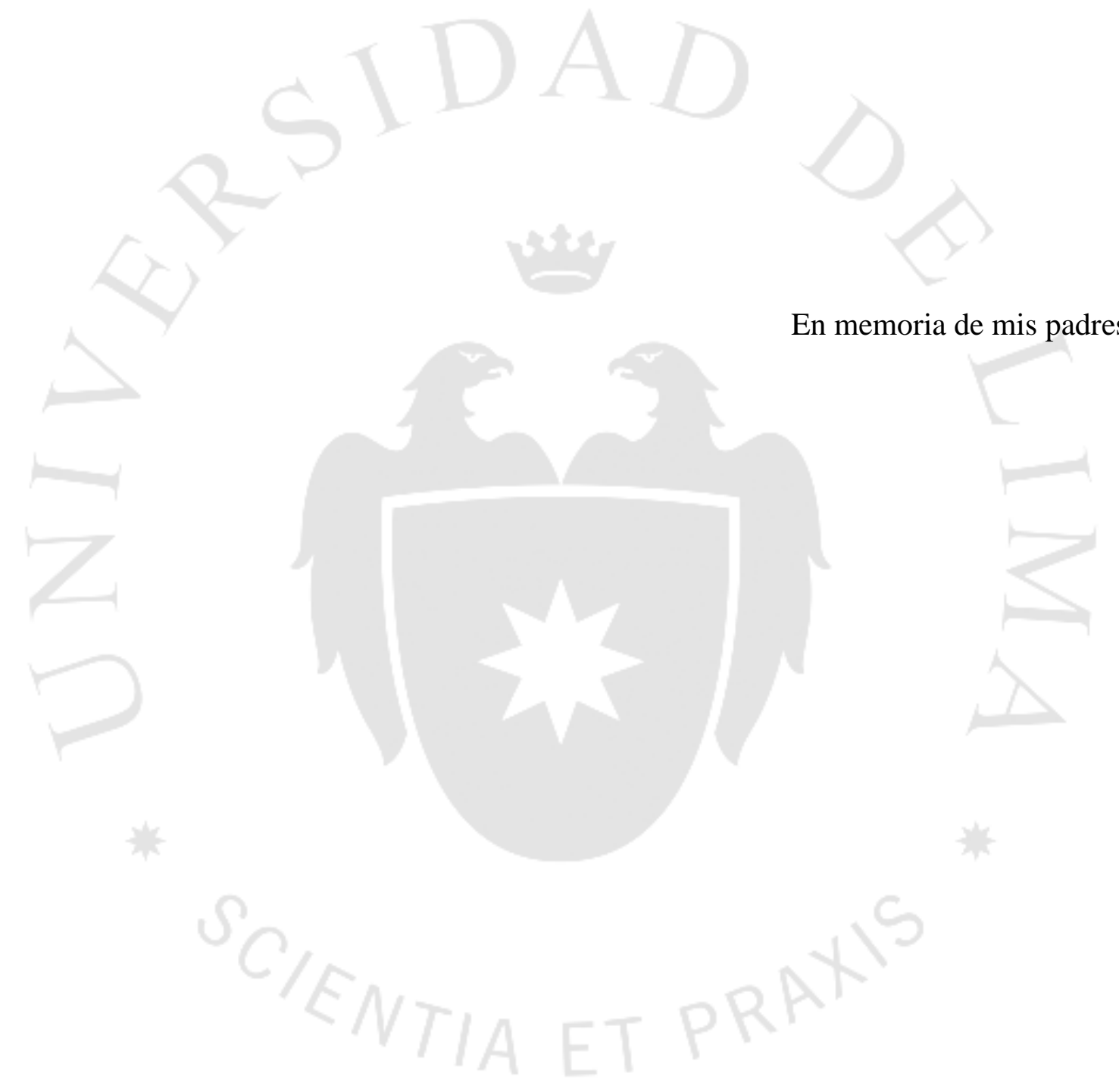




\section{TABLA DE CONTENIDOS}

INTRODUCCIÓN .......................................................................................................1

CAPÍTULO I: EL DERECHO INTERNACIONAL DE LOS DERECHOS

HUMANOS (EN LO QUE SE REFIERE A LAS ACTIVIDADES DE LAS

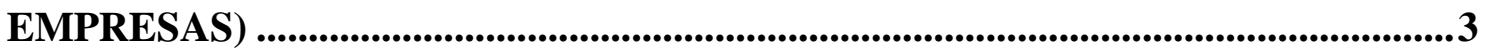

1.2. El rol de los derechos humanos en las empresas ....................................... 4

1.2.1. Instrumentos internacionales de derechos humanos...............................6

1.2.2. Normas y códigos específicos relativos a las empresas y sectores

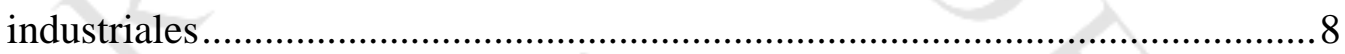

1.2.2.1. Las directrices de la OCDE para las empresas multinacionales.............8

1.2.2.2. Principios voluntarios de seguridad y derechos humanos (negocios

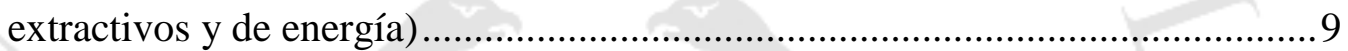

1.2.2.3. Directrices de responsabilidad de las instituciones financieras

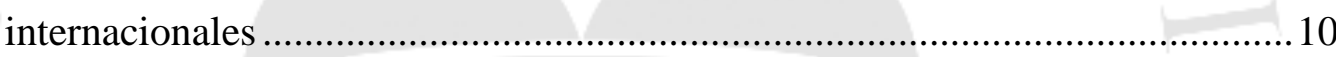

1.2.2.4. El Pacto Mundial de las Naciones Unidas (GC)................................ 11

1.2.2.5. Declaración tripartita de principios sobre las empresas multinacionales

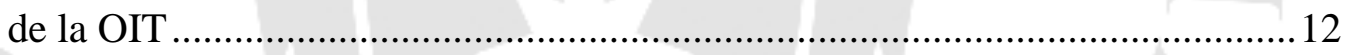

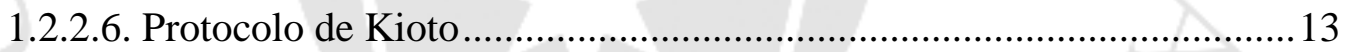

1.2.2.7. Normas en responsabilidades de derechos humanos de corporaciones

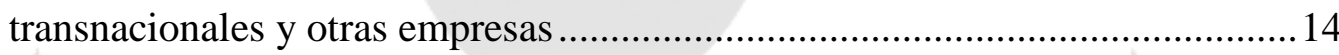

1.3. Principios rectores sobre las empresas y derechos humanos de las Naciones

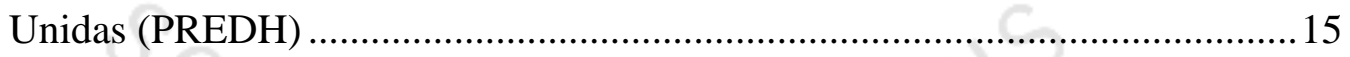

1.3.1. Influencia de los principios en instrumentos internacionales .................. 16

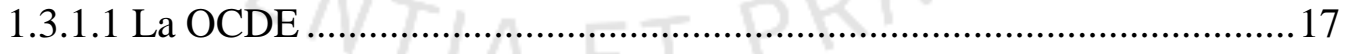

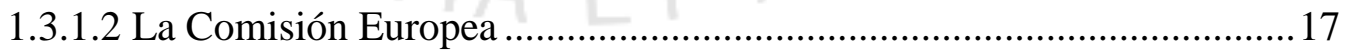

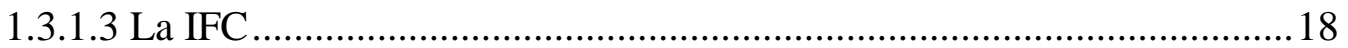

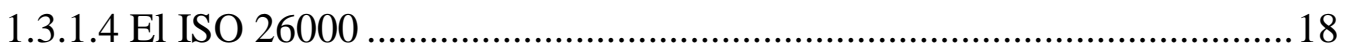

1.4. Tratado para las empresas y los derechos humanos ................................ 19

1.4.1 Argumentos a favor y en contra de un tratado vinculante .......................20

1.5. Conclusiones del Capítulo I..................................................................22

CAPÍTULO II: MARCO JURÍDICO Y EMPRESA ....................................................224 
2.1. Implementación de los PREDH a nivel regional - Unión Europea ...........24

2.2. Implementación de los PREDH en la legislación comparada .....................24

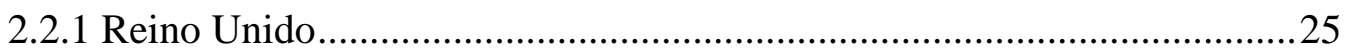

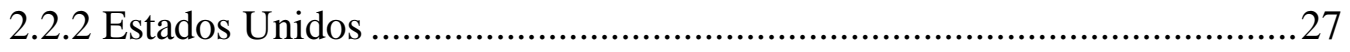

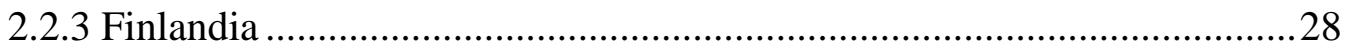

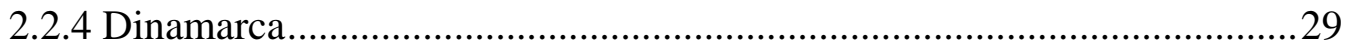

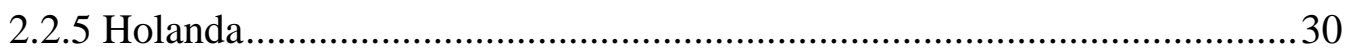

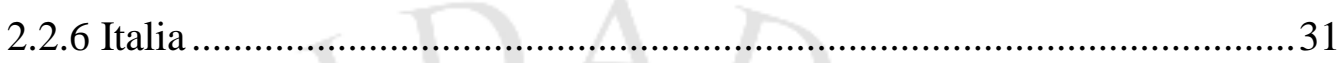

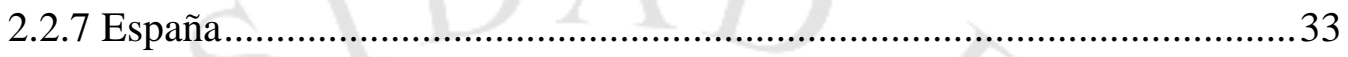

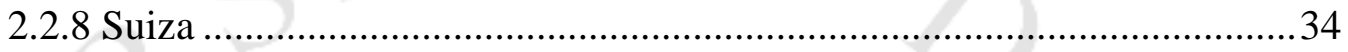

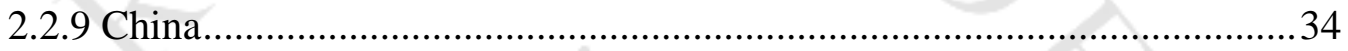

2.3. Implementación de los PREDH en Latinoamérica.................................... 34

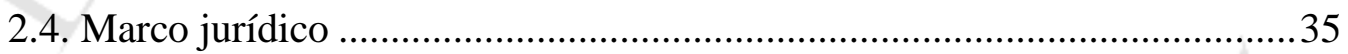

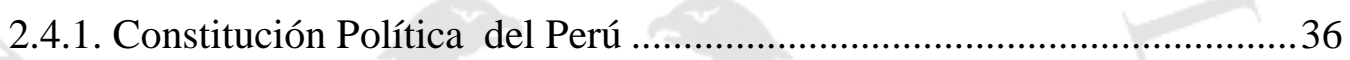

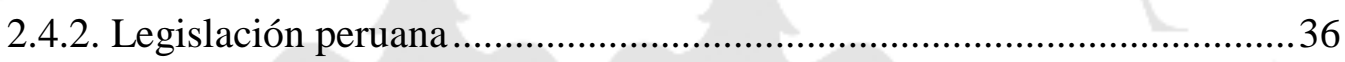

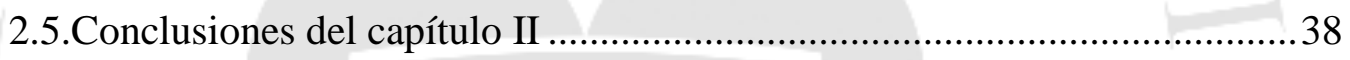

CAPÍTULO III: APLICACIÓN DE LOS PREDH EN EL PERÚ ............................4 40

3.1. Responsabilidad Social Empresarial: tendencias y acontecimientos actuales 40

3.1.1. La responsabilidad social desde la óptica de los derechos humanos.......40

3.1.1.1. Desarrollo sostenible: sostenibilidad ambiental y social ..................... 45

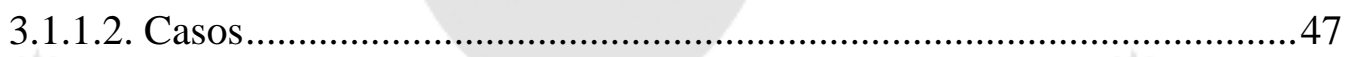

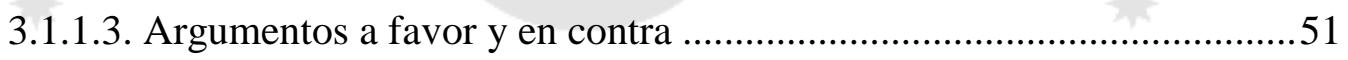

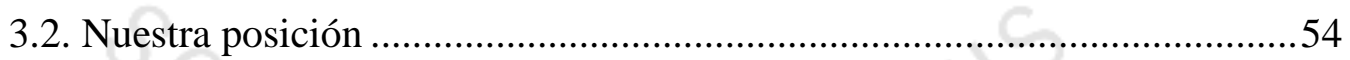

3.2.1. Viabilidad y procedimiento de diligencia debida en derechos humanos.56

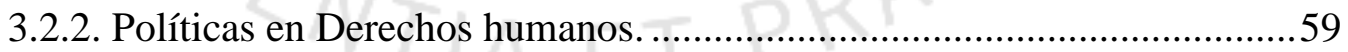

3.2.3. Monitoreo del cumplimiento de los principios...................................... 62

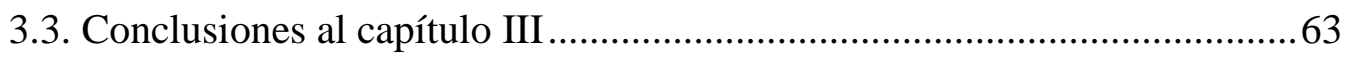

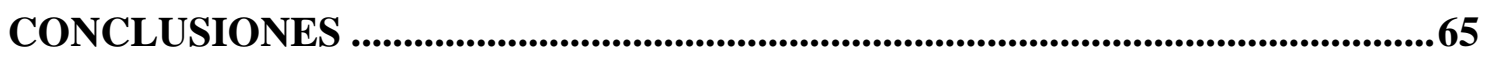




\section{ÍNDICE DE ANEXOS}

Anexo I: Instrumentos internacionales de derechos humanos...................... 75

Anexo II: Instrumentos sobre grupos o poblaciones específicos....................77

Anexo III: Cuadro de Diligencia Debida en Derechos Humanos...................... 78

Anexo IV: Beneficios de los Planes de Acción Nacionales en materia de Derechos

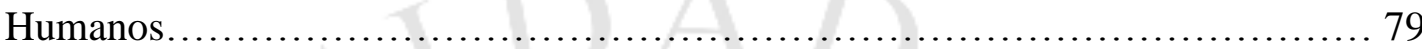

Anexo V: Planes de Acción Nacional en Derechos Humanos y Empresa............. 80 


\section{INTRODUCCIÓN}

El 16 de junio del año 2011 fue emitida la resolución 17/4 mediante la cual el Consejo de Derechos Humanos de la ONU hizo suyos los principios rectores sobre empresas y derechos humanos (PREDH), fruto de un trabajo profundo que se enfocó en identificar los estándares mínimos en los que una empresa se debe desenvolver para prevenir, mitigar y remediar las violaciones o amenazas de violaciones a los derechos humanos cometidas por ella misma. A partir de ese momento, los principios han atraído la atención de empresas, organizaciones y demás interesados en promover su aplicación práctica.

Independientemente de la implementación de los principios en distintos países del mundo y de las medidas de remedio que existan o se puedan impulsar en favor del tratamiento de los casos de abusos contra los derechos humanos por parte de las empresas, consideramos que el segundo pilar (respetar los derechos humanos) debe ser asimilado y aplicado por todos los departamentos y áreas de la organización empresarial en todo momento y lugar. En consecuencia, la empresa obtendrá ventajas en varios niveles como el económico-financiero y legal. Asimismo, la imagen y el posicionamiento de su marca se verán beneficiados, incrementando así la posibilidad de contar con los mejores colaboradores dentro de la organización, entre otros.

Entre las ideas principales se puede resaltar que la empresa necesita de una política de compromiso para respetar los derechos humanos, la misma que no debe ser complicada sino abarcar los impactos potenciales de derechos humanos en el lugar de trabajo y en las comunidades en las que la compañía y su cadena de suministros operan. Teniendo en cuenta el giro del negocio, cada empresa enfrentará distintos tipos de riesgo, por lo que es necesario que se realice un diagnóstico de su situación para poder determinar cuáles serán las acciones a considerar.

En segundo lugar, cabe resaltar que es conveniente que la compañía cuente con un proceso eficiente de diligencia debida en derechos humanos para poder identificar, prevenir o mitigar el impacto potencial o real de riesgos en ese ámbito. Aunque la diligencia debida y la identificación temprana de problemas no son nuevas para las 
empresas, es necesario analizar el carácter especial de un due diligence en derechos humanos, así como su viabilidad e integración en los procesos de identificación existentes. En consecuencia, un primer paso sugerido es conducir un análisis de la compañía a lo largo de su cadena de aprovisionamiento, procesos y procedimientos; luego de lo cual deberá tomar las medidas necesarias donde encuentre impactos adversos a los derechos humanos.

Finalmente, la expectativa de los principios es que una compañía conozca y demuestre respeto a los derechos humanos. Esto puede ser conseguido con la actualización relevante en los reportes de sostenibilidad de la empresa y con el apoyo del área de comunicaciones. Con una imagen sólida y de compromiso al respeto a los derechos humanos, el valor de los intangibles de la empresa y las utilidades experimentarán un incremento significativo: más clientes estarán dispuestos a consumir la marca o contratar los servicios de la empresa, habrá una reducción significativa de riesgos a través de la prevención, la empresa logrará un mejor manejo de recursos, podrá evitar gastos innecesarios y los inversionistas tendrán más confianza y certeza del rendimiento de sus inversiones.

La presente investigación busca describir el contexto en el cual aparecen los principios rectores sobre derechos humanos y empresa - PREDH (capítulo I), la implementación en la legislación comparada, organizaciones y sectores empresariales de los principios en las empresas a través del respeto de los derechos humanos (capítulo II). Finalmente, desarrollamos la aplicación del due diligence en derechos humanos en la empresa y su conexión con la RSE (capítulo III). 


\section{CAPÍTULO I: EL DERECHO INTERNACIONAL DE LOS DERECHOS HUMANOS (EN LO QUE SE REFIERE A LAS ACTIVIDADES DE LAS EMPRESAS)}

\subsection{Corporaciones transnacionales}

El fenómeno de la globalización ha ido creciendo desde fines del siglo pasado junto con la aparición de nuevas tecnologías y las mejoras en los medios de comunicación y transporte, cambios que son factores fundamentales o determinantes en la gesta, expansión y ascenso de las corporaciones transnacionales (TNC) ${ }^{1}$. Por consiguiente, podemos inferir que las corporaciones transnacionales son tanto causa como efecto de la globalización. Por un lado, son causa porque sirven como vehículos para el libre fluir de bienes, servicios y capital a través de las fronteras entre países o regiones. Este libre fluir constituye la esencia de la globalización económica y pone a prueba el poder regulatorio de los Estados. Por otro lado, las corporaciones transnacionales son también efecto de la globalización, dado que el incremento del poder de la corporación resulta de la debilidad del sistema Estado-nación. (Santoro, 2010, p. 286). En efecto, las grandes corporaciones escapan a las jurisdicciones nacionales en tanto que su ámbito de acción no se encuentra circunscrito a un espacio geográfico específico ni está limitado a un solo Estado o Nación. Generalmente, las corporaciones desarrollan sus actividades en distintos puntos del planeta, lo que hace difícil realizar seguimientos.

En la medida que las corporaciones transnacionales aumentan en cantidad y en tamaño se hace más complejo monitorearlas y muchas veces tomamos conocimiento de empresas que caen en ciertos comportamientos o procesos que afectan o vulneran de manera directa o indirecta a los derechos humanos en sus procesos de manufactura o en el desarrollo de sus actividades empresariales.

En esa misma línea, la justificación que usualmente proviene de las corporaciones transnacionales que operan en mercados emergentes es que el crecimiento económico representa una gran oportunidad, sin perjuicio del gran reto que

\footnotetext{
${ }^{1}$ Siglas en inglés de Transnational Corporation.
} 
significa desenvolverse en estos mercados (Jayakumar, 2013, p. 69). ${ }^{2}$ Tomando en cuenta lo anterior, la comunidad internacional ha tenido varios intentos de regular la conducta de las corporaciones multinacionales en diversos documentos que, de una $\mathrm{u}$ otra forma, dirigen la conducta de la empresa hacia el respeto de los derechos humanos. Sin embargo, resulta fundamental el rol de los sistemas jurídicos nacionales, ya que dependerá de ellos que estas normas internacionales se vuelvan de cumplimiento obligatorio para el país.

\subsection{El rol de los derechos humanos en las empresas}

La razón de ser de la empresa es generar ganancias, y de esa forma contribuir al crecimiento económico del país o países en los cuales se desarrolla. En ese sentido, la empresa es la primera aliada de los derechos humanos, ya que es fuente de empleo y procura un salario a sus trabajadores para que estos puedan acceder a una vida digna y a la realización personal y profesional. Adicionalmente, las empresas cuentan con ambientes de trabajo que deben ser adecuados, respetar los estándares de seguridad y cuidar de la vida e integridad de sus trabajadores y de la comunidad en general. No obstante, al intentar obtener mayores rendimientos, muchas empresas dejan de lado el respeto a los derechos humanos debido a que, aparentemente, no respetarlos resulta beneficioso. Sin embargo, a largo plazo termina siendo perjudicial a su imagen con consecuencias a nivel económico, social y ambiental muchas veces irreversibles.

Desde la perspectiva del derecho internacional de los derechos humanos, cuando la causa inmediata de la vulneración recae en el comportamiento de un actor privado en este caso una empresa, se pueden explorar dos caminos para comprometer la responsabilidad de un Estado. Por un lado, se puede responsabilizar al Estado de las vulneraciones cometidas por actores no estatales; ${ }^{3}$ por otro lado, se puede extender y enmarcar la vulneración cometida por una empresa en la obligación del Estado de

\footnotetext{
2 Entre los retos encontramos un ambiente institucional poco desarrollado, gobierno debilitado, corrupción y falta de legislación y normas que regulen aspectos como la transparencia y el respeto a los derechos humanos.

${ }^{3}$ Consideramos que esto puede ser posible sólo en caso de que la empresa haya actuado en nombre del Estado o tenga un vínculo directo con él.
} 
proteger. ${ }^{4}$ Ambas opciones tienen una misma premisa: la idea de que el derecho internacional de los derechos humanos es de obligatorio cumplimiento para los Estados, los mismos que son los primeros responsables de hacerlos cumplir. Siguiendo esta lógica, los mecanismos de protección existentes a nivel internacional están dirigidos a los Estados y no a los actores privados. Adicionalmente, una tercera opción consiste en fortalecer la habilidad del derecho internacional para dirigirse directamente a las violaciones contra los derechos humanos cometidas por actores no estatales. ${ }^{5}$

Las instituciones nacionales, incluyendo a las cortes de justicia, cuentan con mecanismos que les permiten aplicar las normas de derecho internacional de los derechos humanos, por lo que no hay obstáculo en su aplicación a los actores no estatales (entes privados). Aparte de lo señalado anteriormente, tampoco hay obstáculo para permitir que se desarrolle - en el nivel internacional - una regulación vinculante para los Estados con el objetivo de poder vencer la incapacidad o la falta de voluntad del propio Estado de controlar a los actores no estatales adecuadamente. ${ }^{6}$ Ciertamente, esta postura puede ser particularmente relevante en el contexto de globalización económica, por la amenaza que puede presentar a la capacidad regulatoria de los Estados. (De Schutter, 2014). En todo caso, dependerá del ordenamiento jurídico interno - y lo que permita - para la aplicación de las normas internacionales (sean vinculantes o no vinculantes) dentro del territorio nacional.

En el artículo "Post-Westphalia and Its Discontents: Business, Globalization, and Human Rights in Political and Moral Perspective", Santoro (2010) hace un contraste entre el enfoque "post-westfaliano" de los derechos humanos y el de Fair Share o justo compartir. En ese sentido, cita el trabajo de Kobrin en torno a las

\footnotetext{
${ }^{4}$ En este punto, nos quisiéramos detener para aclarar que el Estado cae en omisión. Sin embargo, es un tema muy complejo y operativamente podría llegar a ser difícil de realizar por un Estado que tiene prioridades ya establecidas en las que no se contemple al monitoreo de la actividad empresarial como una de ellas.

${ }^{5}$ Como por ejemplo, las empresas o corporaciones. El sustento jurídico lo encontramos en el último párrafo del preámbulo de la Declaración Universal de Derechos Humanos (DUDH), en el que se señala que: “(...) todos los pueblos y naciones deben esforzarse, a fin de que tanto los individuos como las instituciones, inspirándose constantemente en ella [DUDH], promuevan, mediante la enseñanza y la educación, el respeto a estos derechos y libertades, y aseguren, por medidas progresivas de carácter nacional e internacional, su reconocimiento y aplicación universales y efectivos, tanto entre los pueblos de los Estados Miembros como entre los de los territorios colocados bajo su jurisdicción".

${ }^{6}$ Cabe señalar que en nuestro país las normas internacionales de carácter vinculante pasan por un proceso de adecuación de la legislación interna para su aplicación práctica. Podemos hablar inclusive de un tratado en esta materia. Por otro lado, las normas no vinculantes o recomendaciones, si bien no tienen un carácter de obligatorio, pueden también ser recogidas por nuestra legislación interna.
} 
responsabilidades de las corporaciones transnacionales, en contraste con el suyo sobre la teoría del justo compartir la responsabilidad moral de los derechos humanos. Este trabajo es importante dado que nos da a conocer dos puntos de vista teóricos desde los que se puede estudiar a los derechos humanos, así como las ventajas y desventajas de la aplicación de cada uno. Según Kobrin y el nuevo enfoque post-westfaliano, "las corporaciones transnacionales poseen "poder, autoridad, y derechos" en el plano del derecho internacional, lo que "debería suponer deberes, obligaciones, y responsabilidades". Coincidimos que lo dicho anteriormente obedece a un proceso político transnacional en el que la negociación juega un rol importante, más que a una responsabilidad basada en la moral. (p. 289). Por otro lado, el enfoque del justo compartir implica partir de la premisa que señala que los derechos humanos son derechos morales de tal importancia que acarrean deberes morales. Bajo este enfoque, los derechos humanos se caracterizan por trascender las legislaciones nacionales y su protección es universal. (p. 290)

Un comentario aparte merecen los negocios considerados inclusivos. Ellos se enfocan en un acercamiento que se fija en aspectos de la dignidad humana, cuyo objetivo es descubrir cuan afectada está esta, teniendo en cuenta que se vincula a varios derechos humanos. (Hahn, 2012, p. 47) La noción de dignidad humana y su relevancia en un contexto empresarial puede ser relacionada a diversos aspectos de los derechos humanos. (p. 48) Existen varios ejemplos que ilustran esta tendencia, como el enfoque de ventas, de micro finanzas y de integración, que pueden ser empleados para resaltar y discutir los impactos potenciales de los negocios inclusivos en la dignidad humana y los derechos humanos. Estos negocios demuestran que es posible contar con una política interna de respeto a los derechos humanos y han optado por una fórmula que les resulta eficiente.

\subsubsection{Instrumentos internacionales de derechos humanos}

En América Latina y África, violaciones de derechos sociales, económicos y culturales son sistemáticas, "como cuando se impide que la población tenga acceso a bienes básicos como ser una vivienda digna, agua o electricidad, derechos colectivos relacionados con el desplazamiento de víctimas, como poblaciones campesinas y pueblos indígenas, cuando hay violación de los derechos ambientales por la destrucción 
de ecosistemas" (...) (Más de 80 países piden castigo contra abusos de las transnacionales, 2014, párr. 4)

Dado el creciente número de casos de violaciones a los derechos humanos por parte de las empresas, algunas organizaciones e instituciones internacionales han decidido prestar especial atención al tema y adoptar medidas legales y recomendaciones para limitar los impactos negativos de las actividades de las empresas en las personas y en el medio ambiente.

La insistencia en un mayor control de las actividades de las grandes corporaciones transnacionales formaba parte de la justificación de un "nuevo orden económico internacional" a principios de $1970 .^{7}$ Esta tendencia por lograr un mayor control continúa y aún está en proceso de aceptación e implementación.

El contexto se presentó relativamente favorable para una regulación sobre las actividades de las corporaciones o empresas transnacionales: los países desarrollados temían que ciertos abusos realizados por las corporaciones transnacionales o su interferencia con los procesos políticos locales pudieran generar reacciones hostiles por parte de los países en desarrollo, y posiblemente hacia la imposición de restricciones en los derechos de los inversionistas extranjeros. Es así que el "Grupo de los 77” países (en desarrollo) no alineados insistieron en su soberanía permanente sobre los recursos naturales y en la necesidad de mejorar la supervisión de las actividades de las transnacionales. ${ }^{8}$

En base a un reporte preparado a solicitud del Consejo Económico y Social, un borrador del Código de Conducta de Corporaciones Transnacionales fue preparado hasta el año 1992 dentro de la Comisión de Corporaciones Transnacionales de Naciones Unidas. $^{9} \quad$ El borrador del Código fracasó en ser adoptado debido a grandes discrepancias entre los países industrializados y aquellos en vías de desarrollo; en particular, en referencia al derecho internacional y a la inclusión en el Código de estándares en el tratamiento de las corporaciones transnacionales. Así, mientras los

\footnotetext{
${ }^{7}$ Los Estados descolonizados recientemente impulsaron durante ese período. Ver la resolución adoptada por la Asamblea General de Naciones Unidas el 1 de mayo de 1974, llamando a un Nuevo Orden Económico Internacional UN Doc. A/Res/3201 (S-VI); y seguido, en particular, por la Resolución de AG 3281(XXIX) del 15 de enero de 1975, UN GAOR Supp. (No. 31), UN Doc. A/9631 (1975), la Carta de Deberes y Derechos Económicos d los Estados (Charter of EconomicRights and Duties of States) ${ }^{8}$ http://www.g77.org/

${ }^{9}$ Ver E/1990/94, 12 June 1990.
} 
países industrializados estuvieron a favor de un Código que protege a las Corporaciones del trato discriminatorio por parte de los Estados anfitriones (receptores de las inversiones) que estuvieran vulnerando un mínimo de estándares, los países en desarrollo buscaban principalmente asegurar que las transnacionales estuvieran mejor reguladas y estuvieran prohibidas de interferir con la independencia política o con los objetivos económicos definidos por el Estado receptor de las inversiones. (De Schutter, 2014)

\subsubsection{Normas y códigos específicos relativos a las empresas y sectores industriales}

En esta sección, enumeraremos diversas normas de carácter no vinculante que han sido o pueden ser recogidas por legislaciones nacionales y/o comunitarias. Así mismo, nos parece pertinente elaborar esta lista para tener una idea de los intentos existentes en la regulación relativa a los derechos humanos y las empresas.

\subsubsection{Las directrices de la OCDE para las empresas multinacionales}

En la década de los 70s, la Organización por la Cooperación y Desarrollo Económico (OCDE) adoptó las líneas directrices para empresas multinacionales. Estas directrices fueron revisadas en varias ocasiones desde su adopción inicial en 1976. En el año 2000, el mecanismo de supervisión fue revitalizado y se estipuló una obligación general de "respetar los derechos humanos de aquellos afectados por actividades de multinacionales consistente con las obligaciones y compromisos internacionales de los gobiernos anfitriones". 10

Bajo las directrices de la OCDE, los Estados deben establecer puntos nacionales de contacto $(\mathrm{PNC})^{11}$ para promoverlas y para recibir "instancias específicas" o quejas de las partes interesadas en casos de incumplimiento de las compañías. Cuando dichas instancias son presentadas, estos puntos de contacto operan como mediadores y buscan diseñar una solución al asunto referido en la queja con la colaboración de la compañía involucrada. Al final del proceso pueden publicar un comunicado que contenga los

\footnotetext{
${ }^{10} \mathrm{http} / / / \mathrm{www}$.oecd.org/corporate/mne/

${ }^{11}$ NCPs siglas en Inglés de National Contact Points.
} 
hechos y, de esta manera, describir la solución acordada. Si no se llega a ningún acuerdo, se señala que el asunto queda pendiente de solución. Sea que se llegue a un acuerdo o no trae consecuencias significativas en la reputación de la compañía. ${ }^{12}$

El establecimiento de los puntos de contacto nacionales (NCPs) en todos los Estados miembro de la OCDE provee un mecanismo nuevo y accesible que permite a las partes interesadas denunciar casos de mala conducta corporativa. Sin embargo, las directrices de la OCDE están explícitamente presentadas como instrumentos no vinculantes con respecto a las empresas multinacionales, así su efectividad en lograr un cambio en la conducta y prácticas de las empresas es cuestionable. ${ }^{13}$

Consideramos relevante nombrar a las líneas directrices de la OCDE en esta sección debido a que en nuestro país se encuentran establecidas empresas multinacionales o sucursales de empresas cuyos países de origen son miembros de la OCDE y siguen sus lineamientos en el desarrollo de sus actividades empresariales. ${ }^{14}$ Adicionalmente, las Directrices de la OCDE son tomadas en cuenta para la adopción de normativa comunitaria europea en el tema, la cual es vinculante en los países miembros de la Unión Europea; sin perjuicio de que otros países (que no son miembros de la UE o estén adscritos a la OCDE) puedan adoptar normas similares. ${ }^{15}$

\subsubsection{Principios voluntarios de seguridad $y$ derechos humanos (negocios extractivos y de energía)}

En el año 2000, los gobiernos de los Estados Unidos, el Reino Unido, los Países Bajos y Noruega, las empresas (compañías) de los sectores de extracción de recursos y energía y algunas organizaciones no gubernamentales (ONGs), cooperaron en el desarrollo y lanzamiento de un conjunto de Principios voluntarios de seguridad y derechos humanos

\footnotetext{
${ }^{12} \mathrm{http}: / /$ www.oecd.org/corporate/mne/

13 Loc. Cit.

${ }^{14}$ La Organización para la Cooperación y el Desarrollo Económicos (OCDE) tiene como objetivo promover las políticas destinadas: - a lograr la más fuerte expansión posible de la economía y del empleo y a aumentar el nivel de vida en los países miembros manteniendo la estabilidad financiera y contribuyendo así al desarrollo de la economía mundial; - a contribuir a una sana expansión económica en los países miembros y en los no miembros en vías de desarrollo económico; - a contribuir a la expansión del comercio mundial sobre una base multilateral y no discriminatoria conforme a las obligaciones internacionales.

${ }^{15}$ A través de los procedimientos supranacionales de adopción de decisiones. http://www.europarl.europa.eu/aboutparliament/es/displayFtu.html?ftuId=FTU_1.4.1.html.
} 
con el objetivo de ayudar a las empresas extractivas a mantener la seguridad de sus operaciones dentro de un marco operativo de garantía del respeto a los derechos humanos y las libertades fundamentales $\mathrm{y}$, donde corresponda, del derecho internacional humanitario. A partir del año 2000, se han unido a la iniciativa otras empresas, gobiernos y ONGs. A pesar de que estos principios fueron adoptados en el año 2000, su implementación no resulta fácil y continúa desarrollándose, especialmente cuando las empresas operan en zonas de conflictos o con gobiernos debilitados. (Principios Voluntarios de Seguridad y Derechos Humanos Guía orientativa de implementación). La relevancia que este documento puede tener para nuestro país radica en que nos encontramos en una zona geográfica clave en la que el negocio extractivo forma parte de nuestra economía y es realizado a gran escala.

\subsubsection{Directrices de responsabilidad de las instituciones financieras internacionales}

Los principios de Ecuador III fueron adoptados por entidades financieras para garantizar que los proyectos para los que prestan financiamiento y asesoría se lleven a cabo de manera socialmente responsable, y que reflejen la aplicación de prácticas de gestión ambiental. ${ }^{16}$ En el preámbulo, reconocen la importancia del cambio climático, la biodiversidad y los derechos humanos, y tienen como objetivo común evitar los efectos negativos en los ecosistemas y el clima por la realización de los proyectos. Los principios también mencionan que en caso los impactos sean inevitables se debe optar por minimizarlos, mitigarlos y/o compensarlos. ${ }^{17}$ Tal como lo señalan los principios de Ecuador, “(...) los grandes proyectos de infraestructuras e industriales pueden tener impactos negativos en las personas y en el medio ambiente" (junio de 2013). En los postulados de estos principios encontramos similitud y alineamiento con los PREDH en el sentido de que estos últimos buscan que las empresas realicen el diagnóstico de los

\footnotetext{
${ }^{16} \mathrm{http}: / / \mathrm{www}$. ifc.org/wps/wcm/connect/region_ext_content/regions/latin+america+and+the+caribbean El IFC, miembro del Grupo del Banco Mundial, es la principal institución internacional de desarrollo que centra su labor exclusivamente en el sector privado de los países en desarrollo. Creada en 1956, IFC está conformada por 184 países miembros que trabajan en conjunto para determinar las políticas de la organización. Su labor en más de 100 naciones en desarrollo facilita que empresas e instituciones financieras en mercados emergentes creen empleos, generen ingresos fiscales, mejoren el gobierno corporativo y el desempeño medioambiental y contribuyan a las comunidades locales.

${ }^{17} \mathrm{http}: / /$ www.equator-principles.com/resources/equator_principles_spanish_2013.pdf.
} 
impactos negativos potenciales y reales, directos o indirectos realizados por parte de las empresas y que esto lleve a la empresa a tomar acciones al respecto. ${ }^{18}$

\subsubsection{El Pacto Mundial de las Naciones Unidas (GC)}

A finales de los 90s, el debate de como perfeccionar la responsabilidad en derechos humanos de las corporaciones transnacionales fue relanzado a medida que crecían las preocupaciones sobre los impactos de la globalización económica desenfrenada en valores como el ambiental, derechos humanos y derechos de los trabajadores. En el Foro Económico Mundial de Davos en 1999, el Secretario General de Naciones Unidas, K. Annan propuso formar un grupo denominado Pacto Mundial o Global Compact ${ }^{19}$ basado en valores compartidos en las áreas de derechos humanos, trabajo y medio ambiente, a los que se ha añadido anti-corrupción en el año 2004. Los diez principios a los que los participantes del Pacto Mundial se adhieren están derivados de la Declaración Universal de Derechos Humanos, la Declaración de Principios Fundamentales y Derecho al Trabajo de la Organización Internacional del Trabajo, la Declaración de Río sobre medio Ambiente y Desarrollo, y la Convención anti corrupción de Naciones Unidas. El proceso es voluntario y está basado en la idea de que las buenas prácticas deben ser recompensadas a través de la publicidad, además de ser compartidas para promover un aprendizaje mutuo entre las empresas. Las compañías que acceden al Pacto Mundial deben adoptar, apoyar y actuar en concordancia a los diez (inicialmente nueve) principios en los que está basado. Para el

\footnotetext{
${ }^{18}$ Principios Rectores Sobre las Empresas y los Derechos Humanos. Puesta en Práctica del Marco de las Naciones Unidas Para "Proteger, Respetar y Remediar". Adoptados el 16 de Junio de 2011 en las Naciones Unidas.

${ }^{19}$ Los Diez Principios del Pacto Mundial están basados en Declaraciones y Convenciones Universales aplicadas en cuatro áreas: Derechos Humanos, Medio Ambiente, Estándares Laborales y Anticorrupción. Derechos Humanos: Principio 1: Las Empresas deben apoyar y respetar la protección de los derechos humanos fundamentales reconocidos universalmente, dentro de su ámbito de influencia. Principio 2: Las Empresas deben asegurarse de que sus empresas no son cómplices de la vulneración de los derechos humanos. Estándares Laborales: Principio 3: Las empresas deben apoyar la libertad de Asociación y el reconocimiento efectivo del derecho a la negociación colectiva. Principio 4: Las Empresas deben apoyar la eliminación de toda forma de trabajo forzoso o realizado bajo coacción. Principio 5: Las Empresas deben apoyar la erradicación del trabajo infantil. Principio 6: Las Empresas deben apoyar la abolición de las prácticas de discriminación en el empleo y ocupación. Medio Ambiente: Principio 7: Las Empresas deberán mantener un enfoque preventivo que favorezca el medio ambiente. Principio 8: Las empresas deben fomentar las iniciativas que promuevan una mayor responsabilidad ambiental. Principio 9: Las Empresas deben favorecer el desarrollo y la difusión de las tecnologías respetuosas con el medio ambiente. Anticorrupción: Principio 10: Las Empresas deben trabajar en contra de la corrupción en todas sus formas, incluidas la extorsión y el soborno.
} 
año 2013, más de 10,000 compañías de aproximadamente 130 países se habían unido; lo que lo convierte de lejos en la iniciativa de responsabilidad social corporativa más amplia medida por su número de participantes. Estas empresas reportan anualmente sobre las iniciativas que contribuyen al cumplimiento de estos valores en sus prácticas de negocios, a través de una "comunicación sobre el progreso" presentada en la Secretaría de Pacto Mundial: a fines del año 2011, más de 2,000 compañías participantes habían sido retiradas por haber fracasado en cumplir con los reportes requeridos por más de un año.

Los principios 1 y 2 (GC) hacen referencia al apoyo, respeto, protección y no complicidad en abusos de los derechos humanos proclamados internacionalmente. (Martje y van Huijstee, 2013, p. 25) Adicionalmente, a pesar de que el Pacto Mundial no es un mecanismo para el monitoreo del cumplimiento de los principios que las compañías participantes se comprometen a promover, las alegaciones de abuso sistemático o notorio llevados a la Oficina de Pacto Mundial son examinadas, y la compañía es contactada a menos que la alegación sea calificada de irrelevante, si la compañía no coopera en el proceso o no provee respuestas satisfactorias, puede ser tratada como "no comunicativa" y ser excluida de la lista. El hecho de que una empresa que no cumpla con los principios del Pacto se encuentre listada en la página web es considerado perjudicial para la reputación e integridad del Pacto Mundial. Adicionalmente, la Oficina del Pacto Mundial se reserva el derecho de remover a las compañías que incumplan con el reporte anual de la lista de participantes e indicarlo así en su página web. ${ }^{20}$ Es importante conocer que empresas de nuestro país forman parte de esta iniciativa, así como a las asociaciones que también lo conforman. ${ }^{21}$

\subsubsection{Declaración tripartita de principios sobre las empresas multinacionales de la OIT}

Casi simultáneamente a la adopción de los principios de la OCDE, la Organización Internacional del Trabajo adoptó la declaración tripartita de principios concernientes a

\footnotetext{
${ }^{20}$ En: www.unglobalcompact.org

${ }^{21}$ En el Perú, entre las asociaciones locales que se encuentran listadas en la página web del Global Compact se encuentra la Cámara de Comercio, Procapitales, entre otros. En: http://www.unglobalcompact.org/ParticipantsAndStakeholders/business_associations.html
} 
las empresas multinacionales y política social (adoptado por el cuerpo de gobierno de la OIT en su 204ta sesión de noviembre de 1977 y revisada en la 9na sesión de noviembre del 2000). El propósito de la declaración es fomentar la contribución positiva que las empresas multinacionales pueden hacer al progreso económico y social, además de los aportes que pueden realizar para minimizar y resolver las dificultades que varias operaciones podrían generar, tomando en cuenta las resoluciones de Naciones Unidas que abogan por un nuevo orden económico internacional. ${ }^{22}$

La declaración tripartita también tiene algunos mecanismos de seguimiento, los Estados deben reportar en una base cuatrienal sobre la implementación de los principios listados en ella. A pesar del alto significado moral generado en su adopción por consenso por el cuerpo de gobierno de la OIT (en el que los estados, los empleadores y trabajadores están representados), la declaración tripartita sigue siendo un instrumento no vinculante, como las líneas directrices de la OCDE. Aunque ambos instrumentos contienen ciertas obligaciones de naturaleza procedimental que bien podrían ser tomadas en cuenta por los Estados.

\subsubsection{Protocolo de Kioto}

Consideramos importante hacer referencia al protocolo de Kioto ${ }^{23}$ del año 1998 debido a que este documento tiene como base la promoción del desarrollo sostenible teniendo en cuenta los riesgos ambientales que como motivo de las actividades industriales, extractivas y comerciales se pueden evitar, mitigar o compensar. La importancia de este instrumento es que se alinea con la responsabilidad social que las empresas llevan a cabo en sus operaciones; además de estar en concordancia con los tres pilares en los que se basan los principios rectores de la ONU que son proteger, respetar y remediar. Adicionalmente, sirve de base para la posibilidad de compensar por los daños que irremediablemente se ocasionen al medio ambiente. ${ }^{24}$

\footnotetext{
22 www.ilo.org

${ }^{23} \mathrm{http} / / /$ unfccc.int/kyoto_protocol/items/2830.php

${ }^{24}$ En este punto podemos citar a los llamados Bonos de Carbono que las empresas que ocasionan daños ambientales pagan para la investigación e impulso de tecnologías que evitan daños medioambientales.
} 


\subsubsection{Normas en responsabilidades de derechos humanos de corporaciones transnacionales y otras empresas}

El 14 de agosto de 2003, la Subcomisión de Promoción y Protección de los Derechos Humanos de Naciones Unidas, el grupo de expertos independientes apoyando el trabajo de la Comisión de Derechos Humanos, aprobó en la Resolución 2003-16 una serie de normas en responsabilidades de derechos humanos de corporaciones transnacionales y otras empresas. (E/CN.4/Sub.2/2003/12/Rev.2)

Las normas propuestas por la Subcomisión fueron esencialmente presentadas como una reafirmación de las obligaciones impuestas a las compañías bajo el derecho internacional. Están basadas en la idea de que:

aunque los Estados tienen el deber primario de promover la responsabilidad, asegurar el cumplimiento, respetar, asegurar el respeto y proteger los derechos humanos, las corporaciones transnacionales y otros negocios (empresas), como órganos de la sociedad, son también responsables de promover y asegurar el conjunto de derechos humanos comprendidos en la Declaración Universal de Derechos Humanos (preámbulo tercer considerando)

Y por lo tanto, "las corporaciones trasnacionales y otras empresas, sus funcionarios y personas que trabajan para ellos también están obligados a respetar las responsabilidades y normas generalmente reconocidas contenidas en tratados de Naciones Unidas y otros instrumentos internacionales" (preámbulo cuarto considerando)

Evidentemente, la dirección por la que iba la Subcomisión le recargaba demasiadas responsabilidades a las empresas, con la posibilidad de desencadenar mayores gastos para las mismas. A pesar de que la iniciativa fue recibida con desconfianza y evidente hostilidad, tanto por la comunidad empresarial como por un gran número de gobiernos, sirvió para poner el asunto en la agenda de la Comisión de Derechos Humanos de las Naciones Unidas. 


\subsection{Principios rectores sobre las empresas y derechos humanos de las Naciones Unidas (PREDH)}

Los principios son los primeros estándares aceptados globalmente sobre las responsabilidades de los Estados y las empresas en torno a los derechos humanos, $\mathbf{y}$ contestan la interrogante sobre donde termina la responsabilidad de los Estados y donde comienza la de las corporaciones. ${ }^{25}$ En abril del 2005, la Comisión de Derechos Humanos de la ONU pidió que la Secretaría General designara a un Representante Especial para identificar las maneras a través de las cuales la responsabilidad de las corporaciones transnacionales por violaciones a los derechos humanos pueda ser mejorada y zanjar el debate que por años se venía suscitando. Es en este contexto que el Representante Especial de la Secretaría General, John Ruggie, puso a un lado las normas de la Subcomisión, con el argumento de que ellas comparaban de manera errónea las responsabilidades de las compañías con aquellas de los Estados y de este modo:

Convertiría a las corporaciones transnacionales en versiones más benignas de las Compañías de Indias del siglo 21, perjudicando la capacidad de los países en desarrollo de generar instituciones controladas independiente y democráticamente capaces de actuar en interés público - que [...] es de lejos la forma más efectiva de garantizar los derechos humanos. ${ }^{26}$

Luego de casi tres años de consultas y estudios propuso un esquema que descansaba en las "responsabilidades diferenciadas pero complementarias" de los Estados y las corporaciones. El esquema comprende "tres principios eje: el deber del Estado de proteger contra abusos de derechos humanos por parte de terceros (incluyendo a las empresas), la responsabilidad corporativa de respetar los derechos humanos, y la necesidad de acceso más efectivo a recursos". 27 En primer lugar, se volvía a plantear que los derechos humanos existen para que el Estado los proteja - como lo señala el Derecho Internacional de los Derechos Humanos, el esquema no excluye que las

\footnotetext{
${ }^{25}$ En concordancia con lo que en doctrina se llama desarrollo progresivo de los derechos humanos y en la que los derechos económicos, sociales y culturales se están implementando en el mundo.

${ }^{26}$ Declaración del Representante Especial de la Secretaría general en el tema de empresas y derechos humanos para el Consejo de Derechos Humanos, 25 de setiembre de 2006.

${ }^{27}$ Protect, Respect and Remedy: a Framework for Business and Human Rights. Report of the Special Representative of the Secretary-General on the Issue of Human Rights and Transnational Corporations and Other Business Enterprises, A/HRC/8/5, 7 April 2008, para. 9.
} 
compañías puedan tener responsabilidades de derechos humanos, aunque las compañías esencialmente deben cumplir con el principio de "no ocasionar daños", esto también supone ciertos deberes positivos: "para descargar la responsabilidad de respetar se requiere due diligence en derechos humanos". En principio, el due diligence o diligencia debida describe los pasos que una compañía debe tomar en cuenta para estar alerta, prevenir y enfrentar impactos adversos en derechos humanos.

Luego de que el Consejo de Derechos Humanos renovara el mandato del Representante Especial de la Secretaría General en el asunto de derechos humanos y corporaciones transnacionales y otras empresas, pudo desarrollar esta estructura o esquema y, luego de consultas adicionales y pruebas de algunos conceptos clave por compañías dispuestas a contribuir, propuso los principios rectores sobre empresas y derechos humanos (PREDH) implementando el marco y acompañando comentarios que brindan una guía adicional a los gobiernos y empresas. Luego de los intentos fallidos en el pasado, esta fue la primera vez que se adoptaba un documento autorizado sobre empresas y derechos humanos dentro de las Naciones Unidas. ${ }^{28}$

Consideramos que los principios van más allá de la multitud de iniciativas voluntarias, a menudo provenientes de sectores específicos, que existían hasta el momento. Ellos conforman la base de un nuevo mecanismo de seguimiento dentro del sistema de Naciones Unidas, a través de los grupos de trabajo en empresas y derechos humanos y un foro anual que se realiza sobre este tema.

\subsubsection{Influencia de los principios en instrumentos internacionales}

Lo más notable, sin embargo, es que los PREDH han estado teniendo repercusión fuera de las Naciones Unidas, por el amplio respaldo por parte no solo de los gobiernos, sino también por el apoyo recibido de la comunidad empresarial y - aunque a veces de manera ocasional - la sociedad civil. Los principios vienen siendo adoptados e implementados por gobiernos y diversas instituciones. Asimismo, han sido recogidos en documentos internacionales tales como las líneas directrices para empresas

\footnotetext{
${ }^{28}$ El Consejo de Derechos Humanos aprobó los principios en su resolución 17/4, adoptada el 16 de junio de 2011 .
} 
multinacionales de la OCDE, la Comisión Europea, la International Finance Corporation y el ISO $26000 .^{29}$

\subsubsection{La OCDE}

Cuando la OCDE revisó las líneas directrices para empresas multinacionales en el año 2011, incluyó un capítulo IV sobre derechos humanos, que está basado en el marco del proteger, respetar y remediar. Esta inclusión autoriza o permite a los Puntos Nacionales de Contacto, que los Estados parte deben establecer para promover las directrices y para dirigirse a "instancias específicas", ser mucho más explícitos en relación a la expectativa de que las empresas cumplan con los derechos humanos.

En cuanto al tratamiento de los derechos humanos, en el capítulo IV se establece: el respeto a los derechos humanos: evitar infringir los derechos de otros y abordar los impactos negativos a los derechos humanos; evitar causar o contribuir a impactos negativos de los derechos humanos cuando estos ocurran; buscar formas de prevenir o mitigar los impactos negativos en derechos humanos; tener un compromiso de política para respetar los derechos humanos; llevar a cabo procedimientos de diligencia debida (due diligence) en derechos humanos; y contar con remedios para hacer frente a los impactos adversos en derechos humanos. (Martje \& van Huijstee, 2013, p. 24)

\subsubsection{La Comisión Europea}

La Comisión Europea avala los PREDH, y ha desarrollado guías específicas para varios sectores de la industria así como para la pequeña y mediana empresa. De esta manera, amplía el radio de aplicación de principios, comprueba la versatilidad y de una forma la generalidad con la que han sido redactados, y permite que puedan ser acondicionados para ser aplicados en más de un sector.

\footnotetext{
${ }^{29}$ El ISO es una certificación que es adquirida por las empresas que desean demostrar que cumplen con estándares de alta calidad. En el caso del ISO 26000, el tema principal es la responsabilidad social y esta ha incluido un acápite para tratar el tema de los derechos humanos en las empresas en la misma línea que lo hacen los Principios Rectores de Naciones Unidas.
} 


\subsubsection{La IFC}

Cuando la International Finance Corporation - IFC revisó su marco de sostenibilidad, que incluye tanto principios de sostenibilidad y estándares en procedimientos, se hace referencias a los derechos humanos reflejando los conceptos eje de los PREDH como la responsabilidad de los clientes del IFC de respetar los derechos humanos y ejercer la diligencia debida para asegurar que no se afecten negativamente los derechos humanos. Tal como el profesor John Ruggie ha hecho notar, estos principios y estándares afectan el acceso a capital internacional de las compañías, consecuencia múltiple porque son seguidos por instituciones de préstamos del sector privado que se guían por los principios del Ecuador, que cuentan con más de tres cuartos de todos los proyectos financieros alrededor del mundo. (Ruggie, 2013, at. 11)

\subsubsection{EI ISO 26000}

El ISO 26000 es la herramienta de la responsabilidad social desarrollada por la Organización Internacional de Estandarización, fundada en 1947 y ahora la más grande y de mayor influencia a nivel mundial en establecer estándares para el sector privado. Esta certificación, ahora incluye un capítulo de derechos humanos (capítulo 6.3) el cual sigue de cerca a los principios rectores. ${ }^{30}$ Si bien tampoco se trata de un instrumento vinculante o que obligue a las empresas a optar por él, puede ser aplicado por cualquier empresa que desee obtener la certificación; en otras palabras, las empresas peruanas que estén interesadas en obtener la certificación, tendrían que tomar en cuenta el capítulo 6.3 referente a los derechos humanos en las empresas.

En el capítulo referente a los derechos humanos se evalúan temas como el $d u e$ diligence en derechos humanos; situaciones de riesgo; medidas para evitar la complicidad; absolución de quejas; discriminación y grupos vulnerables; derechos civiles y políticos; derechos económicos, sociales y culturales; y principios y derechos fundamentales en el trabajo.

\footnotetext{
${ }^{30}$ http://www.iso.org/iso/home/standards/iso26000.htm
} 


\subsection{Tratado para las empresas y los derechos humanos}

Como lo habíamos señalado anteriormente, a partir de 1970, comenzó a expresarse preocupación sobre la influencia que las corporaciones transnacionales estaban ejerciendo sobre los Estados en los que operaban, y sobre las dificultades para controlarlas y asegurar que estas provean de grandes beneficios a la comunidad local. En esa época, se tomaron una serie de iniciativas para responder a dicha preocupación. Algunas tuvieron éxito, particularmente dentro de la Organización de Cooperación y Desarrollo Económico (OCDE), el grupo de países industrializados, y dentro de la Organización Internacional del Trabajo (OIT). Sin embargo, esfuerzos similares no prosperaron dentro de las Naciones Unidas. (Ruggie, 2014)

Después del 2000, en respuesta a la nueva ola de globalización económica, la preocupación sobre los derechos humanos jugó un rol de importancia creciente en la comunidad internacional, originando el nacimiento de los PREDH. Estos principios poseen la categoría de instrumento softlaw (no vinculanate), y aclara ciertas expectativas en ambos frentes: los Estados y las empresas, sin evitar imponer nuevas obligaciones vinculantes. El 13 de septiembre de 2013, se llamó a los principios un primer paso en el que otras iniciativas deben construirse, el representante de Ecuador ante las Naciones Unidas, Luis Gallegos en nombre del grupo de Estados, presentó una declaración que llamaba a la adopción de un instrumento legalmente vinculante dentro de las Naciones Unidas para regular a las empresas transnacionales y hacerlas responsables por abusos a los derechos humanos. ${ }^{31}$ El movimiento recibió apoyo de un conjunto amplio de organizaciones de la sociedad civil, que lanzaron una declaración (inicialmente adoptada por el foro de los pueblos en derechos humanos y empresas en Bangkok, 6-7 de noviembre de 2013) llamando a la elaboración de un tratado internacional que:

a) Afirme la aplicabilidad de las obligaciones de derechos humanos para las operaciones de corporaciones trasnacionales y otros negocios;

\footnotetext{
${ }^{31}$ Declaración en nombre de un grupo de países en la $24^{\text {a }}$ edición de sesiones del Consejo de Derechos Humanos. Publicada el 13 de setiembre de 2013. Inciativa Presentada en nombre del Grupo Africano, el Grupo Árabe, Pakistán, Sri Lanka, Kirguistán, Cuba, Nicaragua, Bolivia, Venezuela, Perú y Ecuador.
} 
b) Requiera a los Estados Parte monitorear y regular las operaciones de las empresas bajo su jurisdicción, incluyendo cuando actúan fuera de su territorio nacional, con una visión de prevención de abusos a los derechos humanos en el curso de esas operaciones;

c) Requiera a los Estados Parte proveer de herramientas necesarias para determinar la responsabilidad de las empresas por actos u omisiones que infrinjan los derechos humanos;

d) Requiera a los Estados Parte proveer acceso a remedios efectivos ante cualquier Estado implicado, incluyendo acceso a la justicia por parte de víctimas extranjeras que sufran daños por actos u omisiones de empresas en situaciones en las que hay bases para los Estados involucrados para ejercer sus obligaciones territoriales o extra territoriales de protección;

e) Provea de un mecanismo internacional de monitoreo y responsabilidad;

f) Provea protección a las víctimas, denunciantes y defensores de derechos humanos que buscan prevenir, exponer o asegurar la responsabilidad en casos de abusos de las corporaciones y garantiza su derecho a acceder a información relevante en este contexto. (Ruggie, 2014)

Un tratado internacional en esta materia es un instrumento vinculante que hace que los Estados Parte del mismo tengan la obligación de incluir su contenido en la legislación nacional, sin perjuicio de las reservas que pudieran formular. (Convención de Viena sobre el Derecho de los Tratados, 1969). Sin embargo, encontramos posturas que están a favor y en contra de un tratado en la materia.

\subsubsection{Argumentos a favor $y$ en contra de un tratado vinculante}

Dos resoluciones fueron presentadas al Consejo de Derechos Humanos de Naciones Unidas en su 26 período de sesiones en Ginebra: una primera redactada por Ecuador y Sudáfrica firmada por Bolivia, Cuba y Venezuela que buscaba el establecimiento de un grupo de trabajo intergubernamental con el mandato de elaborar un instrumento legal vinculante sobre los derechos humanos y las corporaciones transnacionales y otras empresas; y la segunda resolución redactada por Noruega y apoyada por 22 países de todas las regiones que incluye una solicitud de que el grupo de trabajo prepare un reporte considerando, entre otras cosas, los beneficios y limitaciones de los documentos legalmente vinculantes. Finalmente, el 26 de junio se adoptó la resolución propuesta por 
Ecuador y Sudáfrica. ${ }^{32}$ El 27 de junio el Consejo adoptó por consenso la resolución Noruega.

Cabe señalar que el Consejo de Derechos Humanos de Naciones Unidas ha mostrado su respaldo a la elaboración de un tratado; sin embargo, organizaciones como la Cámara de Comercio Internacional ${ }^{33}$ tienen una posición en contra de la adopción de un tratado sobre derechos humanos y corporaciones multinacionales. ${ }^{34}$ Uno de los argumentos empleados por quienes están en contra de la elaboración de un tratado es el temor de que esta nueva discusión vaya a poner en peligro los avances en la materia hasta el momento alcanzados por los diferentes países, empresas y organizaciones. El temor principal recae en el riesgo de que la responsabilidad directa de proteger los derechos humanos recaiga en el sector privado. Recordemos que, a la fecha, dicha responsabilidad recae directamente en los Estados y que un cambio en la responsabilidad podría ser perjudicial para las empresas, especialmente cuando estas vienen demostrando la voluntad de implementar los PREDH en su actividad empresarial. Señalan además que la motivación para la adopción voluntaria de los principios es la responsabilidad empresarial a través de un desarrollo económico sostenible que tiene como motor a los derechos humanos.

El temor por parte de aquellos países que se oponen a la adopción de un tratado vinculante reside en el hecho de que las normas vinculantes y de obligatorio cumplimiento sobre las empresas multinacionales "dotarán a los sindicatos de un poderoso instrumento para afrontar las violaciones de los derechos humanos y para detener la competencia por las peores condiciones", ${ }^{35}$ y los sindicatos, en cooperación con la sociedad civil, ejercerán presión para lograr normas significativas. La adopción de un tratado significaría contrarrestar la resistencia que sobre este tema se ha tenido durante más de 40 años por parte de las empresas multinacionales.

\footnotetext{
3220 votos a favor (Argelia, Benín, Burkina Faso, China, Congo, Costa de Marfil, Cuba, Etiopía, India, Indonesia, Kazajistán, Kenia, Marruecos, Namibia, Pakistán, Las Filipinas, Rusia, Sudáfrica, Venezuela, Vietnam), 14 votos en contra (Austria, República Checa, Estonia, Francia, Alemania, Irlanda, Italia, Japón, Montenegro, Corea del Sur, Rumanía, La ex Yugoslavia, Reino Unido, Estados Unidos) y 13 abstenciones (Argentina, Botsuana, Brasil, Chile, Costa Rica, Gabón, Kuwait, Maldivas, México, Perú, Arabia Saudita, Sierra Leona, Los Emiratos Árabes unidos).

${ }^{33}$ En: http://www.iccwbo.org/News/Articles/2014/ICC-disappointed-by-Ecuador-Initiative-adoption/ ${ }_{35}^{34}$ Presentada el 19 de junio y actualizada el 24 de junio de 2014.

35 En: http://www.industriall-union.org/es/la-ue-y-estados-unidos-anteponen-las-empresas-a-losderechos-humanos (visualizado al 7 de julio de 2014)
} 
Definitivamente, un tratado es internacionalmente vinculante y tiene una jerarquía importante en la estructura interna de las Naciones, por lo que debe ser incluida en la legislación interna de los Estados. Sin embargo, aunque podamos decir que un tratado vinculante establece un estándar mundial en la materia, su adopción no escapa de la decisión política, la misma que puede jugar en contra de su pronta adopción, pudiendo no llegar a concretarse. Por otro lado, también existe el riesgo de que la resolución de Ecuador pueda romper el consenso unánime que se había logrado con los PREDH. ${ }^{36}$

\subsection{Conclusiones del Capítulo I}

El objetivo del presente capítulo es presentar un panorama histórico de los intentos de la comunidad internacional de normar el comportamiento de las corporaciones transnacionales dado el creciente y grave índice de vulneraciones que se han presentado en el mundo desde hace varios años. En este recuento, hemos encontrado documentos no vinculantes que tienen en común dar lineamientos o estándares mínimos que las empresas deben cumplir para el respeto de los derechos humanos. Sin perjuicio de que puedan ser recogidos en instrumentos vinculantes o en la legislación nacional de los Estados, es importante conocerlos y analizar la viabilidad de su aplicación práctica.

Al finalizar el panorama histórico, resaltamos la importancia de los PREDH porque, a diferencia de los demás instrumentos, los principios han obtenido un consenso mundial y son citados e incluidos en otros documentos internacionales de alcance regional, por lo que estamos frente a la uniformización en el tratamiento de los derechos humanos por parte de las empresas.

Consideramos que los principios rectores contienen los puntos más concretos y su generalidad permite adecuarlos a cualquier tipo de sector o actividad empresarial. En ese sentido, su implementación en nuestra legislación interna resulta relevante para lograr que consigan la calidad de vinculantes, es decir, de obligatorio cumplimiento. En cuanto al debate por la adopción de un tratado internacional en la materia, lo cual trae

\footnotetext{
36 http://www.ioe-emp.org/index.php?id=1238 (visualizado al 6 de julio de 2014). En esta nota se establece que Organización Internacional de Empleadores lamenta la adopción de la iniciativa de Ecuador temiendo que signifique un retroceso en lo ya avanzado con los principios Rectores adoptados en el 2011.
} 
posiciones a favor y en contra, debe tomarse en cuenta que de adoptarse poseerá carácter vinculante y las legislaciones internas de los Estados deberán implementarlos. 


\section{CAPÍTULO II: MARCO JURÍDICO Y EMPRESA}

\subsection{Implementación de los PREDH a nivel regional - Unión Europea}

A nivel regional, en la Unión Europea se encuentra, de manera potencial, la aplicación de la propuesta 2013/0110 (COD) que modifica la Directiva de Consejo 78/660/EFEC y 83/349/EFEC respecto de la divulgación de información no financiera y diversificada por parte de grandes compañías y grupos empresariales. ${ }^{37}$ Esto es importante porque se incluye el respeto a los derechos humanos por parte de la empresa, adicionalmente a la consulta pública sobre una posible iniciativa de la Unión Europea sobre aprovisionamiento responsable de minerales originarios de áreas afectadas por el conflicto y áreas de alto riesgo. ${ }^{38}$ Dicha iniciativa también está en concordancia con los principios en el sentido de la no complicidad y due diligence, entre otros temas.

\subsection{Implementación de los PREDH en la legislación comparada}

Los Estados son alentados a desarrollar, poner en práctica y actualizar PANs - planes de acción nacional - como parte de su responsabilidad para promover e implementar los PREDH. $^{39}$ El grupo de trabajo de Naciones Unidas ha reconocido los retos y

\footnotetext{
${ }^{37}$ Adoptada el 16 de abril de 2013. El reporte anual debe incluir una revisión justa del desarrollo y la actuación de la compañía en el negocio y la posición que esta tiene. Las compañías cuyo número promedio de empleados durante el último año fiscal supere los 500, y que en cuyo balance, exceda en libros los 20 millones de Euros o una facturación de más de 40 millones de Euros, la revisión también debe incluir declaraciones no financieras que incluya material informativo relacionado con cuestiones ambientales, sociales y laborales, respeto a los derechos humanos, anticorrupción y hechos conexos. Dentro de estas áreas, las declaraciones incluirán (i) una descripción de sus políticas, (ii) resultados y (iii) aspectos relacionados al riesgo. A principios de año, la propuesta estaba siendo considerada por el Parlamento Europeo, el Consejo y los Estados Miembros. La Comisión ha indicado que las compañías no deberían de estar afectadas por ningún requisito adicional hasta el 2017. En: Overview of key Business \& Human Rights Legislation for companies. CLT envirolaw. http://businesshumanrights.org/sites/default/files/media/documents/clt_human_rights_legislation-1.pdf ${ }^{38}$ La consulta fue cerrada el 26 de junio de 2013. La comisión utilizaría los resultados de la consulta para determinar si es posible y como se puede complementar efectivamente o continuar con las iniciativas de diligencia debida (due diligence) vigentes y apoyar al buen gobierno en la minería, particularmente en los países en desarrollo afectados por el conflicto. En: Overview of key Business \& Human Rights Legislation for companies. CLT envirolaw. http://businesshumanrights.org/sites/default/files/media/documents/clt_human_rights_legislation-1.pdf

39 Los Planes de Acción Nacionales o NAPs (siglas en inglés para National Action Plans) son documentos de políticas en los que los Estados articulan sus prioridades y acciones a adoptar para apoyar
} 
dificultades que conlleva elaborar un plan de acción efectivo, y es por eso que ofrece su asistencia a los Estados en este proceso. Asimismo, encontramos una gran variedad de instituciones que se han preocupado en publicar información clave acerca de los puntos importantes que se deben aplicar en los planes nacionales. ${ }^{40}$

Sin perjuicio de lo anterior, dentro de la legislación clave referente a las empresas y derechos humanos, podemos hacer referencia a los planes de acción y a la legislación existente en diversos países. ${ }^{41}$ El Reino Unido, Holanda, Dinamarca e Italia han publicado PANs para la implementación de los PREDH y España cuenta con un borrador que está en espera de la aprobación respectiva. ${ }^{42}$ Como parte de la implementación que se observa en diversos países, se espera que la regulación se incremente. $^{43}$

\subsubsection{Reino Unido}

En Setiembre del 2013 se emitió un plan de acción titulado "Good Business: Implementing the UN Guiding Principles on Business and Human Rights", el plan en mención tiene como objetivo implementar los PREDH en la legislación interna. Los Principios establecen el deber del Estado de proteger los derechos humanos y proveer de un adecuado mecanismo que propicie la reparación en casos de violaciones a los derechos humanos por parte del sector privado. El documento refuerza el compromiso

la implementación de obligaciones y compromisos internacionales, regionales o nacionales con respecto a un área o tema de política dada. La dependencia en los Planes como una herramienta de acercamiento de políticas y gobierno no está limitado al área de los derechos humanos y empresas. Por el contrario, el requerimiento de un Plan de Acción basado en los Principios rectores surge del uso creciente de planes en otras áreas en las recientes décadas. En: http://accountabilityroundtable.org/wp-

content/uploads/2014/06/DIHR-ICAR-National-Action-Plans-NAPs-Report2.pdf

${ }^{40} \mathrm{http}$ ://business-humanrights.org/en/state-national-action-plans (visitado al 6 de Julio de 2014)

41 Overview of key Business \& Human Rights Legislation for companies. CLT envirolaw. http://business-humanrights.org/sites/default/files/media/documents/clt_human_rights_legislation-1.pdf

${ }_{42}$ Lindsay, Rae. Business and human rights - emerging issues for financial institutions. Clifford Chance, London. May 2014. En: http://www.cliffordchance.com/briefings/2014/05/business_and_ humanrightsemergingissuesfo.html

${ }^{43}$ En el mes de febrero del 2015 Lituania presentó un Plan de Acción Nacional. Asimismo, países como Argentina, Azerbayán, Bélgica, Brazil, Chile, Colombia, Francia, Alemania, Grecia, Indonesia, Irlanda, Jordania, Latvia, Malasia, Mauritania, Méjico, Marruecos, Mozambique, Myanmar, Noruega, Portugal, Escocia, Eslovenia, Suiza, y Estados Unidos se encuentran en Proceso de elaborar planes nacionales. Por otro lado, hay iniciativas de la sociedad civil en países como Ghana, Polonia, Kazajistan, Sudáfrica,

Korea del Sur, y Tanzania. En: http://business-humanrights.org/en/un-guiding-principles/implementationtools-examples/implementation-by-governments/by-type-of-initiative/national-action-plans 
del gobierno del Reino Unido de asegurar a las empresas y a otras organizaciones del sector privado a respetar los derechos humanos.

Es importante conocer que en el Reino Unido ${ }^{44}$ el Companies Act $2006^{45}$ contiene una norma efectiva desde octubre del 2013 que señala que las compañías que se encuentran listadas en las bolsas de Londres, el área Económica Europea, Nueva York o Nasdaq deben contar con un reporte estratégico que debe comprender, entre otras informaciones, aquella referente al desarrollo, actuación o posición de la empresa en el entorno social, comunitario y de derechos humanos. Esto incluye la revelación de políticas que tomen en favor de estos temas, y de indicadores clave de actuación en asuntos ambientales y laborales. Si el reporte no contiene información sobre estos temas, debe establecerse las razones en el mismo reporte. Esta legislación es aplicable a compañías cuyo año fiscal culminó en o después del 30 de setiembre de 2013. En ese sentido, cualquier reporte anual publicado por una empresa que cotiza en bolsa con posterioridad a esa fecha debe contar con el mencionado reporte. ${ }^{46}$

Hasta el momento, nos hemos referido a la legislación vinculante en el Reino Unido que se encuentra directamente ligada y en concordancia con la implementación o cumplimiento de los PREDH. Sin embargo, también existen otras normas que también se encuentran relacionadas como: la Consulta del Modern Day Slavery Bill ${ }^{47}$-que es una norma que regula la esclavitud moderna, la Transparencia en la Cadena de Suministros en el Reino Unido (erradicación de la esclavitud) Bill 2012-2013 ${ }^{48}$ y la

\footnotetext{
${ }^{44}$ En: https://www.gov.uk/government/uploads/system/uploads/attachment_data/file/236901/BHR_ Action_Plan_-_final_online_version_1_.pdf

${ }^{45}$ s. 414 (c)(7) Companies Act 2006 (as amended by regulation 3 of the Companies Act 2006 (Strategic Report and Directors' Report) Regulations 2013)

${ }^{46}$ Overview of key Business \& Human Rights Legislation for companies. CLT envirolaw. http://business-humanrights.org/sites/default/files/media/documents/clt_human_rights_legislation-1.pdf ${ }^{47}$ Consultations on Modern Day Slavery Bill. La revisión se abrió en octubre de 2013. Las conclusiones forman parte de un borrador del Modern Slavery Bill que el gobierno intenta publicar para aprobación pre legislativa y que pueda ser introducida en la siguiente sesión. Entre otros puntos, esta revisión busca dirigir como las multinacionales británicas pueden asegurar adecuadamente que su cadena de suministros está libre de esclavitud. En: Overview of key Business \& Human Rights Legislation for companies. CLT envirolaw. http://business-humanrights.org/sites/default/files/media/ documents/ clt_human_rights_ legislation-1.pdf

${ }^{48}$ Transparencia en la cadena de suministros de compañías británicas (erradicación de la esclavitud) esta norma no completó su paso por el parlamento. Sus requerimientos reflejan el equivalente californiano, estableciendo que cada compañía que opera en el Reino Unido y que tiene ingresos mundiales brutos anuales que excedan $£ 100,000,000$ (cien mil libras esterlinas) debe dar a conocer sus esfuerzos para erradicar la esclavitud, el tráfico de personas, el trabajo forzado y el trabajo infantil ilegal desde su cadena de suministros directa de bienes tangibles y servicios comercializados. Actualmente se está
} 
propuesta de una norma sobre tráfico de personas de Escocia. ${ }^{49}$ La norma sobre la transparencia en la cadena de suministros importa porque amplía el deber de la empresa de conocer el funcionamiento de las empresas o instituciones que le sirven de proveedores y prestadores de servicios.

\subsubsection{Estados Unidos}

En los Estados Unidos encontramos la disposición Dodd-Frank sobre extracción ilegal de minerales y la ley de transparencia en las cadenas de suministro de California como instrumentos de obligatorio cumplimiento. Por un lado, la ley de transparencia establece que los vendedores minoristas y fabricantes que tengan un ingreso bruto anual mundial mayor a los \$100 000000 (cien millones de dólares) y que se encuentren establecidos o realicen negocios en el estado de California deben desplegar esfuerzos para erradicar la esclavitud y el tráfico de personas de sus cadenas de suministro de bienes tangibles comercializados. ${ }^{50}$ Por otro lado, la disposición Dodd-Frank requiere que los emisores (nacionales o extranjeros) de la Comisión de Valores e Intercambio de Estados Unidos (US Securities and Exchange Commission - SEC) que fabrican o contratan para fabricar productos donde "minerales en conflicto son necesarios para el funcionamiento o producción" del producto deban informar sobre el uso de dichos minerales originarios de la República Democrática del Congo y 9 países vecinos de África Central ("Países cubiertos"). ${ }^{51}$

considerando una norma en esclavitud moderna. En: Overview of key Business \& Human Rights Legislation for companies. CLT envirolaw. http://business-humanrights.org/sites/default/files/media /documents/clt_human_rights_legislation-1.pdf

${ }^{49}$ Las consultas cerraron el 6 de diciembre de 2013. Entre sus objetivos se incluye una consideración de cómo generar, a través de un enfoque de participación voluntaria, que las compañías que operan en Escocia se responsabilicen para prevenir, identificar y atacar el tráfico de personas en sus cadenas de suministros, reflejando las mejores prácticas de California. En: Overview of key Business \& Human Rights Legislation for companies. CLT envirolaw. http://business-humanrights.org/sites/default/files/ media /documents/clt_human_rights_legislation-1.pdf

${ }^{50}$ La ley de transparencia fue promulgada el 30 de setiembre de 2010 yse encuentra en vigencia desde el primero de enero de 2012.

51 La disposición Dodd-Frank fue promulgada el 21 de julio de 2010 y modificada el 22 de agosto de 2012.

En la actualidad, los minerales en conflicto incluyen a la casiterita, columbita-tantalita, oro and wolframita originarios de los países cubiertos. Se cree que su comercio sirve para financiar el conflicto armado, que lleva al continuo abuso de los derechos humanos en la región. La norma definitiva exime a los minerales en conflicto exime a los minerales en conflicto que están "fuera de la cadena de suministros" antes del 31 de enero de 2013. Los minerales en conflicto están "fuera de la cadena" solo 
A nivel jurisprudencial, se da en la práctica la aplicación controversial del Alien Tort Statute en casos de violaciones a los derechos humanos por parte de empresas norteamericanas o con presencia norteamericana. Esta presunción habilita al sistema judicial estadounidense a conocer de casos que "tocan y conciernen" como país con "fuerza o relevancia suficiente". 52

Por otro lado, a nivel legislativo encontramos iniciativas legislativas para la prohibición de importación de bienes cuando son producto de trabajo forzado o trabajo infantil. ${ }^{53}$ Esto se puede lograr a través de auditorías en las cadenas de suministro de las compañías y sería exigible a aquellas empresas con ingresos mayores al millón de dólares.

\subsubsection{Finlandia}

Los Ministerios de Trabajo y Economía de Finlandia publicaron el 30 de abril de 2014 un borrador de plan de acción sobre empresas y derechos humanos, el mismo que fue elevado a consulta. En una resolución sobre responsabilidad social, aprobada el 22 de noviembre de 2012, el gobierno decidió que Finlandia elaboraría un plan de acción para la implementación de los PREDH. El plan hace referencia a la legislación finlandesa, provisiones constitucionales y acuerdos internacionales, así como a otros procedimientos y prácticas relacionadas a los principios de Naciones Unidas. El objetivo de estas propuestas es iniciar procedimientos que tendrán énfasis en la conexión entre empresas y derechos humanos para ayudar a las empresas a mejorar la forma en la que se enfrentan y toman en cuenta los impactos de los derechos humanos en su actividad. El plan de acción intenta facilitar la realización de una lista de acciones

\footnotetext{
"después de la fundición de la columbita-tantalita, casiterita, y wolframita; luego de que el oro haya sido completamente refinado; o luego de que cualquier mineral en conflicto, o sus derivados, que no hayan sido fundido o completamente refinado esté localizado fuera de los Países Cubiertos". En: Overview of key Business \& Human Rights Legislation for companies. CLT envirolaw. http://businesshumanrights.org/sites/default/files/media /documents/clt_human_rights_legislation-1.pdf $52 \mathrm{http} / / / \mathrm{www}$.lawfareblog.com/2014/07/two-new-ats-decisions-fourth-and-eleventh-circuits-split-onwhether-claims-against-caci-and-chiquita-touch-and-concern-the-territory-of-the-united-states/ (visitado al 30 de Julio de 2014)

${ }^{53}$ En Estados Unidos existe un vacío respecto al tema porque legalmente se permite que se importen bienes provenientes del trabajo forzado por razones de demanda. En el mes de mayo de 2015, http://vargas.house.gov/media-center/press-releases/rep-vargas-introduces-the-stop-blood-tomatoes-actof-2015
} 
en los próximos años; sin embargo, esta lista no es absoluta en el sentido de que nuevas acciones pueden ser agregadas. ${ }^{54}$

Adicionalmente, el aumento de publicaciones en el tema de los derechos humanos y empresas hace que los reguladores sugieran a los negocios a considerar los impactos éticos y sociales negativos que indirectamente les pueden generar responsabilidad. La pregunta para las empresas es si mostrarse desentendidos ante esta creciente responsabilidad que incluye a la responsabilidad legal, les resulta más beneficioso que mostrar conciencia y tomar acciones. En ese sentido, las recomendaciones serán: asegurar que la política de derechos humanos de la organización se encuentre en regla y apostar por un monitoreo interno constante, particularmente en términos de capacitación adecuada de los departamentos pertinentes. Asimismo, es fundamental la colaboración con la cadena de suministros para asegurar que esas políticas, códigos y estándares se encuentren alineados con la organización. ${ }^{55}$

\subsubsection{Dinamarca}

El Plan de Acción Nacional (PAN) danés incluye los tres pilares de los PREDH y es un documento interministerial en el que se resumen los principios, seguidos de las recomendaciones del Consejo Danés para la RSC, iniciativas que han sido implementadas e iniciativas planificadas a implementarse. ${ }^{56}$ Adicionalmente, cuenta con un anexo que muestra un esquema de implementación principio por principio. Según este texto, la parte pertinente al segundo pilar (respeto a los derechos humanos), toma en cuenta los principios rectores en el extremo de que las empresas deben contar con un compromiso de incluir en sus políticas la responsabilidad de respetar los derechos humanos; contar con un proceso de diligencia debida en dicha área para prevenir, mitigar y dar cuenta de cómo manejar los impactos adversos; además de contar con procesos para permitir el remedio a los impactos que ellos causen o que les

\footnotetext{
54 http://business-humanrights.org/en/pdf-finland-draft-national-action-plan-on-business-human-rightsfor-consultation-ty\%C3\%B6ryhm\%C3\%A4n-ehdotus-ykn-yrityksi\%C3\%A4-ja-ihmisoikeuksiakoskevien-ohjaavien-periaatteiden-kansalliseksi

55 En: Overview of key Business \& Human Rights Legislation for companies. CLT envirolaw. http://business-humanrights.org/sites/default/files/ media /documents/clt_human_rights_ legislation1.pdf

${ }_{56}$ Danish National Action Plan - implementation of the UN Guiding Principles on Business and Human Rights
} 
sean atribuidos. Dentro de las acciones tomadas se cita el apoyo del gobierno danés a principios internacionales en RSC. ${ }^{57}$ Existe la expectativa de que las empresas e inversionistas respeten los derechos humanos, lo que será evaluado en los reportes de RSC en las compañías listadas en bolsa, y el premio al mejor reporte no financiero. ${ }^{58}$ Cabe señalar que el gobierno danés cuenta ya con un PAN sobre RSC (2012-2015) que incluye iniciativas para implementar los PREDH y demuestra su compromiso de continuar con la implementación.

\subsubsection{Holanda}

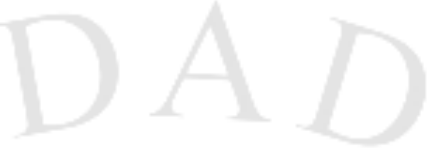

A diferencia de los planes elaborados por otros países, el plan de Holanda no señala su aplicación en un plano temporal, tampoco hace mención sobre cómo va a ser el proceso de implementación y el monitoreo del plan, ni cómo se obtendrá el presupuesto para hacerlo. ${ }^{59}$ El objetivo del plan recae en prevenir que las empresas abusen de los derechos humanos, sea directamente o dentro de su cadena de abastecimiento o suministros. Respecto de las soluciones que se puedan dar cuando los abusos han sido cometidos, se ha comisionado un estudio para definir los sectores que corren el mayor riesgo de abusos; sin embargo, a pesar de la innovación y expectativa de este acercamiento, todo dependerá del monitoreo y obligatoriedad de los acuerdos y normas que al respecto se aprueben.

Adicionalmente, se toca el apoyo del gobierno y la iniciativa de incluir el cumplimiento de la RSC como condición para proveer de asistencia financiera a los negocios internacionales y misiones comerciales. A Holanda aún le queda por definir el criterio que emplearán los diferentes tipos de apoyo gubernamental, la evaluación que se dará dentro de las compañías y las sanciones posibles a ser impuestas si no se cumplen determinadas condiciones. Según el PAN, la toma de conciencia y la capacitación en el tema son prioritarias. Por otro lado, se sugiere que la diligencia debida sea tomada en el sentido que lo hacen los PREDH ya que ello facilitará la identificación de riesgos reales y posibles que puedan ocurrir dentro de una empresa o

\footnotetext{
${ }^{57}$ Responsabilidad Social Corporativa

58 http://csrgov.dk/communication_and_reporting

${ }^{59}$ Dutch National Action Plan on Business and Human Rights Feb 17, 2014 En: http://mvoplatform.nl/news-en/dutch-national-action-plan-on-business-and-human-rights
} 
cadena de suministros, así como las medidas para prevenirlas, mitigarlas y remediarlas. Se espera que Holanda aliente la transparencia corporativa, relacionada al Transparency Benchmark, la futura regulación europea de reportes no financieros y el Código de gobierno Corporativo. ${ }^{60}$ Sin embargo, el principio de diligencia debida aún no ha encontrado un lugar dentro de las iniciativas de transparencia.

Por otro lado, se han levantado críticas adicionales al plan en el sentido de la posibilidad de adicionar capítulos o cláusulas relacionadas a la sostenibilidad de los acuerdos de inversión y comercio, debido a que en la realidad los acuerdos se tendrían que transformar para contribuir a la protección de los derechos humanos. Se critica que en la práctica las embajadas se verán en la necesidad de priorizar entre las oportunidades que el mercado les da para promover la exportación (con el correspondiente bono en caso de promoción exitosa) y promover la conciencia de los riesgos a los derechos humanos. También se critica el acceso a remedios por parte de las víctimas de abusos relacionados por las empresas porque a pesar de las medidas preventivas, aún se presentan abusos serios que requieren la creación de procedimientos que las víctimas puedan seguir, lo que puede ser explicado por la preocupación del gobierno de favorecer al sector privado en este aspecto.

\subsubsection{Italia}

De acuerdo al sistema político italiano, tanto el Ministerio de Trabajo y Políticas Sociales como el de Desarrollo Económico son competentes para aplicar políticas nacionales en RSC. A partir del 2011, el Gobierno de Italia ha centrado su atención en el desarrollo y actualización de sus políticas en RSC, empresas y derechos humanos. (Bordignon, 2012-2013, p. 122) En setiembre del 2013 se publicó el PAN italiano en RSC con el objetivo de cumplir con el comunicado de la UE sobre RSC. Los Ministerios italianos involucrados han seleccionado como autoridad líder al Ministerio de Relaciones Exteriores para la elaboración del PAN sobre empresas y derechos humanos.

\footnotetext{
${ }^{60}$ Investigación anual sobre el contenido y la calidad de la responsabilidad social corporativa de las empresas holandesas.
} 
El PAN italiano ${ }^{61}$ abarca dos de los tres pilares de los PREDH que son el primer pilar (el deber del Estado de proteger los derechos humanos) y el tercer pilar (acceso a remedios para las víctimas). Sin embargo, no se han considerado provisiones efectivas sobre las acciones a implementar en el futuro. Tal como lo demuestra la gran variedad de sectores involucrados, el PAN ha sido el resultado del esfuerzo conjunto de varios ministerios.

Respecto del deber del Estado de proteger, lista las políticas ya implementadas en los sectores de mayor relevancia como la agricultura, medio ambiente y desarrollo sostenible, trabajo, inversión extranjera directa y crédito a las exportaciones, adquisiciones públicas, libertad de religión e iniciativas de capacitación para funcionarios públicos. (Bordignon, 2012-2013, p. 128) Del mismo modo, se hace referencia a las regulaciones vigentes referidas al acceso a los remedios judiciales y no judiciales.

Cabe señalar que el Gobierno italiano también toma en cuenta el punto de vista de los inversionistas y tiene en agenda una serie de eventos para promover la política exterior por la Sostenibilidad, la misma que incluye el respeto a los derechos humanos por parte de las empresas. ${ }^{62}$

${ }^{61}$ The foundations of the Italian action plan on the United Nations "Guiding Principles on business and Human Rights” En: http://business-humanrights.org/sites/default/files/media/documents/foundationsungps-nap-italy.pdf

${ }^{62}$ Los Objetivos estratégicos que recaen en el borrador sobre Política Exterior de Sostenibilidad incluye: (1) la elaboración de un marco nacional para el respeto a los derechos humanos y la promoción de actividades empresariales sostenibles; (2) apoyo paralelo a iniciativas que tengan como base la sostenibilidad que debe ser integrada en un enfoque basado en los derechos humanos; (3) la contribución al desarrollo económico y social de países emergentes; y, (4) un gran compromiso en agencias internacionales e instituciones de derechos humanos creadas para abordar los retos emergentes sobre sostenibilidad. Además, la Fundación Global Compact italiana en colaboración con la Dirección General, ha creado un Grupo de Trabajo en Derechos humanos compuesto de representantes de las empresas multinacionales italianas más importantes, bancos y compañías de seguros, con el objetivo de generar conciencia sobre los Principios Rectores sobre Empresas y Derechos Humanos, compartiendo con ellos herramientas y asesorías, así como políticas para la implementación de la diligencia debida. Finalmente, el Gobierno italiano tiene un rol importante en la iniciativa para la protección ambiental de la OCDE, a través de la elaboración de una nueva versión del llamado 'Enfoques Comunes en materia de medio ambiente y de crédito a la exportación con apoyo oficial', actualizado por última vez en el 2012. El Sub-grupo de derechos humanos de la OCDE, que asesora al grupo de crédito a la exportación de la OCDE en el desarrollo de los enfoques basados en los derechos humanos, ha indicado algunas áreas de interés que deben ser incluidas en las acciones futuras de la OCDE, tal como las potenciales violaciones a los derechos humanos por parte de las actividades de exportación, los estándares de la IFC y el Banco Mundial en este campo y las políticas de diligencia debida requeridas por los Principios Rectores de Naciones Unidas. En: Bordignon, Marta. The challenge of implementing the UN "Protect, Respect and Remedy" framework by States and the European Union through the UN guiding principles: The British, 


\subsubsection{España}

España cuenta con la estrategia nacional de responsabilidad social empresarial y con el plan de empresas y derechos humanos. En relación a este último, se destaca que el borrador del Plan se encontró abierto a consulta de todos los interesados (empresas, $\mathrm{OSCs}^{63}, \mathrm{ONGs}^{64}$, autoridades públicas y círculos académicos), quienes tuvieron la oportunidad de tener una participación activa en las distintas fases de su elaboración. El Plan contiene los ejes prioritarios y el marco internacional de referencia en los que se basa, dentro de los cuales hace referencia a todos los principios junto con las medidas requeridas para adaptarlos a la legislación e implementarlos en las empresas. El plan establece un ámbito temporal de 5 años desde su aprobación y prevé la creación de una comisión de seguimiento que evaluará anualmente la ejecución de las medidas y elaborará propuestas e informes de diagnóstico. Esta Comisión hará pública su actividad a los sectores interesados, ciudadanía general, a los representantes de la RSE de los Estados miembros de la UE, órganos europeos y Naciones Unidas.

Respecto del segundo pilar, se plantea la creación de un sistema de incentivos tanto a grandes empresas como a pymes que cuenten con políticas adecuadas en el ámbito de los derechos humanos, estos incentivos pueden ser económicos, comerciales, de presencia, visibilidad e imagen, o de otra índole. Para acceder a los incentivos, las empresas tendrán que acreditar fehacientemente que han implementado procedimientos adecuados de diligencia debida y de reparación de las consecuencias negativas que sobre los derechos humanos y medio ambiente hayan provocado. ${ }^{65}$ Asimismo, el gobierno se compromete a sensibilizar a las empresas sobre su deber de reparar o contribuir a reparar, promoviendo el diálogo y mecanismos de reparación. ${ }^{66}$

Spanish and Italian Cases. Tésis doctoral del XXVI ciclo del corso di dottorato della Facolta' di giurisprudenza della Universitá Degli Studi di Roma Tor Vergata. Anno Accademico 2012/2013. p. 122 ${ }_{63}$ Organizaciones de la Sociedad Civil.

${ }^{64}$ Organizaciones No Gubernamentales.

${ }^{65}$ Medida 27 del borrador plan de empresas y derechos humanos. En: http://www.foretica.org/segundo_ borrador_plan_de_empresa_y_derechos_humanos.pdf

${ }^{66}$ Medida 29 del borrador plan de empresas y derechos humanos. En: http://www.foretica.org/segundo_ borrador_plan_de_empresa_y_derechos_humanos.pdf 


\subsubsection{Suiza}

La Coalición para la Justicia Corporativa Suiza lanzó en abril de 2015 una iniciativa pública cuyo objetivo es requerir a las empresas Suizas respetar los derechos humanos y estándares ambientales en su territorio y en el extranjero. La iniciativa comprende la enmienda de la Constitución Federal en torno a las empresas responsables. Con esta iniciativa el due diligence en derechos humanos y ambientales es obligatorio e incluye la valoración del riesgo, medidas para prevenir y eliminar posibles violaciones a los derechos humanos y daños al medio ambiente; así como el reporte de políticas y acciones tomadas, dependiendo del tamaño y ámbito de aplicación de cada empresa. ${ }^{67}$

\subsubsection{China}

China ha estado adoptando rápidamente estándares paralelos, y está impulsando y promoviendo el estándar del ISO 26000 empleando los medios de comunicación para que las empresas los adopten. (Wang, 2012, p. 46-47) Al involucrar a los medios de comunicación, también está involucrando a la comunidad empresarial e informando a la población (público consumidor, usuario y empleado). En varios casos, China ha tomado medidas inusuales de mecanismos de reclamación acordes a los principios rectores. Por ejemplo, la embajada China en Myanmar $^{68}$ cuenta con una página en Facebook en la que los miembros de la comunidad pueden interactuar con las autoridades. ${ }^{69}$

\subsection{Implementación de los PREDH en Latinoamérica}

Como se había detallado en el capítulo anterior, la propuesta de Ecuador de elaborar un tratado ha tenido eco en otros países y los Estados Miembros de Naciones Unidas ya se encuentran en camino de su pronta elaboración. Sin perjuicio de las opiniones vertidas por distintos Estados e instituciones, queda clara la posición en contra que tienen los

\footnotetext{
${ }^{67}$ http://www.corporatejustice.ch/media/medialibrary/2015/01/150119_sccj_-_press_release__popular_initiative_on_responsible_business.pdf (visualizado al 24 de marzo de 2016) ${ }^{68} \mathrm{https}: / / \mathrm{www}$. facebook.com/pages/Chinese-Embassy-in-Myanmar/191612647581463

${ }^{69} \mathrm{https}: / / \mathrm{www}$. youtube.com/watch?v=bJw1bwS5_nU
} 
Gobiernos que representan los intereses de los grandes capitales. ${ }^{70}$ Poniendo este tema aparte ya sea que se adopte o no un tratado en la materia, la implementación de los principios, al día de hoy, resulta de un compromiso voluntario tanto de los Estados como de las empresas. En ese sentido, hemos encontrado que en Latinoamérica, específicamente en Colombia, ${ }^{71}$ se viene trabajando el tema de la implementación con un diálogo constante entre el Estado, la empresa y la sociedad civil; optándose por la implementación por sectores. En el caso de Argentina, esta cuenta con la guía de derechos humanos para empresas desde el año $2012 .^{72}$ En Chile, se viene elaborando un PAN en derechos humanos y empresas. ${ }^{73}$ Por otro lado, en el Perú contamos con el Plan Nacional de Derechos Humanos que hace alusión a los derechos humanos y empresas en dos de los lineamientos estratégicos que contiene. ${ }^{74}$ Asimismo, contamos con diversas iniciativas de responsabilidad social empresarial que de algún modo coinciden con los PREDH.

\subsection{Marco jurídico}

Como ya lo habíamos señalado anteriormente, los principios no poseen una naturaleza vinculante; sin embargo, nuestro país tiene la voluntad de cumplir con su rol de protección de los derechos humanos. Es así que en julio del 2012 se suscribió la

70 En: http://business-humanrights.org/es/estados-unidos-y-pa\%C3\%ADses-de-la-uni\%C3\%B3neuropea-en -contra-de-resoluci\%C3\%B3n-para-elaborar-normas-vinculantes-para-multinacionales-yderechos- humanos (visitado el 7 de julio de 2014)

71 http://archive.ideaspaz.org/index.php/guias-colombia/multimedia/1073-implementacion-de-losprincipios-rectores-de-las-naciones-unidas-para-el-tema-de-empresas-y-derechos-humanos-en-colombia 72 http://www.ar.undp.org/content/dam/argentina/Publications/Pacto\%20Global/PNUDArgentGu\%C3\%ADa-Empresas-DDHH-final.pdf y http://argentina.corresponsables.com/actualidad/unaveintena-de-entidades-forman-el-grupo-de-trabajo-empresas-y-ddhh-de-pacto-global-arge

${ }^{73} \mathrm{http} / / / \mathrm{www} . \mathrm{minrel}$.gob.cl/canciller-munoz-dio-inicio-a-proceso-de-elaboracion-de-plan-de-accionnacional-de-derechos-humanos-y-empresas/minrel/2015-04-24/185248.html

${ }^{74}$ Plan Nacional de Derechos Humanos 2014-2016. Aprobado por Decreto Supremo N 005-2014-JUS Lineamiento Estratégico $N^{o} 3$ Diseño y ejecución de políticas a favor de los grupos de especial protección (...) Objetivo $\mathrm{N}^{\mathrm{o}}$ 23: Incrementar los niveles de confianza entre el Estado y los pueblos indígenas, mediante la consolidación de espacios de coordinación y diálogo permanente. (...) Acción vinculada: Evaluar el impacto de la actividad empresarial en el respeto a los derechos humanos en el Perú, con el fin de establecer lineamientos y marcos de acción. Entidades involucradas: PRODUCE, MEM, MTC, MINCETUR Lineamiento Estratégico $N^{\circ} 4$ Fortalecimiento del ordenamiento jurídico interno, a través de la implementación de instrumentos internacionales para la promoción y protección de los derechos humanos (...) Objetivo $\mathrm{N}^{0}$ 2: Implementar tratados y estándares internacionales sobre Derechos Humanos, Derecho Internacional Humanitario y Derecho Penal Internacional. (...) Adopción de Planes, Programas y Mecanismos (...) Evaluar el impacto de la actividad empresarial en el respeto a los derechos humanos en el Perú, con el fin de establecer lineamientos y marcos de acción. Entidades involucradas: PRODUCE y MINJUS MINAM, MINAG, MEM, MTPE. 
Declaración de Lima, mediante la cual se fomenta el compromiso de respeto a los derechos humanos que deben tener las empresas e instan a cumplirlo en todo momento. Por otro lado, aunque la mencionada declaración no posea carácter vinculante, el texto de la misma comprende manifestaciones de voluntad o compromisos que se ajustan a los PREDH. En ese sentido, los pilares de proteger y remediar son claramente distinguidos. $^{75}$

\subsubsection{Constitución Política del Perú}

En el Perú, la empresa tiene un reconocimiento constitucional en el capítulo correspondiente al régimen económico bajo el régimen de la economía social de mercado. $^{76}$ Del mismo modo, la Constitución recoge en su texto los derechos fundamentales, aquel núcleo básico de derechos humanos que se encuentran en los tratados internacionales. Por lo tanto, podemos afirmar que nuestro país incluye en su legislación la protección constitucional de los derechos humanos.

\subsubsection{Legislación peruana}

En este punto, existe en Perú mecanismos de defensa de derechos humanos tanto a nivel interno como a nivel internacional. La efectividad de esos mecanismos va a depender de otros factores como la excesiva carga judicial, falta de preparación y conocimiento en los temas de derechos humanos por parte de la población y administradores de justicia, entre otros. $^{77}$

En cuanto a la responsabilidad penal, cabe señalar que en nuestro país no se contempla la responsabilidad penal de la persona jurídica, sino solo responsabilidad civil subsidiaria (art.104 del Código Penal) y medidas aplicables a las empresas cuando

\footnotetext{
${ }^{75}$ Contar con la posibilidad de denunciar a dirigentes de empresas que violen los derechos humanos ante la Corte Penal Internacional también constituiría una forma de remedio.

${ }^{76}$ Artículo $58^{\circ}$. La iniciativa privada es libre. Se ejerce en una economía social de mercado. Bajo este régimen, el Estado orienta el desarrollo del país, y actúa principalmente en las áreas de promoción de empleo, salud, educación, seguridad, servicios públicos e infraestructura.

77 A nivel interno, nos referimos específicamente al derecho constitucional, específicamente al Tribunal Constitucional y a nivel internacional, contamos con la Comisión y la Corte Interamericana de Derechos Humanos (a nivel regional) y los mecanismos de Naciones Unidas (universal). También somos parte del Estatuto de Roma, que crea la Corte Penal Internacional y por consiguiente, estamos bajo la jurisdicción de la misma en los casos de su competencia, bajo condiciones y requisitos de procedibilidad.
} 
el hecho punible sea cometido en "la actividad de cualquier persona jurídica o utilizando su organización para favorecer o encubrir" (art. 105 Código Penal). Recientemente se aprobó en el pleno del congreso una norma que fija la responsabilidad administrativa de las empresas en los delitos de cohecho internacional cometidos en su nombre, por parte de sus ejecutivos o representantes legales. (Aprueban ley que fija responsabilidad de empresas en casos de corrupción internacional, 2016, Revista Poder)

Cabe señalar también que en el Perú contamos con una extensa legislación en cuanto a los temas laborales; adicionalmente, el Perú es parte de la OIT y ha adecuado sus decisiones a la legislación interna. El incumplimiento y sanción por incumplimiento de estas normas también se encuentra normado en nuestro ordenamiento jurídico.

En cuanto a nuestra legislación ambiental, esta está más desarrollada en sectores específicos de la economía como puede ser la extracción de minerales e hidrocarburos. Igualmente la legislación sobre participación ciudadana, dado que los yacimientos mineros y petrolíferos se encuentran en zonas cercanas o conectadas a poblaciones campesinas o nativas que usualmente se manifiestan con protestas sociales que generan pérdidas a las empresas inversionistas en proyectos de inversión minera y energética. Asimismo, el Perú cuenta con un Ministerio del Medio Ambiente, Ministerio de Energía y Minas, gobiernos locales y regionales que son los entes que intervienen estableciendo pautas y especificaciones técnicas para los proyectos. ${ }^{78}$

De lo señalado anteriormente queda claro que uno de los principales objetivos del país es atraer la inversión extranjera. Es así que los gobiernos adoptan medidas legislativas para proteger a la inversión privada, más aún cuando el historial de un país lo coloca en alto riesgo para ser elegible de inversión. En nuestro país, el Decreto Legislativo 662 otorga a las empresas estabilidad tributaria y laboral. Asimismo, el Decreto Legislativo 757, ley marco para el crecimiento de la inversión privada, desarrolla de manera más amplia cómo es que los inversionistas privados son dotados

\footnotetext{
${ }^{78}$ En el Perú contamos con documentos como la Agenda Nacional de Acción Ambiental Agenda ambiental Perú 2013-2014, Ejes estratégicos de la Gestión Ambiental, Política Nacional de Educación Ambiental, Política Nacional del Ambiente, Lineamientos de Compensación Ambiental. El portal web Peru2021 trata el tema de la Responsabilidad Social en el Perú. Adicionalmente, también contamos con normativa sobre participación ciudadana en el sector minero y de hidrocarburos, cuyo fin está orientado a la conducción de procesos de información y consulta en comunidades cercanas a las áreas en las que se desarrollan proyectos mineros y extractivos. Sin embargo, a pesar de la normatividad existente, debemos tener en cuenta que los conflictos sociales siguen emergiendo, muchos de ellos tienen una cuota de interés político que también debe ser evaluado y estudiado.
} 
de una protección especial que les permite invertir de forma segura en nuestro país. A pesar de ello, día a día somos testigos de la enorme cantidad de conflictos sociales que existen, lo que hace que aunque contemos con legislación favorable a la inversión esta disminuya.

En cuanto al tema de la responsabilidad social, esta es de origen unilateral porque generalmente es la propia empresa la que decide ser socialmente responsable. Sin embargo, muchas empresas han decidido adoptar políticas de responsabilidad social motivadas principalmente por los beneficios económicos y el prestigio que pueden obtener. En el Perú, contamos desde el año 2011 con el programa Perú Responsable que es una certificación que otorga el gobierno peruano a las empresas que adoptan políticas de responsabilidad social empresarial. ${ }^{79}$

Tal vez se puede afirmar que los derechos humanos, su protección y respeto, ya están incluidos en la responsabilidad social de las empresas; es por esa razón que en el capítulo tres haremos un acercamiento a ese enfoque.

\subsection{Conclusiones del capítulo II}

En el presente capítulo hemos hecho referencia a los PANs en derechos humanos y empresas, implementación de los PREDH, además de la legislación nacional y comparada.

Respecto de los PANs, varios países se han adelantado a elaborar - o se encuentran en camino de elaborar - planes que permiten implementar los PREDH en el derecho interno, así como a realizar modificaciones a las normas ya vigentes que estén alineadas a los principios.

En el Perú, el tema no es tan claro y menos se habla de un plan nacional sobre la materia. Si bien contamos con el Plan Nacional de Derechos Humanos que marca una pauta de los avances proyectados, la inclusión de los PREDH no se encuentra plenamente expuesto. En todo caso, siempre existe la posibilidad de que se elaboren planes nacionales en Responsabilidad Social y Desarrollo Sostenible que se encuentren alineados con los principios. Cabe resaltar que la sola elaboración del plan denota la

\footnotetext{
${ }^{79}$ DS-015-2011-TR
} 
voluntad del Estado de cumplir y hacer cumplir los derechos humanos, parte del deber que es también reconocido en los PREDH.

Resulta fundamental incorporar el enfoque de los principios en los planes nacionales y de desarrollo empresarial a través de la participación amplia, consulta e intercambio interdisciplinario debido a que la implementación es un proceso que interesa a las empresas, a los actores locales de la sociedad civil (en particular las organizaciones, defensores de derechos humanos y consumidores), y al Estado (a nivel local, regional y nacional).

En cuanto a la legislación, el derecho comparado nos sirve de parámetro para observar la postura de los diferentes Estados y la forma en la que la que abordan o no su implementación dentro de sus respectivos ordenamientos jurídicos. Además de permitir que empresas peruanas, que operan o desean operar en países con legislaciones distintas, puedan realizar un cálculo efectivo de los costos que esto les puede generar y tomar las precauciones correspondientes para evitar cualquier tipo de contingencias.

En el Perú es importante contar con una legislación que haga exigible la aplicación de los PREDH, esto se puede lograr si se introducen incentivos externos como pueden ser incentivos económicos o tributarios - que logren que la empresa cumpla con respetar los derechos humanos. Una ventaja de ser reconocida como empresa que respeta los derechos humanos - o de obtener una distinción que lo acredite y demuestre fehacientemente - le resultará beneficioso en varios aspectos. Por un lado, le será mucho más fácil acceder a mayores segmentos de mercado, fidelizar clientes externos e internos, acceder al crédito a nivel internacional, minimizar pérdidas por conflictos sociales en proyectos de inversión, entre otros beneficios. En otras palabras, cumplir con respetar los derechos humanos significa para la empresa aumentar su valor, por ende, adquirir mayores y mejores beneficios económicos. Por otro lado, una política de sanciones proporcionales, justas y adecuadas también es necesaria como contrapeso y medida disuasiva del incumplimiento del segundo pilar de los PREDH. 


\section{CAPÍTULO III: APLICACIÓN DE LOS PREDH EN EL PERÚ}

\subsection{Responsabilidad Social Empresarial: tendencias y acontecimientos actuales}

La Responsabilidad Social Empresarial (RSE) es definida por la Comisión Europea como la integración voluntaria, por parte de las empresas, de las preocupaciones sociales y medioambientales en sus operaciones comerciales y sus relaciones con sus interlocutores.(Comisión Europea, 2011, p. 4) A través de su práctica, las empresas obtienen beneficios, reducen costos, aprovechan recursos, gestionan riesgos, administran mejor sus recursos humanos, incrementan el nivel de confianza de los clientes y trabajadores, hacen crecer a la empresa, amplían sus actividades, agregan valor a los intangibles tanto como a la marca e imagen, obtienen la licencia social para operar, entre otros. Un nuevo concepto define a la RSE como "la responsabilidad de las empresas por su impacto en la sociedad”. (ibid, p. 7) Esta definición recoge el impacto que tiene la RSE cuando es aplicada y empleada como una estrategia en la gestión empresarial. $^{80}$

\subsubsection{La responsabilidad social desde la óptica de los derechos humanos}

Tal como lo habíamos mencionado en el capítulo anterior, la fórmula por la que varios países han optado para alinear la política del país a los PREDH es a través de la elaboración de PANs en derechos humanos y empresas. En la práctica, muchos planes de acción sobre RSE como materia principal, incluyen las políticas a seguir en materia de derechos humanos y empresas; del mismo modo lo hacen los planes de acción de derechos humanos. Siguiendo esta línea, en su política del 2011 en RSC, la Comisión Europea instó a los Estados Miembro de la Unión Europea (UE) a desarrollar planes de

\footnotetext{
${ }^{80}$ Los gobiernos de los diferentes países e instituciones internacionales pueden ofrecer incentivos para la adopción de la RSE en una empresa tales como certificaciones, publicidad en medios, o sentido de pertenencia a un grupo selecto de empresas con RSE. La RSE también es conocida como RSC o Responsabilidad Social Corporativa.
} 
acción nacionales en $\mathrm{RSC}^{81}{ }^{2}$ así como planes para implementar los PREDH. A pesar de que la comunicación de la UE sobre RSC solicitaba a los Estados Miembros a elaborar por separado planes de RSC y planes sobre los PREDH, algunos de los planes de RSC abordan la implementación de los principios. Cabe señalar que para promover que los Estados Miembro implementen y mejoren sus respectivos planes, la Comisión Europea estableció un proceso de revisión mutua entre pares (peer review process) de los planes sobre RSC en el año 2013, lo que implicó un trabajo colaborativo entre pequeños grupos de Estados para analizar las medidas tomadas en una base constructiva y así compartir sus mejores prácticas.

El hecho de que se elaboren planes para cada materia - por un lado PANs de RSE y por otro lado planes para la implementación de los PREDH - no se contrapone. Resulta que el propio texto de los principios rectores permite implementarlos en base a planes ya establecidos o normas ya dadas. En ese sentido, la RSE puede incluir dentro de su estrategia a la implementación de los PREDH, o reforzar aquella estrategia ya tomada con la convicción y fundamento de que se es congruente con los principios rectores en estudio. ${ }^{82}$

En nuestro país la RSC o RSE era exclusiva de empresas con capitales extranjeros, pero en los últimos años empresas medianas y de capitales nacionales vienen adoptando medidas de $\mathrm{RS}$ en su gestión. ${ }^{83}$ El resultado de esta tendencia es que se generan debates concentrados en la elaboración y adopción de regulaciones con el propósito de mejorar el estándar de control sobre las actividades de la compañía y a minimizar su impacto negativo. ${ }^{84}$ De hecho, la nueva definición de RSC dada por la

\footnotetext{
${ }^{81}$ Hasta fines del año 2013, 24 de los 28 estados miembros de la UE habían desarrollado, o se encontraban en proceso de desarrollar un PAN en RSC.

${ }^{82}$ Por ejemplo, en el caso de las empresas extractivas que realizan trabajos de exploración cerca a Comunidades Indígenas, aparte de cumplir con las normas legales sobre participación ciudadana y con el procedimiento de consulta previa, tendrá que haberse cumplido con un procedimiento de due diligence en derechos humanos en el que previamente se habrá identificado los impactos (reales y potenciales) aplicables al caso.

${ }^{83}$ Según Peru 2021, la Responsabilidad Social Empresarial es “(...) una forma ética de gestión que implica la inclusión de las expectativas de todos los grupos de interés (Accionistas/Inversionistas, Colaboradores y sus familias, Comunidad, Clientes, Proveedores, Medio Ambiente y Gobierno) alrededor de la empresa, para lograr el desarrollo sostenible. La RS ayudará a la empresa a tomar conciencia de su rol en el desarrollo de nuestro país, reconociéndose como agente de cambio para mejorar la calidad de vida y la competitividad de su entorno.” En: http://www.peru2021.org/principal/categoria/conceptos-deresponsabilidad-social/9/c-9

84 "Responsabilidad de una organización ante los impactos que sus decisiones y actividades ocasionan en la sociedad y el medio ambiente, mediante un comportamiento ético y transparente que: Contribuya al
} 
doctrina internacional como reacción a la falta de responsabilidad empresarial de las empresas multinacionales, como lo define Muchlinski (2012, 145-177) fue inspirada por el concepto filosófico de "contrato social" y por la necesidad de preservar la dignidad humana.

Desde este punto de vista, tanto la RSE como los derechos humanos tienen en común una preocupación por la mejora y bienestar tanto de los clientes internos, los clientes externos y las comunidades cercanas a las actividades de la empresa. Sin embargo, una diferencia fundamental entre la RSE y el enfoque de derechos humanos es que la primera tiene un origen voluntario y su esencia es que permanezca así, caso contrario se producirá una desnaturalización de la misma y dejaría de ser RSE para convertirse en norma de obligatorio cumplimiento. En el caso de los derechos humanos, tenemos claro que su cumplimiento no es en esencia voluntario, el respeto a los derechos humanos es obligatorio por parte de todo individuo e institución, independientemente del Estado en el que se encuentre porque los derechos humanos son de carácter universal, inherentes a la persona humana, inalienables, plenamente exigibles e imprescriptibles. ${ }^{85}$ La lista de derechos humanos es bastante amplia, han sido categorizados y recogidos en diversos instrumentos internacionales y también en las legislaciones internas de los Estados. Podemos entender que algunos expertos

desarrollo sostenible, incluyendo la salud y el bienestar de la sociedad; Tome en consideración las expectativas de sus partes interesadas; Cumpla con la legislación aplicable y sea coherente con la normativa internacional de comportamiento; Esté integrada en toda la organización y se lleve a la práctica en sus relaciones.” En: http://www.peru2021.org/principal/categoria/conceptos-de-responsabilidadsocial/9/c-9

${ }^{85}$ Mujica señala que "Los derechos humanos comparten un conjunto de características intrínsecas, que incluyen las de considerárselos innatos o inherentes (esto es, que le pertenecen a la persona por su condición de ser humano), inalienables e intransferibles (vale decir que no solo nadie puede, sin renunciar a su dignidad, renunciar a sus derechos y libertades fundamentales, sino que tampoco los Estados pueden disponer de los derechos de sus ciudadanos sin afectar su dignidad; pueden, es verdad, en circunstancias extremas y justificadas, limitarlos o suspenderlos, pero en ningún caso alienarlos —es decir, eliminarlos o extinguirlos-), universales (los derechos humanos no derivan del hecho de que hombres y mujeres sean oriundos de un determinado Estado, sino que tienen como fundamento los atributos de la persona humana), indivisibles (esto quiere decir que no es posible garantizar la vigencia de unos derechos con prescindencia o, peor aún, con desmedro de otros), interdependientes (dado que todos los derechos humanos se consideran fundamentales, no es posible establecer una jerarquía entre ellos, y menos creer que unos son más importantes que otros; su pertenencia a una totalidad cuyo propósito es asegurar la dignidad humana explica su indivisibilidad e interdependencia), Inviolables (nadie está autorizado a atentar, lesionar o destruir los derechos humanos) y también plenamente exigibles (los dominios, prerrogativas o atributos que los derechos humanos reconocen en las personas imponen obligaciones a los Estados que estos no pueden rehuir. Por el contrario, el Estado se encuentra obligado a adoptar medidas oportunas y adecuadas para garantizar la plena realización de los derechos)". Mujica Petit, Javier. Desarrollo Internacional de las Obligaciones Legales de las Empresas Respecto de los Derechos Humanos. En: Derecho PUCP Nº3. p. 166. 
critiquen las dificultades que existen en definir el rango de los derechos humanos a respetar y promover por parte de las compañías y en comprometer en este proceso a los accionistas, las ONGs, OSC $^{86}$ y comunidades locales, dado que cada grupo tiene intereses y objetivos que muchas veces se contraponen. Pensando en esto, los principios rectores se refieren a un conjunto de derechos humanos fundamentales que deben ser respetados (Anexo 1) sin perjuicio de otros derechos que también son aplicables por recaer en grupos humanos especiales, así como por el tipo de sector, actividad, tamaño, u ordenamiento jurídico en el que se encuentra la empresa.

En resumen, la RSE involucra la toma de acciones de las empresas por sobre sus obligaciones legales en favor de la sociedad y el medio ambiente. Algunas medidas legales o regulatorias crean un ambiente más propicio para que las empresas voluntariamente cuenten con la RSE. ${ }^{87}$ En el caso de los PREDH, al ser voluntarios, su cumplimiento también está supeditado a que las empresas los adopten voluntariamente. Sin embargo, su inclusión en normas jurídicas internas es altamente recomendable para otorgarles un carácter mandatorio.

Una de las posturas que asocia a la RSE con los derechos humanos se desprende del concepto actual de la Comisión Europea, la misma que define a la RSE como la responsabilidad de las empresas por sus impactos en la sociedad. Entendemos que se refiere a impactos positivos en la sociedad. Recordemos que los PREDH, especialmente en torno al respeto de los derechos humanos, tienen como objetivo que las empresas realicen el due diligence en derechos humanos como parte de su gestión. Este mecanismo permite detectar los impactos negativos en derechos humanos en los cuales la empresa ha incurrido o potencialmente puede incurrir, en función de sus actividades o relaciones comerciales.

Otro punto concordante entre la RSE y los derechos humanos lo encontramos en el caso de la UE, donde la promoción de la responsabilidad social y ambiental a través de la cadena de suministros, y la revelación de información no financiera, son considerados asuntos interrelacionados. En los PREDH, la cadena de suministros de una empresa es tratada como pieza fundamental en el respeto a los derechos humanos debido a que muchas de las violaciones, como puede ser el trabajo infantil o las nuevas

\footnotetext{
${ }^{86}$ Organizaciones de la Sociedad Civil.

${ }^{87}$ http://eur-lex.europa.eu/LexUriServ/LexUriServ.do?uri=COM:2011:0681:FIN:EN:PDF
} 
formas de esclavitud moderna, se llevan a cabo en las empresas proveedoras de las grandes multinacionales. Estas empresas recurren a contratar con empresas extranjeras que les ofrecen precios muy bajos, pero con un costo social muy elevado que en lugar de combatir problemas de desempleo, pobreza y salud en la región terminan acrecentándolos.

La responsabilidad social también puede provenir de parte de los colaboradores de las empresas, quienes al identificar un problema son capaces de organizarse y dar solución al mismo. En esa línea, y dentro de las expresiones de la responsabilidad social, la Comisión Europea ha adoptado una comunicación en la que reconoce al voluntariado de los empleados como una expresión de RSE. (Comisión Eurepea, 2011) Por otro lado, en el caso de los PREDH, su diseño está orientado a los Estados y a las empresas. Por consiguiente, las iniciativas e implementación de los principios a nivel empresarial son una decisión de los puestos directivos y de gestión más que una decisión de los trabajadores.

Adicionalmente, en el día a día vemos que la RSE cubre al menos prácticas en derechos humanos (pueblos indígenas, sectores vulnerables, participación y el desarrollo de la comunidad, la integración de discapacitados, intereses de los consumidores y respeto al derecho a la intimidad), trabajo y empleo (como entrenamiento, diversidad, igualdad de género y bienestar y salud de los empleados), asuntos ambientales (como la biodiversidad, cambio climático, eficiencia de recursos, determinación del ciclo de vida y prevención de la contaminación), además de preocuparse por la erradicación del soborno y la corrupción en complicidad con la empresa. Prácticas que de una u otra forma reflejan el cumplimiento de los principios rectores en cuanto al respeto a los derechos humanos y en ello radica la estrecha relación entre ambos.

Para concluir, podemos inferir que las empresas tienen como deber aplicar la legislación y los acuerdos entre socios aplicables a ellas, además de identificar y planificar sus actividades en función de las preocupaciones y riesgos económicos, sociales, ambientales, éticos y de derechos humanos. Para lograrlo, la globalización y el acceso a la información llevan a la empresa a plantearse estrategias eje en colaboración directa con los actores involucrados para maximizar recursos y valor para todos los intervinientes de la relación comercial (accionistas, cadena de suministros, 
consumidores, sociedad, etc.). Adicionalmente, en aplicación de los principios rectores, la empresa debe identificar, prevenir y mitigar los impactos adversos en derechos humanos, sean estos reales o posibles con una diligencia debida en derechos humanos. Lo anterior servirá para crear e incrementar de valor a la empresa y ofrecer beneficios a la sociedad y al medio ambiente.

\subsubsection{Desarrollo sostenible: sostenibilidad ambiental y social}

La comunidad internacional demuestra preocupación en torno a los temas ambientales y sociales. La motivación en torno a la creciente toma de conciencia de temas relacionados al medio ambiente obedece a los grandes daños ambientales (muchas veces irreversibles) causados por industrias (especialmente las extractivas) y por el cambio climático que nuestro planeta viene afrontando. En cuanto a la sostenibilidad social, esta se manifiesta como reacción a los constantes conflictos sociales que se presentan en protesta contra sectores o actividades empresariales cuyo accionar afecta a determinados grupos de la sociedad. Las ONG y OSC también han tenido - y mantienen - estos temas en el foco de atención.

En cuanto a los comportamientos que se adhieren a los principios de desarrollo sostenible, y que constituyen un pilar fundamental de cualquier estrategia o reporte de RSE, se observa que son más urgentes en negocios cuyas inversiones se encuentran en países con estándares ambientales menos estrictos que aquellos de los países de origen. La disposición de medidas de protección contra cualquier forma de contaminación de aguas, tierra y aire, así como de sobreexplotación de recursos naturales, son la base de los derechos humanos a la vida y a la salud que los negocios están llamados a respetar y hacer respetar. En el mundo, son numerosos los casos donde el derecho a la vida y a la salud se entrelazan con la protección ambiental. (Gobierno de Italia, 2014, p. 20)

Por otro lado, existen iniciativas legales en favor de la preservación del medio ambiente, así como las medidas de prevención de daños ambientales, mitigación y remediación de daños que son parte de los Estudios de Impacto Ambiental y Social (EIA). Nuestra legislación requiere la elaboración de Estudios de Impacto Ambiental y Social para los proyectos de exploración y explotación de recursos minerales y energéticos, medida que es adoptada por diversas legislaciones para prevenir conflictos 
futuros. ${ }^{88}$ En nuestro país se ha criticado la elaboración idónea de estos EIA por la omisión de detalles fundamentales para las comunidades, falta de exactitud o veracidad de las consecuencias reales que las actividades de exploración o explotación traen consigo, falta de difusión o una difusión deficiente de la información, entre otros. ${ }^{89}$

Una iniciativa en favor de la preservación del medioambiente es el llamado Negocio Verde o econegocio. Esta es una iniciativa que toman las empresas para demostrar o difundir que son respetuosas de la sostenibilidad ambiental. En los últimos años, iniciativas similares han funcionado básicamente por la gran acogida que tiene en el público consumidor y en el impacto positivo en los valores intangibles de la marca, su imagen y reputación. ${ }^{90}$

Otra iniciativa que vale la pena mencionar es la llamada empresa azul, ${ }^{91}$ concepto que nace de la concepción de economía azul de Gunter Pauli, bajo la cual se promueve la creación de empresas de emisión cero, las mismas que toman las ideas de negocio de la naturaleza con propuestas creativas y que evitan el daño al medio ambiente promoviendo la sostenibilidad de los recursos. A diferencia de otras teorías económicas, la economía azul se encuentra al alcance de todos y resulta más ventajosa porque desde el origen de la empresa se cuida la no afectación al medio ambiente. ${ }^{92}$

Los principios rectores propuestos en el año 2011 también están alineados con las nuevas corrientes económicas conservacionistas y promotoras del cambio empresarial a través de la defensa y protección del medio ambiente. Asimismo, tal como las nuevas corrientes económicas, han sido inspirados en la problemática ambiental y en los casos de impunidad por daños al medio ambiente.

\footnotetext{
${ }^{88}$ En materia ambiental, es política del Estado la defensa y preservación del medio ambiente. Nuestro país cuenta con un Código de medio ambiente (D. Leg. 613).

${ }^{89}$ Un caso muy sonado fue el caso de Minera Buena Ventura, en Oyón-Lima. En este caso los pobladores se quejaban de las consecuencias que para sus actividades agrícolas habían acarreado los trabajos de la Minera. En: https://www.youtube.com/channel/UCOf1FKQ9KAmgUHNUF_SFz2w

${ }^{90}$ En cuanto a los recursos energéticos que se obtienen de las fuentes renovables, estos tienen desventajas como la discontinuidad (en el caso de la energía eólica). Comparando la obtenida de las fuentes tradicionales, las energías renovables suelen no ser tan eficientes o poder ofrecer la misma fuerza o intensidad aparte de su alto costo.

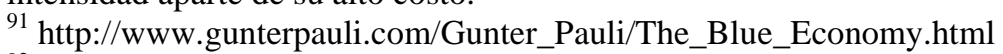

92 Esto permite que la incidencia por conflictos sociales que se escudan en los daños potenciales o reales al medio ambiente no prosperen.
} 


\subsubsection{Casos}

Las formas societarias se hacen más complejas a medida que el mundo empresarial va evolucionando. También se crean nuevas relaciones contractuales a través de franquicias y consorcios empresariales que dificultan la identificación de los responsables en casos de graves violaciones a los derechos humanos, ya sea como responsables directos o cómplices. ${ }^{93}$ Dichas violaciones cometidas por las empresas son reales y tienen consecuencias jurídicas independientemente del lugar en el que se realiza la vulneración; en la actualidad, existen varias medidas jurídicas que se han caracterizado por actuar cuando el daño ya ocurrió. En muchos casos la falta de legislación, una legislación débil, los vacíos legales, el alto índice de corrupción y la ausencia de un Estado de Derecho pueden hacer que los casos queden impunes. En ese sentido, el incremento de litigios contra las matrices de empresas multinacionales por las acciones de sus filiales, subsidiarias o incluso de las empresas que se encuentran en su cadena de abastecimiento, ocupan espacios en los juzgados de los países de origen y que tienen legislaciones más fuertes en torno al deber de proteger los derechos humanos.

Sonados casos de empresas que han sufrido el boicot de los consumidores ilustran lo anteriormente expuesto: que las grandes corporaciones no pueden exhibir un comportamiento empresarial inadecuado sin afectar el éxito de sus negocios. (Oxfam Internacional y Social Capital Group, 2997, p. 54) De modo similar, casos judicializados en países como Estados Unidos, Europa o Latinoamérica en los que la responsabilidad por violaciones a los derechos humanos recae en las empresas, también son relevantes. Entre los casos, encontramos aquellos que vulneran derechos humanos específicos (igualdad de género, no discriminación, trata de personas o libertad de asociación), las relativas a las normas fundamentales del trabajo (incluyendo el trabajo infantil, el trabajo penitenciario forzoso o el derecho a la negociación colectiva) y a los temas ambientales (contaminación, inutilización permanente de recursos).

En el Perú, la mayoría de casos se encuentran dentro de la actividad minera y de hidrocarburos. Una gran cantidad de los casos con conflictos sociales se encuentran documentados en la Defensoría del Pueblo y han surgido justamente por una falta de

\footnotetext{
93 En todo caso, dadas las normas legales, la responsabilidad queda en los operarios más que en los cargos directivos.
} 
respeto a los derechos humanos por parte de las empresas. ${ }^{94}$ Podemos citar a los conflictos por contaminación ambiental como ejemplo de los desafíos que enfrentan las empresas cuando operan en países donde se prioriza una actividad, sin percatarse de los potenciales riesgos a los que se enfrentan y dejando de lado la protección a los derechos humanos.

Debido al fenómeno de la globalización, las corporaciones multinacionales son más poderosas que los gobiernos y son más difíciles de ser rastreadas cuando cometen algún abuso. A continuación, citaremos casos ocurridos en distintas partes del mundo que sirven para demostrar que las violaciones a los derechos humanos no son exclusivas de un sector determinado o de una región geográfica única, sino que son casos que pueden ocurrir en cualquier lugar del mundo y sector. Los primeros casos se ubican en la industria del azúcar: el primero involucra a Coca Cola y el segundo a la empresa Tate \& Lyle. $^{95}$

\section{- Caso Coca Cola}

El 13 de agosto del 2014, la Comisión Nacional de Derechos Humanos en Tailandia $(\text { NHRCT })^{96}$ corroboró las quejas respecto de la compañía Mitr Phol, que suministra azúcar a Coca Cola, sobre la apropiación ilegal de tierras de los aldeanos en la provincia de Oddar Meanchey y que había violado sus derechos humanos. La queja fue interpuesta por la NHRCT en mayo del año 2013 por los pobladores con la ayuda de ONG locales, y acusaba a la Compañía de haberles robado sus granjas hace cinco años atrás empleando armas de fuego contra el ganado y usando a la policía y a los juzgados locales para vencer, hostilizar y demandar a los aldeanos. Según las noticias, la presión de las ONG consiguió que Coca-Cola anunciara el lanzamiento de una investigación internacional sobre dichas alegaciones.

\footnotetext{
${ }^{94}$ http://www.defensoria.gob.pe/conflictos-sociales/home.php La Defensoría hace un seguimiento y emite reportes periódicos respecto de la situación de los conflictos sociales del país.

${ }^{95}$ Fuente: http://www.cambodiadaily.com/news/thai-human-rights-body-says-plantations-stole-land66456/ http://sea-globe.com/sugar-cambodia/ http://www.phnompenhpost.com/national/sugar-giantspotlight-abuse http://business-humanrights.org/en/cambodia-villagers-reject-tate-lylesugar\%E2\%80\%99s-latest-offer-to-settle-uk-lawsuit-company-resigns-from-bonsucro-due-to-samelawsuit http://www.cambodiadaily.com/news/evictees-reject-latest-settlement-offer-from-uk-sugar-firm$60869 /$

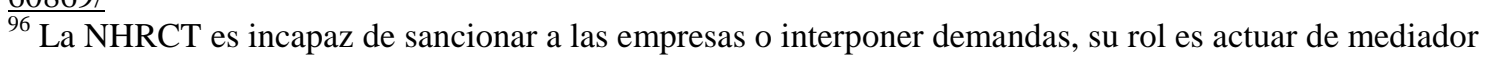
y elaborar reportes que pueden ser usados en los litigios.
} 


\section{- Caso Tate \& Lyle}

Una queja por separado fue interpuesta por la NHRCT en enero del año 2010 por las comunidades de la provincia de Koh Kong contra la empresa azucarera tailandesa KSL. Las investigaciones preliminares de julio del año 2012 respaldaron las acusaciones y el reporte final formó parte del reporte final del mes de octubre. Relativo a este caso, en marzo de 2013 los pobladores de Koh Kong (Cambodia) entablaron una demanda en Londres contra la empresa Tate \& Lyle por haber comprado azúcar de KSL y haberse beneficiado de ello. En el mes de octubre de 2014 fue la primera audiencia y los demandantes habían rechazado la última oferta de arreglo extrajudicial propuesto por Tate \& Lyle sugar.

\section{- Caso Hershey Co.}

Por otro lado, tenemos abusos cometidos en la figura de trabajo infantil en la cadena de suministros en la industria alimentaria. ${ }^{97}$ Estos casos han levantado el interés y la preocupación internacional y son de conocimiento público. En el año 2012, Hershey Co. fue demandada por un accionista por el supuesto de trabajo infantil en el oeste del África. Como resultado de esa demanda, en marzo del año 2014 el juez del caso Louisiana Municipal Police Employees' Retirement System v. Hershey Co., ordenó a la Compañía remitir los archivos y documentos sobre las granjas de cacao africanas que podían estar empleando a niños de manera ilegal. Una situación similar vivió Nestle algunos años atrás; sin embargo, ellos elaboraron un plan de acción para combatir el

\footnotetext{
${ }^{97}$ Fuentes: http://www.confectionerynews.com/Regulation-Safety/Hershey-sued-over-alleged-childlabor-abuses

http://news.bbc.co.uk/panorama/hi/front_page/newsid_8583000/8583499.stmhttp://courts.state.de.us/opin ions/download.aspx?ID=197350 http://www.businessweek.com/news/2013-04-12/hershey-shouldsupply-child-labor-records-academics-say http://www.businessweek.com/news/2014-03-18/hersheyjudge-says-shareholders-can-seek-child-labor-files-1 http://www.bloomberg.com/news/2014-0318/hershey-judge-says-shareholders-can-seek-child-labor-files-1-.html http://www.confectionerynews.com/Regulation-Safety/Numerous-child-labour-violations-found-inNestle-supply-chain-as-company-promises-action http://www.cocoainitiative.org/en/newsmedia/news/210-the-future-of-children-in-cocoa-bbc-takes-a-close-look-at-ici-s-work-in-cote-d-ivoire http://www.cocoainitiative.org/en/news-media/news/206-the-international-cocoa-initiative-teams-upwith-natra http://www.confectionerynews.com/Manufacturers/Children-and-chocolate-The-sweetindustry-s-bitter-side http://www.phnompenhpost.com/national/newspaper-threatened-over-child-labourstory
} 
trabajo infantil que incluía, entre otras medidas, el monitoreo y la remediación. El tráfico de personas y el trabajo infantil son aún problemas actuales que causan gran preocupación a pesar de que muchas empresas (por ejemplo Natra, compañía de chocolate española) han tomado parte de las muchas iniciativas contra el trabajo infantil como la de la International Cocoa Initiative (ICI) establecida en el año 2002.

\section{- Caso CACI}

En el caso de Al Shimari V. CACI se aplicó el Alien Tort Statute (ATS) con alcance extraterritorial por ser CACI un contratista del sector defensa de los Estados Unidos. El caso había sido presentado por ex detenidos en la prisión de Abu Ghraib, los mismos que alegaron haber sido torturados por empleados de CACI. Expusieron cuestiones de jurisdicción, violaciones de derecho estadounidense e internacional. ${ }^{98}$

\section{- Caso Chiquita}

En la decisión del onceavo circuito, se ordenó el rechazo de la solicitud del ATS solicitado por un grupo de demandantes colombianos contra Chiquita Brands, sobre el pago a las fuerzas paramilitares de Colombia. En el 2007, Chiquita admitió haber realizado pagos a cambio de protección a sus trabajadores. Los demandantes clamaban que la compañía sabía o debía de haber sabido sobre el apoyo económico dado a los paramilitares. ${ }^{99}$

Estos dos últimos casos grafican como en el lapso de pocos meses, dos juzgados de apelación federales han empleado el estándar "touch and concern" del caso Kiobel v. Royal Dutch Petroleum a las cuestiones de jurisdicción de casos ATS, pero llegando a conclusiones totalmente distintas. Esta presunción se aplica cuando los casos afectan o

\footnotetext{
${ }^{98}$ Tortura; tratos crueles, inhumanos y degradantes; crímenes de Guerra; lesiones; crímenes sexuales; imposición intencional y negligente de estrés emocional; contratación y supervisión negligente.

${ }^{99} \mathrm{http}$ ://www.lawfareblog.com/2014/07/two-new-ats-decisions-fourth-and-eleventh-circuits-split-onwhether-claims-against-caci-and-chiquita-touch-and-concern-the-territory-of-the-united-states/ (visionado al 30 de Julio de 2014) El cuarto circuito de apelaciones, en el caso sostuvo que la presunción contra la extraterritorialidad no aplicaba a casos llevados por demandantes Iraquíes contra la empresa contratista del gobierno de los Estados Unidos que proveía servicios relacionados a la interrogación a los militares norteamericanos en Iraq, concluyendo que la jurisdicción era propia dado que los demandantes habían presentado suficientes hechos o pruebas para vencer la presunción (respecto al caso CACI).
} 
involucran a los Estados Unidos con "fuerza o relevancia suficiente"; sin embargo, la falta de uniformidad de criterios pone en riesgo el futuro del empleo del ATS para procesar judicialmente a empresas por violaciones a los derechos humanos, debilitando el Alien Tort Act y dando pie a la impunidad de este tipo de casos.

\subsubsection{Argumentos a favor y en contra}

Tal vez a simple vista parezca que no es necesaria una implementación de los PREDH en nuestro país porque contamos con normas que están alineadas con los principios mencionados y que de una u otra forma respetan los tratados internacionales en materia laboral, ambiental y de derechos humanos. Sin embargo, los constantes conflictos sociales, los casos de esclavitud moderna, el trabajo infantil, los daños irreversibles al medio ambiente, la dificultad en obtener - o alcanzar - la "licencia social" para operar, y la corrupción, son señales de que nuestro ordenamiento jurídico y nuestras políticas carecen de una efectiva estrategia de prevención. Justamente, el objetivo de que las empresas internalicen el due diligence en derechos humanos es poder prevenir, mitigar y remediar violaciones a los DDHH, ahorrando costos y maximizando ganancias. Las empresas muchas veces ven mermada su inversión de manera significativa a causa de los constantes conflictos de índole socio-ambiental que se presentan en el país. En caso una empresa haya incurrido ya en una violación a los derechos humanos, el due diligence tendrá un papel fundamental en las acciones a considerar para remediar y mitigar los daños causados, además de ofrecer soluciones efectivas.

Una opción para la adopción o implementación de los PREDH - a nivel Estado - es que estos principios sean incluidos en un plan nacional especial para tales efectos, en el plan nacional de derechos humanos, en el de competitividad o en el de responsabilidad social empresarial; tal y como la experiencia comparada lo ha trabajado. Aparte de su inclusión en planes nacionales, es fundamental que la legislación haga obligatorios los principios y que los haga cumplir. De esta forma se producirá un cambio efectivo a través de normas que podrán encontrarse desde las 
ramas del derecho penal, civil, administrativo o regulatorio y deberán determinar el grado de responsabilidad de las empresas dependiendo de la tipificación. ${ }^{100}$

A modo de ejemplo, quisiera mencionar la resolución de la Superintendencia de Banca y Seguros sobre la gestión del riesgo social y ambiental. ${ }^{101}$ En la actualidad, el riesgo socio-ambiental es tomado en cuenta cuando un banco va a otorgar un préstamo; en consecuencia, las empresas que desean financiar sus proyectos tienen que incluir también un análisis de los posibles riesgos (vulneraciones a los derechos humanos inclusive) que puedan ocurrir. Con este ejemplo podemos observar que las empresas adoptan medidas alineadas con los PREDH, sin la necesidad de que exista una legislación expresa o exclusiva ya establecida para que las empresas los tomen en cuenta en sus procedimientos y procesos. Las obligaciones legales pueden originarse en la exigencia misma de las entidades públicas o privadas respecto de temas variados como el otorgamiento de créditos a los proyectos de inversión.

La resolución en mención, es aplicable a todos los bancos en cuanto a los créditos que otorgan a los proyectos valorizados en más de 10 millones de dólares. A nuestro criterio, lo que hace la resolución es estandarizar el momento y establecer los montos presupuestados para los proyectos en los que es exigible que se practique un análisis de riesgo socio-ambiental. En la exposición de motivos del proyecto se hace mención los PREDH, además de otros documentos internacionales que respaldan la resolución. Podemos concluir que las entidades financieras solicitan a las empresas aplicar el due diligence en derechos humanos al establecer los posibles riesgos socioambientales que puede generarse en función de los proyectos que se pueden ubicar en el sector de industrias extractivas, alimentarias, de construcción, entre otros. En ese sentido, los bancos inversionistas se preocupan en un retorno efectivo de la inversión realizada.

Habíamos mencionado que la empresa puede de motu propio promover planes internos de responsabilidad social que involucren a los derechos humanos;

\footnotetext{
${ }^{100}$ Hélène Dragatsi realizó un trabajo interesante sobre la responsabilidad Penal de las Corporaciones Canadienses por crímenes internacionales. Dragatsi, Hélène. Criminal Liability of Canadian Corporations for International Crimes. CarswellPublication. March 2011. 254 p.

${ }^{101} \mathrm{http}: / /$ www.sbs.gob.pe/app/pp/preproyectos/proyecto_aviso.asp?p=2988 Prepublicación de la resolución SBS del "Reglamento para la Gestión del Riesgo Social y Ambiental". Aprobado en Marzo del 2015 y aplicable desde febrero del 2016 En: http://sinia.minam.gob.pe/normas/aprueban-reglamentogestion-riesgo-social-ambiental
} 
adicionalmente, los reportes de sostenibilidad también se muestran como una alternativa interesante. No obstante, y como ya habíamos mencionado anteriormente, se trata de una decisión unilateral de la empresa que será difícilmente monitoreada.

Otro punto a tomar en cuenta es que si bien las normas legales son de obligatorio cumplimiento y son una forma adecuada de establecer una obligación $\mathrm{u}$ otorgar un beneficio (tributario o una fórmula similar a la ley de obra por impuesto); ${ }^{102}$ el monitoreo y la fiscalización resultan imprescindibles para que ello funcione.

Por otro lado, la obtención de certificaciones o premios son otra alternativa que las empresas pueden estudiar. En ese sentido, que la empresa forme parte del Pacto Mundial u obtenga el ISO26000 supone que el due diligence en derechos humanos es parte de su gestión. El Estado podría impulsar o lanzar una campaña que incentive a las empresas a conseguir dichas certificaciones, tal y como lo viene realizando con las iniciativas de promoción de la RSE. ${ }^{103}$

No descartamos que los PANs puedan ayudar a establecer las pautas y la progresividad en la que se realizará la inclusión de la diligencia debida en derechos humanos para todas las empresas. Además de marcar las pautas de la política interna de un país en temas que fundamentalmente requieren implementación, pueden servir para realizar un seguimiento de los hitos trazados. Sin embargo, recalcamos nuevamente que eso no debe ser obstáculo para que las empresas incluyan políticas de respeto a los derechos humanos de manera voluntaria.

Las empresas que ya realizan en sus procedimientos análisis de riesgos pueden incluir la cuantificación del riesgo o del impacto en derechos humanos y traducirlo en lenguaje financiero o contable. En estos casos, simplemente se adicionará o adecuará algún procedimiento para determinar los impactos negativos en derechos humanos en los que la actividad empresarial incurre o puede incurrir. Del mismo modo se puede proceder respecto de los derechos laborales y ambientales.

Otro tema que podemos tratar en este punto es el de los contratos que se celebran tanto con la cadena de suministros como con el Estado. Las empresas pueden plasmar su voluntad de respetar los derechos humanos a través de los contratos que

\footnotetext{
${ }^{102}$ Ley 29230. Ley de impuesto por obra.

${ }^{103}$ Ver portal Peru2021
} 
suscriben, y así hacer su protección y cumplimiento exigibles de manera bilateral. Los especialistas en contratos deberán, en consecuencia, tomar conocimiento de esta nueva tendencia que se abre con la aparición de los PREDH para poder plasmarlos y reconocerlos adecuadamente.

Desde el punto de vista comercial, resulta ventajoso adoptar e incluir a los principios en la política de la empresa por varios motivos. La buena reputación de la empresa, la transparencia de las operaciones, una mayor competitividad y el mejor posicionamiento de la marca son algunas de las ventajas que consiguen las empresas que se alinean a los principios. Por otro lado, debemos tener en cuenta que los principios vienen siendo recogidos por diversos ordenamientos jurídicos con los que el Perú tiene relaciones comerciales; en consecuencia, las empresas que pertenecen a esos ordenamientos jurídicos van a exigir o preferir contratar con empresas que cumplen con respetar los derechos humanos y lo demuestran (sea a través de un reporte de sostenibilidad o de procedimientos diligencia debida en derechos humanos). Asimismo, si una empresa peruana decide ingresar en el mercado internacional, debe tener en cuenta el valor que representa el respeto a los derechos humanos para la comunidad internacional.

\subsection{Nuestra posición}

El principal problema al que se enfrentan los PREDH es que son de adopción voluntaria. Los principios rectores están dentro de lo que en doctrina se conoce como soft law; es decir, no son legalmente vinculantes. ${ }^{104}$ Los países suelen adoptar este tipo de principios en sus planes nacionales o en su legislación, en otros casos se pueden suscribir como participantes, aunque el hecho de no hacerlo no implique sanción alguna. Para tener el estatus de obligatorio, los PREDH tendrían que estar plasmados en un tratado; en ese sentido, un tratado tendría la fuerza legal para los Estados Parte del mismo y sería de obligatorio cumplimiento tanto para los Estados como para las empresas. A pesar de que existe la voluntad de plasmarlos en uno, el texto final y la adhesión al mismo van a depender de la voluntad política. La elaboración de un tratado que comprenda a los principios rectores no es incompatible con la aplicación de los

\footnotetext{
${ }^{104}$ http://www.voluntaryprinciples.org Fecha de visualización: 6 de marzo de 2016.
} 
mismos por parte de las empresas. Actualmente, son varias las que consideran a los principios dentro de su gestión y procedimientos; sin embargo, al no existir en nuestro ordenamiento norma jurídica que los haga de cumplimiento obligatorio, no habría mayor sanción a la empresa que decida no adoptarlos.

Adicionalmente a los principios y a la valoración moral que se les pueda dar, no debemos olvidar que en la actualidad contamos con mecanismos legales para procesar casos de violaciones a los derechos humanos. Tal es el caso de aquellas empresas o corporaciones contra las que la sociedad civil, ONGs o determinada comunidad, plantean demandas judiciales. La sociedad civil tiene la potestad de alzar su voz de protesta a través boicots comerciales (dejar de comprar o contratar determinado producto o servicio), actos que la empresa puede calificar de hostiles. La desventaja es que las reacciones y judicialización de los casos emblemáticos ocurren después de ocurridos los abusos o vulneraciones a los derechos humanos, sin la oportunidad de aplicar mecanismos previos para evitar o mitigar sus efectos.

El tema puede ser abordado desde distintos frentes y una medida común es que la implementación se trabaje con la adopción de medidas por sectores industriales y segmentando a las empresas por su tamaño. También hemos visto que los Estados incluyen pautas para la implementación progresiva de los principios con el respectivo seguimiento en sus planes de acción. ${ }^{105}$

Aparte de las medidas que se puedan tomar a nivel de estado, las empresas pueden incorporar la responsabilidad corporativa de respetar los derechos humanos. Precisamente, el segundo pilar de los principios trata sobre la responsabilidad corporativa de respetar los derechos humanos. Esto significa que las empresas deben evitar infringirlos y deben hacer frente a los impactos negativos con los que están involucrados. Esto incluye a los impactos que las propias actividades de las empresas puedan causar o en las que puedan contribuir, sea que estén directa o indirectamente ligadas a sus operaciones, productos o servicios por una relación comercial.

Cumplir con la responsabilidad de respetar significa que una empresa debe adoptar e integrar políticas de compromiso de respetar los derechos humanos en toda la organización, desarrollar e implementar procesos de diligencia debida en derechos

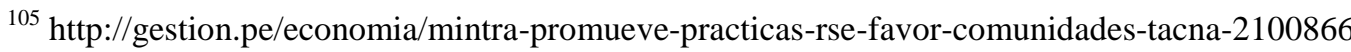


humanos, y contar con procesos para remediar los daños en derechos humanos que las empresas causen o contribuyan a causar. (Anexo 3)

En su informe final del año 2009, Ruggie señala que la obligación de respetar no debe ser concebida como la obligación de no hacer cosas que puedan afectar a los derechos humanos. Esta responsabilidad obliga a las empresas a ejercer la diligencia debida para conocer y prevenir los efectos negativos que ellas pueden causar en los DDHH y responder por ellos. También señala que es necesario para una empresa contar con mecanismos a nivel operacional donde las comunidades puedan presentar reclamos por violaciones o amenazas de violaciones a los derechos humanos. Se trata de que la empresa cambie de un rol pasivo a un rol activo en cuanto al respeto de los derechos humanos.

\subsubsection{Viabilidad y procedimiento de diligencia debida en derechos humanos}

En primer lugar, tenemos que entender que la diligencia debida en derechos humanos es un proceso que permite a las empresas identificar y contrarrestar los impactos reales (actuales) y potenciales en derechos humanos. El procedimiento consiste en evaluar impactos, tomar acciones en respuesta a la identificación de los mismos basados en la forma de intervenir de la empresa, hacer un seguimiento y monitorear los esfuerzos que ella hace en contrarrestar los impactos negativos. Cuando una empresa contribuye o está directamente relacionada a un impacto a través de una relación comercial, se espera que emplee sus ventajas o influencias para alentar a terceros a abstenerse de involucrarse en conductas que resulten en violaciones a los derechos humanos. Ello no significa que las partes no dominantes en una relación comercial dejen de hacer lo posible para influir positivamente en terceros. (IBA, 2014, p. 5)

En la ISO 26000, la diligencia debida es definida como un:

Proceso exhaustivo y proactivo para identificar los impactos negativos reales y potenciales de carácter social, ambiental y económico de las decisiones y actividades de una organización a lo largo del ciclo de vida completo de un proyecto o de una actividad de la organización, con el objetivo de evitar y mitigar dichos impactos negativos. (Ibañez \& Ordoñez, 2014, p. 219-246) 
En la guía para la interpretación sobre la responsabilidad de las empresas de respetar los derechos humanos se define lo siguiente:

Se ha definido la diligencia debida como "la medida de prudencia, actividad o asiduidad que cabe razonablemente esperar, y con la que normalmente actúa, una [persona] prudente y razonable en unas circunstancias determinadas; no se mide por una norma absoluta, sino dependiendo de los hechos relativos del caso en cuestión" (...) En el contexto de los Principios Rectores, la diligencia debida en materia de derechos humanos constituye un proceso continuo de gestión que una empresa prudente y razonable debe llevar a cabo, a la luz de sus circunstancias (como el sector en el que opera, el contexto en que realiza su actividad, su tamaño y otros factores) para hacer frente a su responsabilidad de respetar los derechos humanos. (p. 7) ${ }^{106}$

La diligencia debida en derechos humanos exige que la actuación de las empresas ocurra mediante una consideración previa de todos los riesgos, impactos y posibles vulneraciones que su actividad implica para los derechos humanos y que esos riesgos se reduzcan, se eviten o se mitiguen. (Ibañez \& Ordoñez, 2014, p. 224-225) La Organización de Naciones Unidas asocia a la diligencia debida con esa medida de prudencia o mínimo deber de cuidado respecto de una actividad determinada, teniendo en cuenta las circunstancias. (ibid) También se adiciona al concepto de debida diligencia el concepto de riesgo en derechos humanos:

Se entienden como riesgos de una empresa relacionados con los derechos humanos los riesgos de que sus actividades puedan acarrear una o más consecuencias negativas sobre los derechos humanos. Así pues, guardan relación con su impacto potencial sobre los derechos humanos. En la evaluación del riesgo tradicional, en el riesgo influyen tanto las consecuencias de un suceso (su gravedad) como la probabilidad de que ocurra. En el contexto del riesgo relacionado con los derechos humanos, la gravedad es el factor predominante. La probabilidad puede ser importante a la hora de ayudar a establecer prioridades en el orden en que deben abordarse las posibles consecuencias negativas en determinadas circunstancias (...) Es importante entender que el riesgo de una empresa para los derechos humanos es el riesgo que su actividad plantea para esos derechos. Es distinto del riesgo que la implicación en unas consecuencias negativas sobre los

\footnotetext{
${ }^{106}$ La responsabilidad de las Empresas de respetar los derechos humanos. Guía para la interpretación. Naciones Unidas. New York, Ginebra 2012. P.7 En http://www.ohchr.org/Documents/Publications/HR. PUB.12.2_sp.pdf (2012).
} 
derechos humanos pueda suponer para la empresa, aunque ambos están cada vez más estrechamente relacionados. (p. 8) ${ }^{107}$

Podemos concluir que, son cinco los puntos que una empresa debe tomar en cuenta. En primer lugar, debe respetar los derechos humanos en sus proyectos y operaciones. Según la actividad que desarrolle, la empresa debe remitirse a las normas de derechos humanos que sean más propensos a vulnerar así como a los convenios de la OIT (Anexo1 y Anexo 2). En segundo lugar, se encuentra la prevención y mitigación de riesgos potenciales a los derechos humanos causados directamente por los proyectos y operaciones de la empresa. Adicionalmente, otra responsabilidad que estas deben asumir es no ser cómplices de violaciones o vulneración a los DDHH (incluyéndose así no solo la infracción directa sino también la pasiva). Para poder conseguir lo anterior, es necesario que la empresa tenga una política de manejo y prevención de riesgos potenciales en derechos humanos. Este tercer punto lo puede implementar la empresa de manera independiente, creando códigos de conducta, departamentos especiales para el tratamiento exclusivo del tema, o puede incluirlo en sus políticas actuales. La forma en la que se implementen esas políticas es libre porque cada empresa es distinta y los riesgos también lo son, aunque se puede generalizar una propensión a riesgos determinados dependiendo del sector en el que se encuentre la actividad empresarial. En cuarto lugar, que la empresa exprese públicamente la intención de respetar los derechos humanos no es suficiente porque esta declaración debe estar acompañada de las políticas o acciones de la empresa para que exista congruencia. Finalmente, el cumplimiento de la diligencia debida en derechos humanos consiste en realizar evaluaciones de riesgos y tomar medidas al respecto.

En resumen, en función de la especialidad y variedad de actividades empresariales que hay en el mundo, es necesario que cada empresa realice un análisis de hechos y datos a la luz de los estándares internaciones de protección a los derechos humanos y los parámetros establecidos por las normas nacionales para cada sector. (Ibañez \& Ordoñez, 2014, p. 226) La identificación temprana del problema es la razón de ser del establecimiento de un proceso de diligencia debida en derechos humanos para

\footnotetext{
${ }^{107}$ La responsabilidad de las Empresas de respetar los derechos humanos. Guía para la interpretación. Naciones Unidas. New York, Ginebra 2012. P.8 En http://www.ohchr.org/Documents/Publications/HR. PUB.12.2_sp.pdf (2012).
} 
identificar, prevenir o mitigar el impacto real o potencial. Esto último no es nuevo para las empresas y los asuntos de derechos humanos pueden ser integrados en los procesos de identificación existentes. En consecuencia, un primer paso sugerido para entender lo que se busca es conducir un análisis del impacto potencial en los derechos humanos de la compañía a lo largo de su cadena de suministros (proveedores, negocios relacionados a él, etc.).

Las empresas deben implementar procesos de contingencia para mitigar los impactos adversos a los derechos humanos que detecten. Finalmente, la expectativa de los principios es que una compañía sabrá y demostrará que respeta los derechos humanos. Esto puede ser conseguido con la actualización y publicación en los reportes de sostenibilidad de la compañía, notas de prensa, participación u obtención de distinciones, y en la inclusión de noticias relacionadas en los medios de comunicación. $^{108}$

\subsubsection{Políticas en Derechos humanos.}

La implementación global de los PREDH es relevante para la empresa en vista de que la compromete al respeto de los derechos humanos en su ámbito de acción. Al respecto, las empresas encuentran retos y oportunidades que son clave y van a depender del sector en el que se encuentre o desarrolle su actividad empresarial. Sin embargo, el respetar los derechos humanos es una posición intrínseca que debe tener cada empresa en su reglamentación interna. En ese sentido, las empresas deben darse cuenta de los beneficios de hacer cumplir este segundo pilar de los principios rectores a través del respeto a los DDHH. Específicamente en el tema de costos, que no solo implica el costo económico sino el costo social, y más aún los costos a largo plazo que con la adopción de una postura de respeto a los derechos humanos se pueden evitar. En ese

\footnotetext{
${ }^{108}$ http://www.triplepundit.com/2014/11/adidas-announces-human-rights-complaint-process/ La empresa Adidas puede ser un referente o ejemplo en cuanto a lo descrito, toda vez que han implementado mecanismos de queja dentro de la gestión empresarial que maneja, del mismo modo, sus políticas se encuentran alineadas con los Principios Rectores sobre Empresas y Derechos Humanos. Recordemos que la empresa ha sido objeto de duras críticas y campañas de desprestigio por la vulneración de los Derechos Humanos en la cadena de suministros en el pasado, frente a lo cual experimentó el desprestigio de su imagen acompañado de pérdidas económicas por el rechazo del público consumidor.
} 
sentido, la diligencia debida en derechos humanos, en cualquiera de sus formas, va a beneficiar enormemente al sector empresarial.

[...] no obstante lo anterior y a pesar de que actualmente se vincule la responsabilidad de las empresas, los Estados conservan sus obligaciones frente a la protección, respeto y garantía de los derechos humanos, y por ello dentro de los principios de Ruggie también hay responsabilidades que le competen en exclusividad a los Estados.(Ibañez \& Ordoñez, 2014)

En el capítulo anterior hemos hecho referencia a los PANs como punto de inicio o de partida para delimitar y establecer las prioridades que tiene el gobierno respecto de la implementación en materia de derechos humanos y empresas. En ese sentido, hemos visto que los planes de acción pueden tener diversos temas y pueden comprometer a terceros como a los inversionistas o empresarios, quienes podrían ser de gran apoyo a la consecución de los objetivos trazados en los planes. En el caso peruano, si bien las políticas en derechos humanos se plasman en planes nacionales con vigencia preestablecida, nada impide que se puedan adoptar otros planes similares.

Nuestro Plan Nacional de Derechos Humanos ${ }^{109}$ no hace alusión expresa a las medidas que el Perú tomará en cuanto a la implementación de los PREDH en el Perú; sin embargo, en el texto del Plan hemos encontrado medidas y estrategias que van acorde a los principios en el caso de los pueblos indígenas y el tema de consulta previa.

Asimismo, notamos que respecto de la implementación de tratados y estándares internacionales se puede recurrir a la elaboración y seguimiento de planes, programas y mecanismos que evaluarán el impacto de la actividad empresarial en el respeto de los derechos humanos en el Perú como punto de partida o diagnóstico que servirá para adoptar medidas posteriores. Ese diagnóstico servirá para la adopción de medidas

\footnotetext{
${ }^{109}$ Plan Nacional de Derechos Humanos 2014-2016, Publicado el 5 de julio de 2014. En el lineamiento estratégico $\mathrm{N}^{\mathrm{o}} 3$ que trata sobre el diseño y ejecución de políticas a favor de los grupos de especial protección, el objetivo $\mathrm{n}^{\circ} 23$ busca incrementar los niveles de confianza entre el Estado y los pueblos indígenas, mediante la consolidación de espacios de coordinación y diálogo permanente. Una de las acciones vinculadas a este tema es evaluar el impacto de la actividad empresarial en el respeto a los derechos humanos en el Perú, con el fin de establecer lineamientos y marcos de acción. Del mismo modo, el lineamiento estratégico número 4 , sobre el fortalecimiento del ordenamiento jurídico interno, a través de la implementación de instrumentos internacionales, para la promoción y protección de los derechos humanos, el objetivo $\mathrm{N}^{\mathrm{o}} 2$ : Implementar tratados y estándares internacionales sobre Derechos Humanos, Derecho Internacional Humanitario y Derecho Penal Internacional, en cuanto a la adopción de Planes, programas y mecanismos contiene acciones similares. Las entidades involucradas en ello son PRODUCE y MINJUS, MINAM, MINAG, MEM Y MTPE.
} 
dependiendo del sector empresarial al que vaya dirigido; por ejemplo, distinto será el riesgo a contaminar el medio ambiente de parte de una empresa minera en comparación con el riesgo en esa materia por parte de una empresa que presta servicios de mensajería en la ciudad.

Sin embargo, la falta de planes nacionales o de voluntad política del Estado de querer implementarlos no impide que las empresas incluyan los principios referentes a la responsabilidad corporativa de respetar los derechos humanos. En otras palabras, la empresa necesita una política de compromiso de respetar los derechos humanos que no necesita ser complicada sino abarcar los impactos potenciales de derechos humanos en el lugar de trabajo y en las comunidades en las que la compañía y su cadena de suministros operan.

Es por ese motivo que resulta importante que las empresas comprendan como es que los riesgos a los derechos humanos pueden cambiar a través del tiempo y como responder ante ellos. La diligencia debida en derechos humanos permitirá observar los factores internos y externos que pueden implicar riesgos en esta área, así como los recursos que pueden ayudar a contrarrestarlos. Esta diligencia debida debe comenzar en la etapa pre contractual del ciclo de vida de un proyecto y continuar a lo largo de las operaciones, hasta las etapas de culminación y entrega. La diligencia debida es de naturaleza dinámica y trata de procesos en marcha que se dan de forma continua y que son distintos a los reportes anuales o evaluaciones que se dan al inicio o término de los proyectos. La ventaja que tienen muchas compañías es que ya cuentan con sistemas en los que se puede direccionar o desarrollar la diligencia debida en derechos humanos. Podemos citar como ejemplos a la diligencia debida que se da en asuntos ambientales o de salud y otros procesos de revisión regular de riesgos. Sin embargo, las empresas también podrían optar por tener un proceso de diligencia debida en derechos humanos independiente en vez de integrarlo a procesos ya existentes. ${ }^{110}$

\footnotetext{
${ }^{110}$ Putting respect to human rights into practice - shift project. En: http://www.shiftproject.org/sites/default/files/OG/ECHRSG.OG.6.pdf
} 


\subsubsection{Monitoreo del cumplimiento de los principios}

Si bien el monitoreo inicial nace de la propia empresa, el incumplimiento de sus políticas de respeto a los derechos humanos sólo será punible cuando se presente una vulneración efectiva del derecho humano atribuible directamente a la empresa, lo que traerá como consecuencia gastos por litigios, desprestigio de la imagen o marca, pérdida en las ganancias proyectadas en función a la reacción de los consumidores, campañas de la sociedad civil, y demás acciones que afectan el prestigio de la empresa.

El monitoreo involucra entonces un compromiso real de la empresa y la convicción de cumplir con los principios rectores en lo que le corresponde (respetar). Cabe hacer la salvedad de que esta decisión de la empresa de hacer públicos sus logros en este campo en reportes de sostenibilidad, en su página web o mediante comunicados de prensa y publicidad, le generará mayores ingresos al elevar el valor comercial de la empresa, la marca e intangibles. Además, le abre la posibilidad de obtener contratos y socios que comparten la misma visión, que respetan los derechos humanos y que cuentan con legislaciones que les obligan a contratar con empresas que también los respeten. De esta manera, la empresa será más competitiva a nivel internacional. ${ }^{111}$

En esa misma línea, y haciendo referencia al tema medioambiental, cabe resaltar que en el mundo existen los llamados bonos de carbono, los mismos que surgen a raíz del alto índice de contaminación y problemas medio ambientales que ciertas actividades, sobre todo extractivas, generan. ${ }^{112}$ En el caso de los principios rectores, sería complicado aplicar una fórmula similar porque resulta inconcebible que una empresa compre algún tipo de bono para continuar vulnerando derechos humanos. El sustento de este razonamiento es la misma naturaleza y jerarquía de los derechos que están en juego. (Anexo 1)

Hasta el momento hemos realizado un estudio en el escenario de la implementación de los PREDH como se encuentran en la actualidad. Sin embargo, en

\footnotetext{
${ }^{111}$ Recordemos como ejemplo que en el caso de Estados Unidos existe la disposición Dodd-Frank y la Ley de Transparencia de California; y el Reino Unido existen normas vinculantes respecto a la prohibición de las formas modernas de esclavitud, además de la obligación de presentar reportes estratégicos para las empresas listadas en bolsa. (Referencia: Capítulo II)

${ }^{112}$ Los bonos de carbono son comercializados entre empresas que mantienen una emisión baja de CO2 y empresas que no pueden reducir su emisión de $\mathrm{CO} 2$, pero que adquieren estos bonos para poder emitirlos y de esta manera mantener controlada la emisión de $\mathrm{CO} 2$ con el consiguiente calentamiento global o efecto invernadero.
} 
caso de que se apruebe un tratado vinculante en la materia, y el Perú sea parte del mismo, el Estado estará obligado a realizar cambios en la legislación para implementar ese tratado. Por experiencia sabemos que la adopción de un tratado, así como como su implementación, obedecen más a motivaciones políticas que jurídicas y que el tiempo en el que se hacen efectivas las normas puede tardar varios años. ${ }^{113}$

Un aspecto que no hemos tocado a profundidad en la investigación es la responsabilidad penal (Dragatsi) que también tendría que ser tipificada en la legislación internacional con jurisdicción de la Corte Penal Internacional o a través de mecanismos alternos como la creación de una corte creada para tales fines (con todo lo que ello implicaría). Habría que analizar si en el espectro de acción de la CPI se podría incluir la responsabilidad penal de la persona jurídica. De ser así, los Estados tendrían que adecuar sus legislaciones penales internas y tipificar los delitos en su legislación nacional.

\subsection{Conclusiones al capítulo III}

Queda claro que la implementación de los principios rectores, a nivel Estado, se puede llevar a cabo en diversas etapas: se pueden realizar por niveles o sectores, como por ejemplo en el sector de hidrocarburos o en el sector de telecomunicaciones; a nivel doméstico o nacional, a través de legislación interna que adopte los principios y los plasme en leyes que serán vinculantes dentro del territorio nacional; a nivel regional, por ejemplo, a nivel de unión europea o comunidad andina; a través de un tratado a ser firmado por los Estados; y con la creación de una corte internacional para tales efectos.

Asimismo, se puede integrar esta necesidad de las empresas a respetar los derechos humanos en las políticas de inversión internacional y en los contratos que las empresas suscriben entre sí y con el Estado. No obstante, para que las empresas se vean motivadas a realizar una implementación en su estructura organizacional y esta sea viable, los gobiernos podrían ofrecer beneficios favorables al sector empresarial. Para citar un ejemplo, podemos pensar en políticas de reducción de impuestos o beneficios

\footnotetext{
${ }^{113}$ Tal como fue el caso de la adopción y establecimiento de la Corte Penal Internacional, así como su adecuación a la legislación penal nacional.
} 
tributarios para aquellas empresas que cumplan con implementar las políticas en derechos humanos cumpliendo con los estándares internacionales.

Por otro lado, también resulta importante implementar un mecanismo de monitoreo permanente y efectivo, que en principio es más sencillo de realizar con empresas listadas, que abarque al $100 \%$ de las empresas sin importar tamaño, rubro o ingreso, entre otras características.

Otra consideración que deberán tomar en cuenta las empresas es que cuando el Estado en el que operan no cumple con su deber de protección de los derechos humanos, son las propias empresas que operan en estos países las llamadas a respetarlos y hacerlos respetar. En ese sentido, toda empresa que aplique la diligencia debida en derechos humanos podrá prevenir los impactos negativos que ella pudiera ocasionar como estrategia de prevención. Además, podrá mitigar los impactos y establecer estrategias de remediación en caso ya se hayan configurado violaciones a los derechos humanos.

Podemos afirmar que la implementación de los principios es un proceso que interesa a las empresas, a los actores locales de la sociedad civil (en particular las organizaciones y defensores de derechos humanos), y al Estado (local, regional, nacional). Por un lado, el objetivo de la implementación de la diligencia debida en derechos humanos es lograr que la empresa tome conciencia de su rol activo como parte de la solución a los problemas económicos, sociales y medioambientales estructurales.

De no implementarse la diligencia debida en derechos humanos en las políticas de las empresas, continuarán las vulneraciones a los derechos humanos por parte de ellas y sus cadenas de suministros con una impunidad que será cada vez mayor y más difícil de erradicar. Los conflictos sociales no cesarán y hasta aumentarán su espectro a otros sectores comerciales y/o sociales (como ya ocurre en la actualidad). Las víctimas de los abusos harán uso de mecanismos legales que tal vez no puedan resolver el fondo del problema con la justicia o celeridad necesarias; tampoco les asegurará que vulneraciones similares no se vuelvan a realizar. La lista no pretende ser exhaustiva sino mostrar que la motivación para optar por una política de respeto a los derechos humanos ahorra a las empresas costos económicos, sociales, medioambientales y legales. 


\section{CONCLUSIONES}

- La empresa debería ser la primera aliada de los derechos humanos al ser fuente de empleo y mejora de la calidad de vida de las personas; en ese sentido, es indiscutible el rol que tiene en la economía mundial y su desenvolvimiento debe estar siempre dentro del marco de respeto a los derechos humanos. A pesar de ello, la experiencia nos ha demostrado que en Estados con ordenamientos jurídicos debilitados, que adolecen de una efectiva protección de los derechos humanos, empresas transnacionales han incurrido en vulneraciones graves. Algunas de estas empresas han sido demandadas por la vía judicial y han recibido fuertes críticas por parte de la sociedad civil - consumidora final de sus productos o servicios, lo que afecta directamente la rentabilidad e imagen de la empresa.

- En respuesta a los casos de violaciones a los derechos humanos, la comunidad internacional ha intentado normar a las empresas transnacionales sin éxito. En el año 2011, por primera vez se llegó al consenso mundial a través de los Principios Rectores de Naciones Unidas sobre Empresas y Derechos Humanos (PREDH). No obstante, se trata de normas no vinculantes, las empresas deben ser conscientes de que tomar en cuenta los principios rectores (y en especial el segundo pilar sobre el respeto a los derechos humanos) en el manejo de la empresa y en sus diversas labores le traerá beneficios, sea que se enfrente a riesgos reales o potenciales en derechos humanos.

- Por otro lado, la tendencia actual es variada y apunta en varias direcciones entre las que se encuentra la adopción de un tratado vinculante en la materia de los derechos humanos y empresa, la adopción unilateral por parte de los Estados de los PREDH, la creación o adecuación de medidas legislativas que se encuentren en concordancia con los principios y la decisión unilateral de la empresa de incluir a los principios en su política. A su vez, las relaciones comerciales no se circunscriben a un territorio nacional o regional, sino a un mercado mundial que ya está implementando en sus empresas y ordenamientos jurídicos normas que se alinean a los principios. En este punto, si una empresa desea mantener sus niveles de competitividad y ser elegible como proveedora, cliente, o ser parte de la cadena 
de suministros, debe adecuar sus políticas a los PREDH. De esta manera, para cuando los principios se tornen de obligatorio cumplimiento (sea por su adecuación en la legislación nacional o por medio de un tratado), serán parte de la política de la empresa, lo que redundará en la economía de la misma.

- Paralelamente, muchos Estados han adoptado planes de acción nacional en la materia. Estos planes son guías útiles si los Estados los promueven e involucran a los empresarios, sociedad civil, gobiernos locales y regionales, sector financiero y demás actores relevantes. En el caso de los principios rectores, estos pueden ser incluidos en los planes de acción en derechos humanos o de RSE; sin embargo, su inclusión en la legislación nacional e internacional es lo que le dará mayor exigibilidad. No debemos olvidar que estos planes son parte de una política integrada en materia de derechos humanos y que su cumplimiento será voluntario a menos que se legisle.

- Antes de ser incluidos en la legislación nacional consideramos que es necesario realizar una sistematización de normas y de entidades que están relacionadas e interesadas en desarrollar los PREDH en el Perú tanto a nivel gubernamental como empresarial. Se trata de una sistematización normativa que se puede realizar por sectores de producción o a nivel regional (geográfico). En cuanto a la sistematización a nivel interno de las empresas, se puede realizar a través de códigos de conducta, de la gestión y de las políticas de responsabilidad social empresarial.

- La salida más viable y rápida es la adopción de los principios por parte de las empresas de manera voluntaria dentro de sus propias políticas, las mismas que deben guardar concordancia con lo avanzado por la comunidad internacional, sin entrar en controversias sobre la adopción de tratados o documentos vinculantes en la materia, decisión que le corresponde exclusivamente a los Estados. Por lo tanto, consideramos que la diligencia debida o due diligence en derechos humanos debe formar parte de las políticas de las empresas, ya sea de manera específica o dentro de las regulaciones preestablecidas. A manera de ejemplo, se pueden establecer mecanismos de contratación, elección o evaluación de socios estratégicos y de la cadena de suministros. Esto llevará a una humanización de las empresas a través del respeto a los derechos humanos y la colocará en ventaja respecto de las demás empresas del sector en el que se desenvuelve. 
- Finalmente, no es necesario que los PREDH sean vinculantes para que se puedan cumplir. En esa línea, cualquier Estado puede recomendar a los inversionistas la inclusión de cláusulas que obliguen a las partes respetar los derechos humanos o realizar el due diligence en derechos humanos de manera periódica, de modo tal que se dé cumplimiento a los principios. A su vez, por parte de las empresas, estas pueden comenzar a incluir cláusulas de similar contenido en contratos privados, práctica que viene siendo adoptada por un creciente número de empresas demostrando que en la práctica empresarial también existe voluntad de alinearse con los principios. 


\section{REFERENCIAS}

Amerson, J. M. (2012). The End of the Beginning?: A Comprehensive Look at the U.N.'s Business and Human Rights Agenda From a Bystander Perspective. (XVII)71 p. 871-941,. Fordham Journal of Corporate \& Financial Law.

Arnold, D. G. (Julio del 2010). Transnational Corporations and the Duty to Respect Basic Human Rights. Business Ethics Quarterly.; 29, p. 371-399,

Blitt, R. C (Otoño 2012). BeyondRuggie's Guiding Principles on Business and Human Rights: Charting an Embracive Approach to Corporate Human Rights 48(1). Texas International Law Journal., p33-62. 30 p.

Buhmann, K. (Verano 2012) Damned If You Do, Damned If You Don't? The TheLundbeck Case of Pentobarbital, the Guiding Principles on Business and Human Rights, and Competing Human Rights Responsibilities. Journal of Law, Medicine \& Ethics. p.206-219, 14p.

Buhmann, (2009). Regulating Corporate Social and Human Rights Responsibilities at the UN Plane: Institutionalising New Forms of Law and Law-making Approaches? 78(1) Nordic Journal of International Law., p 1-52. 52p.

Cassel, D. (2009). Empresas multinacionales y complicidad en violaciones de los derechos humanos: confusión judicial estadounidense. (63) Derecho PUCP $p$ 255- 281, 27p.

Chandler, G. (Primavera del 2009). The Amnesty International UK Business Group: Putting Human Rights on the Corporate Agenda. Journal of Corporate Citizenship, (33) p29-34. 6p.

Cragg, W. (Enero del 2012) Ethics, Enlightened Self-Interest, and the Corporate Responsibility to Respect Human Rights: A Critical Look at the Justificatory Foundations of the UN Framework. Business Ethics Quarterly.; p. 9-36, 28p.

Cragg, W; Muchlinski, P. y Denis, G. A. (Enero del 2012) Guest Editors' Introduction Human Rights and Business. Business EthicsQuarterly, p. 1-7, 7p.

Delgado Azar, I. y Hernández Baqueiro, A.(2008). Prácticas culturales, actores no estatales y el paradigma del Estado en la realización de los derechos humanos. Fundamentos en Humanidades, Universidad Nacional San Luis - Argentina. Año IX (18); p.111-144. 34 p.

Dragatsi, H. (Marzo del 2011). Criminal Liability of Canadian Corporations for International Crimes. CarswellPublication.. p. 254

Edjua, T. y Crockett, A..(Octubre del 2009). Human rights not negotiable. International Financial Law Review. Energy Supplement, p4-5. 2p. 
Groulx, E. y Diggs, L. (Junio del 2013). Saqueo de recursos naturales en cadenas de aprovisionamiento global. Lexis Nexis, Emerging Issues., 24 p.

Hamann, R (Mayo del 2009). A Point of Departure in Muddy Waters: Protect, Respect and Remedy: A Framework for Business and Human Rights. Environment. 51(3), p52-56. 5p.

Hamann, R. (Marzo/Abril del 2012). The Business of Development: Revisiting Strategies for a Sustainable Future. Environment; p. 18-29, 12p.

Hahn, R. (Enero del 2012). Inclusive business, human rights and the dignity of the poor: a glance beyond economic impacts of adapted business models. Business Ethics: A European Review. 21(1), p. 47-63, 16p.

Harvard Law Review. (Mayo del 2009) Organizational Irrationality and Corporate Human Rights Violations. 122(7), p 1931-1952. 22p.

Hoffman, W. M. y McNulty, Robert E. (Invierno del 2009) International Business, Human Rights, and Moral Complicity: A Call for a Declaration on the Universal Rights and Duties of Business. Business \& Society Review (00453609)., 114(4) p541-570. 30p.

Kolstad, I. (Junio del 2012) Human rights and positive corporate duties: the importance of corporate-state interaction. Business Ethics: A European Review. 21 (3); p. 276-285, 10p.

Lazala, M. (2009). Empresas y Derechos Humanos: Aún queda mucho por hacer. Debates IESA. XIV(4)., p. 59-61. 3p.

Lee, J.-Y. and Hunt, P..(Verano del 2012). Human Rights Responsibilities of Pharmaceutical Companies in Relation to Access to Medicines. Journal of Law, Medicine \& Ethics.; p. 206-219, 14p.

Lewis, C. (Diciembre del 2012). Businesses' Human Rights Responsibilities. Forced Migration Review. Issue 41, p25-26. 2p.

Lindsay, R. y Crockett, A. (Julio del 2011). Does Money Mind If We Say It's Evil? International Financial Law Review., 2p.

Lusverti P., Carlos F. (2008). La Empresa y la Declaración Universal de Derechos Humanos._Debates IESA. XIII(4) p. 13-14, 2p.

Mantilla, G.(Abril-Junio del 2009). Emerging International Human Rights Norms for Transnational Corporations. Global Governance., 15(2), p279-298. 20p.

McIntosh, M. (Spring 2009) Landmarks in the history of corporate citizenship: 'a slippery slope' Journal of corporate Citizenship. Greenleaf Publishing Ltd (33) p. 7-10, 4p. 
Miretski, P. P. y Bachmann, S.-D. (2012). The UN "Norms on the Responsibility of Transnational Corporations and Other Business Enterprises with Regard to Human Rights": A Requiem. Deakin Law Review 17(1); p. 5-41, 37p.

Muchlinski, P. (Verano 2011) The Changing Face of Transnational Business governance: Private Corporate Law Liability and Accountability of Transnational Groups in a Post-Financial Crisis World. Indiana Journal of Global Legal Studies 18 (2). Indiana University Maurer School of Law; pp. 665705, $41 \mathrm{p}$.

Mujica Petit, J.(2009) Desarrollo Internacional de las Obligaciones Legales de las Empresas Respecto de los Derechos Humanos. Derecho PUCP (63) p. 165-185, $21 \mathrm{p}$.

Prandi, M.(2009) Los Derechos Humanos en la Empresa: ¿Qué son y para qué sirven?. Debates IESA. XIV(4), p. 56-58. 3p.

Puterman S, P. (2009). Una Norma ISO para la Responsabilidad Social y los Derechos Humanos. Debates IESA. XIV(4). p. 65-66. 2p.

Rapacioli, S. (Mayo del 2012) A new way of doing business.Financial Management, .p. 16

Santoro, M. A. (Abril del 2010). Post-Westphalia and Its Discontents: Business, Globalization, and Human Rights in Political and Moral Perspective. Business Ethics Quarterly; p. 285-297, 13p.

Sherman III, J F. (Invierno del 2013) The UN Guiding Principles Practical Implications for Business Lawyers. In-HouseDefenseQuarterly., p50-57. 8p.

Tangarife-Pedraza, M. A.(2008). De la Responsabilidad de la Empresa y los Derechos Humanos. Revista Colombiana de Derecho Internacional. Ildi Bogotá (12), Edición Especial, p. 145-182, 37 p.

Thews, M. y van Huijstee, M. (Diciembre del 2013). Corporate Responsibility Instruments. SOMO. 43pp.

Triponel, A. (2008) Business \& Human Rights Law: Diverging Trends in the United States and France. American University International Law Review 23 (5), p855913. 59p.

Wood, S. (Enero del 2012). The Case for Leverage-Based Corporate Human Rights Responsibility. Business Ethics Quarterly, p. 63-98, 36p.

Bordignon, M. (2012/2013). The challenge of implementing the UN "Protect, Respect and Remedy" framework by States and the European Union through the UN guiding principles: The British, Spanish and Italian Cases. (Tésis doctoral del XXVI ciclo del corso di dottorato della Facolta' di giurisprudenza della Universitá Degli Studi di Roma Tor Vergata) p. 160. Recuperado de: http://business-humanrights.org/sites/default/files/media/documents/phdimplementing-ungp-uk-sp-it-jun-2014.pdf. 
De Schutter, O. (2014) Transnational Corporations and Human Rights. En: Material de lectura del curso online International Human Rights de la Universidad Católica de Louvain.

Lindsay, R. (Mayo del 2014). Business and human rights - emerging issues for financial institutions. London: Clifford Chance. Recuperado de: http://www.cliffordchance.com/briefings/2014/05/business_and_humanrightsem ergingissuesfo.html

Moran, Theodore, H. (2009). The United Nations and transnational corporations: a review and a perspective. Recuperado de:

http://unctad.org/en/docs/diaeiia200910a4_en.pdf

Rasche, A. (2012). The United Nations and Transnational Corporations How the UN Global Compact Has Changed the Debate. University of Warwick, Business School. Recuperado de: http://www.sagepub.com/upm-data/47439_chp_3.pdf.

Ruggie, John G.(Enero del2014). A UN Business and human rights Treaty. An Issues Brief by 28 January 2014. Harvard John F. Kennedy School of government. Recuperado de: http://business-humanrights.org/media/documents/ruggie-on-unbusiness-human -rights-treaty-jan-2014.pdf

Wang, Chen. (Mayo del 2012). ISO 26000 in China. 360 En: ISO Focus+ May 2012. P. 46-47. Recuperado de: www.iso.org/iso/livelinkgetfileisocs?nodeId $=16115417$.

Dhir, A. A. (Enero 2012) Shareholder Engagement in the Embedded Busines Corporation: Investment Activism, Human Rights, and TWAIL Discourse. Business Ethics Quarterly., p. 99-118, 20p.

Muchlinski, P. (Enero 2012). Implementing the New UN Corporate Human Rights Framework: Implications for Corporate Law, Governance, and Regulation. Business Ethics Quarterly.; p. 145-177, 33p.

Velasquez, Manuel G. (Julio 2012). Ética en los negocios. Conceptos y Casos. ( $\left.7^{\circ} \mathrm{ed}\right)$ Editorial Pearson. p. 496

Wettstein, F. (Octubre 2012).CSR and the Debate on Business and Human Rights: Bridging the Great Divide. Business Ethics Quarterly.; p. 739-770, 32p.

Jayakumar, T. (Octubre, Diciembre 2013). MNC CSR in Emerging Economy Conflict Zones- A Case Study of HUL's North-East Operations in India. Vikalpa. 38(4). p69-82. 14p.

Zapata Gutierrez, L. I.(2012) Aproximación a una legislación nacional en responsabilidad social empresarial para la emisión de reportes de sostenibilidad. (Tesis para optar el grado de Magíster en la Maestría de Derecho de la Empresa con Especialidad en Gestión Empresarial) Lima - Perú. 2012. p. 102 


\section{BIBLIOGRAFIA}

Borrador del Plan de Empresas y Derechos Humanos español. Recuperado de:

http://www.foretica.org/segundo_borrador_plan_de_empresa_y_derechos_humanos.pdf

Business \& Human Rights Resource Centre ( 22 de Mayo del 2014). Does the World Need a Treaty on Business and Human Rights? Weighing the Pros and Cons. Recuperado de: http://www.youtube.com/watch?v=0AIq9dtbkXI

Carta Internacional de Derechos Humanos.

Colloque (21 de marzo de 2011). La responsabilité internationale des entreprises en zones de conflit. Ministère des affaires étrangères - Paris. P. 131

Communication from the Commission to the European Parliament, the Council, The European Economic and Social Committee and the Committee of the Regions. A renewed EU strategy 2011-14 for Corporate Social Responsibility. Recuperado de: http://eur-

lex.europa.eu/LexUriServ/LexUriServ.do?uri=COM:2011:0681:FIN:EN:PDF.

Constitución Política del Perú. (1993)

Convención Americana de Derechos Humanos, 1969.

Convenios de la OIT referentes a: la libertad de asociación y de negociación colectiva, la eliminación del trabajo forzoso y obligatorio, la eliminación de la discriminación respecto del empleo y la ocupación, y la eliminación del trabajo infantil.

D.S. N 071-2006-EM que aprobó el formato de Convenio para el aporte económico, voluntario, extraordinario y temporal denominado "Programa Minero de Solidaridad con el Pueblo", modificado por D.S. N 033- 2007-EM, R.M. №324-2007-MEM/DM, R.M. N 356-2007-MEM/DM.

Declaración Universal de Derechos Humanos, 1948.

Decreto Supremo que crea el programa Perú Responsable. DS 015-2011-TR.

Draft for distribution and discussion. Report of pilot business survey on implementation of the corporate responsibility to respect human rights. Initiated by the United Nations Working Group on Business and Human Rights, and drafted for the first UN Annual Forum on Business and Human Rights (December 4th and $5^{\text {th }}$, December 2nd 2012) Geneva

Fuertes, F. (coord.) (2012) Guía de derechos humanos para empresas. Proteger, Respetar y Remediar. Todos ganamos. $\left(1^{\circ} \mathrm{ed}\right)$. - Buenos Aires: Programa Naciones 
Unidas para el Desarrollo - PNUD; Red Argentina Pacto Global,. 76 p. Recuperado de: http://www.ar.undp.org/content/dam/argentina/Publications/Pacto\%20Global/PNUDAr gent-Gu\%C3\%ADa-Empresas-DDHH-final.pdf

Good Business. Implementing the UN Guiding Principles on Business and Human Rights. UK (Setiembre 2013)

ICT Sector Guide on Implementing the UN Guiding Principles on Business and Human Rights. European Commission.

Lee Kuan Yew School of Public Policy. (1 de Julio del 2013). Just Business, Not As Usual. Recuperado de: https://www.youtube.com/watch?v=bJw1bwS5_nU

Ley de impuesto por obras. Ley 29230.

Líneas Directrices de la OCDE para Empresas Multinacionales. (Revisión 2011)

Naciones Unidas (2011). Principios Rectores Sobre las Empresas y los Derechos Humanos. Puesta en Práctica del Marco de las Naciones Unidas Para "Proteger, Respetar y Remediar".

OECD (10 de Diciembre del 2010). Prof. John Ruggie on businesses and human rights. Recuperado de: http://www.youtube.com/watch?v=dVDupBFJiqE

Organización de Naciones Unidas, (21 de marzo de 2011). Informe del representante especial del Secretario General para la cuestión de los derechos humanos y las empresas transnacionales y otras empresas. Principios rectores sobre las empresas y los derechos humanos: puesta en práctica del marco de las Naciones Unidas para "proteger, respetar y remediar". Anexo. A/HRC/17/31. Distr. General

Overview of key Business \& Human Rights Legislation for companies. CLT envirolaw. (2014) Recuperado de: https://business-humanrights.org/en/pdf-overview-of-keybusiness-human-rights-legislation-for-companies-europe-uk-usa

Pacto internacional de Derechos Civiles y Políticos.

Pacto internacional de Derechos Económicos, Sociales y Culturales.

Plan Nacional de Derechos Humanos 2014-2016 DECRETO SUPREMO No 005-2014JUS.

Resolución SBS 1928-2015. Reglamento para la gestión del riesgo social y ambiental.

Sherman, J. F. (4 de Abril del 2012). The UN Guiding Principles for the Corporate Legal Advisor: Corporate Governance, Risk Management, and Professional Responsibility. III General Counsel and Senior Advisor. p 17.

The "State of Play" of Human Rights Due Diligence.Anticipating the next five years. Institute for Human Rights and Business. I: General Overview. 2011. 
The foundations of the Italian action plan on the United Nations "Guiding Principles on business and Human Rights".

The UN Guiding Principles on Business and Human Rights A guide for the legal profession. By Advocates for International Development. En: www.a4id.org.

UN Human Rights (23 de Diciembre del 2013) Second annual UN Forum on Business and Human - 2-4 December 2013 (playlist de videos). Recuperado de: https://www.youtube.com/playlist?list=PLYUVFvBUloceMJo57pWMfFpNcfvWsws 


\section{Anexo I: Instrumentos internacionales de derechos humanos $^{114}$}

\section{Los derechos contenidos en la Carta Internacional de Derechos Humanos y en los convenios fundamentales de la Organización Internacional del Trabajo.}

\section{A. La Carta Internacional de Derechos Humanos}

La Carta Internacional de Derechos Humanos está integrada por la Declaración Universal de Derechos Humanos y los principales instrumentos en que se ha codificado: el Pacto Internacional de Derechos Civiles y Políticos y el Pacto Internacional de Derechos Económicos, Sociales y Culturales. En disposiciones similares de los Pactos se estipulan la no discriminación y la igualdad de género como principios fundamentales que deben aplicarse en conjunción con los derechos específicos. En ambos Pactos se reconocen y se definen más detalladamente los derechos contenidos en la Declaración Universal de la siguiente manera:

\section{Pacto Internacional de Derechos Civiles y Políticos}

Artículo 1: $\quad$ Derecho de libre determinación

Artículos 2 a 5: Principios generales

Artículo 6: Derecho a la vida

Artículo 7: Derecho a no ser sometido a torturas ni a penas o tratos crueles, inhumanos o degradantes

Artículo 8: Derecho a no estar sometido a esclavitud, servidumbre o trabajo forzoso

Artículo 9: $\quad$ Derecho a la libertad y a la seguridad personales

Artículo 10: Derecho de las personas privadas de libertad a ser tratadas humanamente

Artículo 11: Derecho a no ser encarcelado por el solo hecho de no poder cumplir una obligación contractual

Artículo 12: $\quad$ Derecho a la libertad de circulación

Artículo 13: Derecho de los extranjeros a las debidas garantías en el proceso de expulsión

Artículo 14: Derecho a un juicio imparcial

Artículo 15: Derecho de toda persona a que no se le aplique la legislación penal con efecto retroactivo

Artículo 16: Derecho de toda persona al reconocimiento de su personalidad jurídica

Artículo 17: $\quad$ Derecho a la intimidad

Artículo 18: Derecho a la libertad de pensamiento, de conciencia y de religión

Artículo 19: Derecho a la libertad de opinión y de expresión

Artículo 20: Derecho a estar libre de la propaganda en favor de la guerra y de toda apología del odio nacional, racial o religioso

Artículo 21: Derecho de reunión pacífica

Artículo 22: Derecho a asociarse libremente con otras personas

Artículo 23: Derecho a la protección de la familia y a contraer matrimonio

Artículo 24: Derecho de los niños a gozar de protección

Artículo 25: Derecho a participar en la vida pública

Artículo 26: Derecho a la igualdad ante la ley, a la igual protección de la ley y a la no discriminación

Artículo 27: Derechos de las minorías

${ }^{114}$ La responsabilidad de las Empresas de respetar los derechos humanos. Guía para la interpretación. Naciones Unidas. New York, Ginebra 2012. Anexo 1. 


\section{Pacto Internacional de Derechos Económicos, Sociales y Culturales}

Artículo 1: $\quad$ Derecho a la libre determinación

Artículos 2 a 5: Principios generales

Artículo 6: Derecho al trabajo

Artículo 7: $\quad$ Derecho a unas condiciones de trabajo equitativas y satisfactorias

Artículo 8: Derecho de toda persona a fundar sindicatos y a afiliarse al de su elección y

derecho de huelga

Artículo 9: $\quad$ Derecho a la seguridad social, incluso al seguro social

Artículo 10: Derecho a la vida familiar

Artículo 11: Derecho a un nivel de vida adecuado. (Incluye el derecho a una alimentación suficiente, a una vivienda adecuada y la prohibición de los desalojos forzosos. Se ha interpretado que este derecho incluye también el derecho al agua potable y al saneamiento.)

Artículo 12: Derecho a la salud

Artículos 13 y 14: Derecho a la educación

Artículo 15: Derecho de toda persona a participar en la vida cultural, a gozar de los beneficios del progreso científico y de sus aplicaciones y a beneficiarse de la protección de los intereses morales y materiales que le correspondan por razón de las producciones científicas, literarias o artísticas de que sea autora

\section{B. Convenios fundamentales de la OIT}

En 1998, la OIT adoptó la Declaración relativa a los principios y derechos fundamentales en el trabajo. En virtud de esa Declaración, los miembros se comprometían a respetar cuatro principios y derechos fundamentales en el trabajo: la libertad de asociación y negociación colectiva; la eliminación del trabajo forzoso u obligatorio; la eliminación de la discriminación en materia de empleo y ocupación; y la abolición del trabajo infantil. Cada uno de ellos se ha codificado en dos convenios y juntos conforman las ocho normas laborales básicas de la OIT.

1. Convenio sobre la libertad sindical y la protección del derecho de sindicación, 1948 ( $\left.\mathrm{N}^{\mathrm{o}} 87\right)$.

2. Convenio sobre el derecho de sindicación y de negociación colectiva, 1949 ( $\left.\mathrm{N}^{\circ} 98\right)$.

3. Convenio sobre el trabajo forzoso, 1930 ( $\left.\mathrm{N}^{\circ} 29\right)$.

4. Convenio sobre la abolición del trabajo forzoso, 1957 ( $\left.\mathrm{N}^{\circ} 105\right)$.

5. Convenio sobre igualdad de remuneración, 1951 ( $\left.\mathrm{N}^{\mathrm{o}} 100\right)$.

6. Convenio sobre la discriminación (empleo y ocupación), 1958 ( $\left.\mathrm{N}^{\circ} 111\right)$.

7. Convenio sobre la edad mínima, 1973 ( $\left.\mathrm{N}^{\circ} 138\right)$.

8. Convenio sobre las peores formas de trabajo infantil, 1999 ( $\left.\mathrm{N}^{\circ} 182\right)$. 


\section{Anexo II: Instrumentos sobre grupos o poblaciones específicos $^{115}$}

\section{Instrumentos de las Naciones Unidas en materia de derechos humanos en que se analizan los derechos de las personas pertenecientes a grupos o poblaciones específicos}

La Convención Internacional sobre la Eliminación de todas las Formas de Discriminación Racial.

La Convención sobre la eliminación de todas las formas de discriminación contra la mujer.

La Convención sobre los Derechos del Niño.

La Convención Internacional sobre la protección de los derechos de todos los trabajadores migratorios y de sus familiares.

La Convención sobre los derechos de las personas con discapacidad.

La Declaración de las Naciones Unidas sobre los derechos de los pueblos indígenas.

La Declaración sobre los derechos de las personas pertenecientes a minorías nacionales o étnicas, religiosas y lingüísticas.

En la mayoría de los casos, los derechos que se contemplan en esos instrumentos son inherentes a las personas de los grupos correspondientes. En la Declaración de las Naciones Unidas sobre los derechos de los pueblos indígenas se contemplan tanto los derechos humanos de las personas indígenas como los derechos colectivos de los pueblos indígenas.

${ }^{115}$ La responsabilidad de las Empresas de respetar los derechos humanos. Guía para la interpretación. Naciones Unidas. New York, Ginebra 2012, p. 14 


\section{Anexo III: Cuadro de Diligencia Debida en Derechos Humanos $^{116}$}

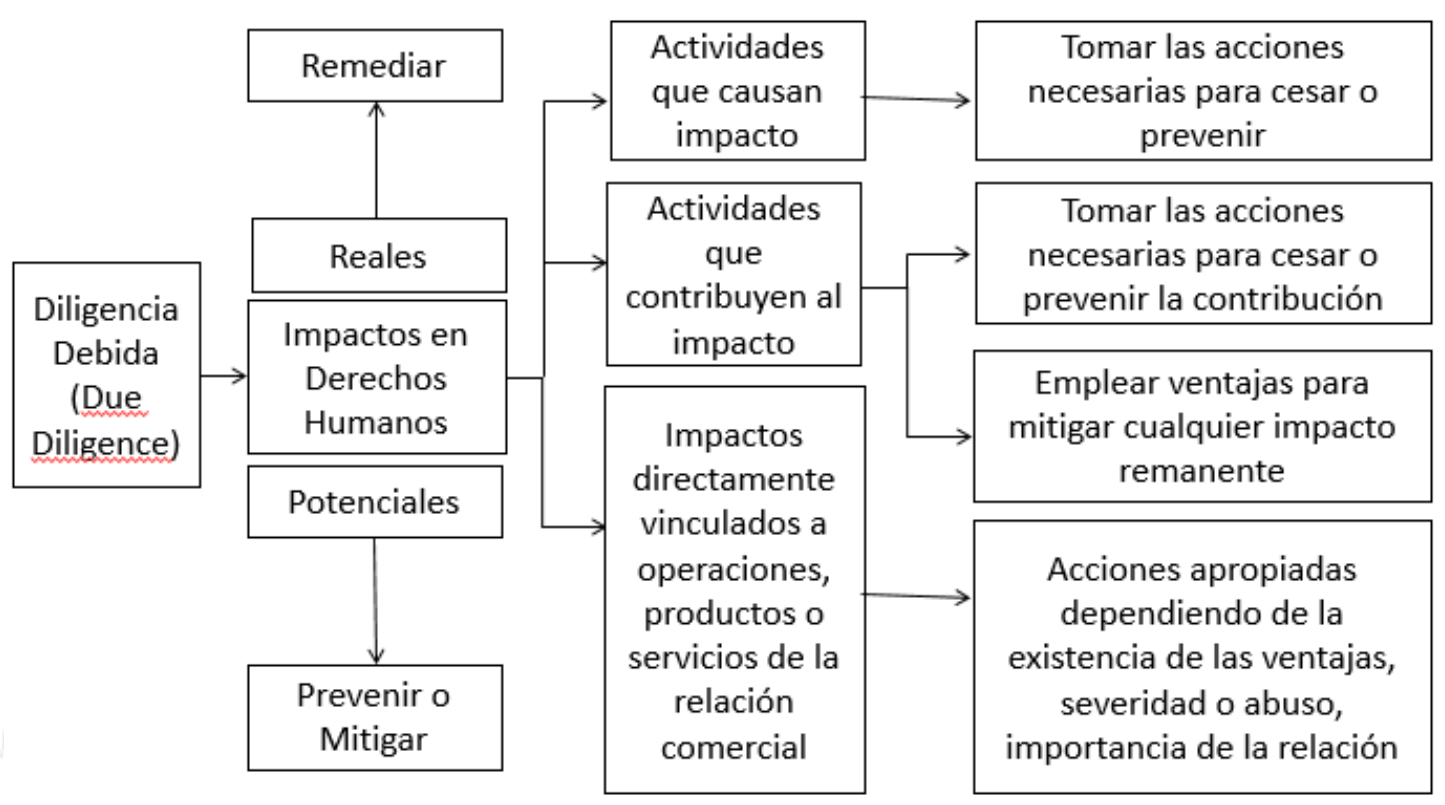

${ }^{116}$ Fuente:

http://www.cliffordchance.com/briefings/2014/05/business_and_humanrightsemergingissuesfo.html 


\section{Anexo IV: Beneficios de los Planes de Acción Nacionales en materia de Derechos Humanos ${ }^{117}$}

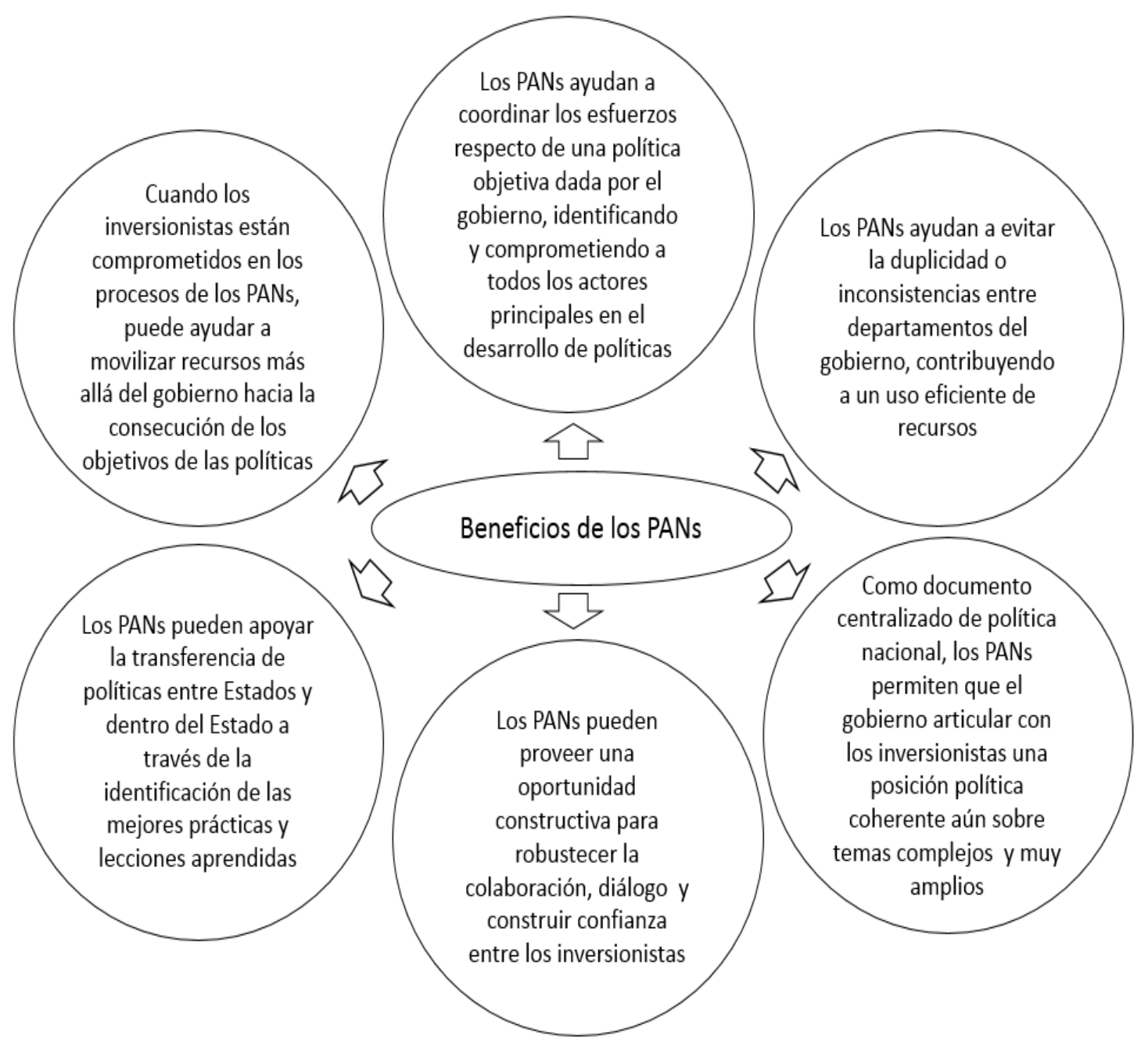

117 Fuente:http://accountabilityroundtable.org/wp-content/uploads/2014/06/DIHR-ICAR-NationalAction-Plans-NAPs-Report2.pdf 


\section{Anexo V: Planes de Acción Nacional en Derechos Humanos y Empresa $^{118}$}

Estados que cuentan con un Plan de Acción Nacional

- Reino unido - Setiembre 2013

- Holanda (Países Bajos) - Diciembre 2013

- Italia - Marzo 2014

- Dinamarca - Abril 2014

- España - verano del 2014 (pendiente de aprobación por el Consejo de Ministros Español)

- Finlandia - Octubre 2014

- Lituania - Febrero 2015

- Suecia - Agosto 2015

Estados que se encuentran en proceso de elaborar un plan de acción nacional o se han comprometido a elaborar uno:

- Alemania

- Argentina

- Azerbaiyán

- Bélgica

- Chile

- Colombia

- Eslovenia

- Estados Unidos

- Grecia

- Guatemala

- Irlanda

- Isla Mauricio

- Jordania

- Malasia

- México

- Mozambique

- Myanmar

- Noruega

- Portugal

- Suiza

Estados en los que instituciones de derechos humanos o la sociedad civil han comenzado a participar en el desarrollo de un plan de acción nacional.

- Filipinas

- Ghana

- Kazajistán

- Nigeria

- Sudáfrica

- Tanzania

${ }^{118}$ En: http://www.ohchr.org/EN/Issues/Business/Pages/NationalActionPlans.aspx. 